\title{
Husbandry of the Carnivorous Land Snail, Powelliphanta augusta (Gastropoda: Pulmonata: Rhytdidae)
}

\author{
By
}

Thomas Edward Allan

A thesis submitted to the Victoria University of Wellington in fulfillment of the requirements for the degree of Master of Science in Ecological Restoration

Victoria University of Wellington

2010 


\begin{abstract}
Key aspects of the captive husbandry of Powelliphanta augusta, a newly-described New Zealand land snail are investigated: how they should be managed and fed to provide individuals for release, and how a long-term captive population can be maintained as an insurance against extinction in the wild. This project arises from almost all members of this species having been brought into captivity due to their displacement in the wild by an opencast coalmine.
\end{abstract}

Powelliphanta (F: Rhytididae) is a genus of endemic carnivorous snails, which includes 10 species, 27 subspecies and numerous undescribed taxa. As well as its diversity, Powelliphanta is renowned for the large size of its members (up to 90mm diameter) and their attractively-patterned shells. Most taxa are threatened due to habitat loss and predation by introduced mammalian predators.

The study commences with a literature review to refine husbandry methods and to assess requirements for captive breeding of snails. From this review investigations are made into stocking densities, substrate, reproductive biology, body condition and growth of the $P$. augusta captive population.

To determine an appropriate stocking density for $P$. augusta groups of six snails were kept at two densities; with either $720 \mathrm{~cm}^{2}$, or $1440 \mathrm{~cm}^{2}$ per group. Survival and weight gain were compared over 52 weeks. There was no difference in weight gain between treatments, but survival was significantly reduced at the highest density. The agent responsible for mortality was not identified, but previous studies on snails implicate disease.

The effect of calcium supplementation on reproductive output was assessed by introducing limestone chip to the captive substrate of sphagnum moss. The experiment was aborted after eight months because of the apparently lethal effects of treatment. Egg production during this time was negligible, probably due to the lack of appropriate environmental cues.

P. augusta showed evidence of size-specific fecundity, with a significant increase in clutch size with parental shell volume. Size-specific fecundity is predicted to cause size-assortative mating, but experiments determined that mate-choice is random with respect to shell size. 
Body condition was studied using the residuals from a regression of mass and size at time of capture. Condition in the wild showed strong seasonal variation, with a high in December and January. Body condition in captive snails remained stable, at a level equivalent to the peak of condition in the wild.

The growth of captive snails was modeled using a Gompertz curve. Using a 30mm shell diameter as a reproductive indicator, snails hatching in captivity are predicted to reach maturity in approximately eight years.

The study concludes by discussing the implications of the research for husbandry. Updates and expansions to the analyses are suggested, as well as methods for effectively monitoring the captive population. 


\section{Acknowledgements}

I am indebted to Chris, Kath, Mark, Tom (Slater), Sophie, Pauline and the numerous people in the snail lab for their help collecting data, feeding, measuring and re-housing snails, etc. Also for tolerating my frequent interfering in the daily routine. Thanks to Mike Slater, DOC West Coast and Solid energy for assistance in kind and all those people on the 'hill' for their meticulous capture effort. Special mention for John Lyall for continued support and free access to the snails. Dr Ian Stringer shared with me both his many ideas and his snail reference library. Thanks to Rodney Phillips and Kerry Weston for providing additional data.

Dr Nokuthaba Sibanda and Dr Ian Westbrooke provided statistical advice regarding the use of survival analysis in chapter three. Jessie Prebble and Cielle Stephens read over the chapters, offering much-needed proofing as well as intelligent and useful comments. Thank you to Dr Ben Bell and the centre for Centre for Biodiversity and Restoration Ecology for financial assistance to present the research at the World Congress of Malacology in Thailand.

Thank you to Kath Walker for eagerly answering my countless questions, and most of all for serving the genus and the people of New Zealand over so many years. I am most grateful to Dr Ingrid Gruner who essentially co-supervised me during my time in Hokitika, planning all the experiments with me and providing on-going assistance and tolerance.

Lastly, I'd like to thank my supervisor Dr Murray Williams for everything you've done for me, not only during this thesis, but also its long gestation period. For luring me in to postgraduate study in the first place, and your vital assistance in getting me to Thailand. 


\section{Contents}

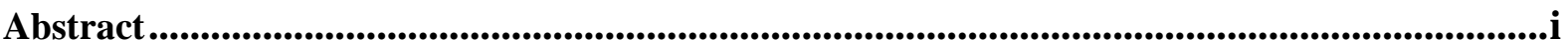

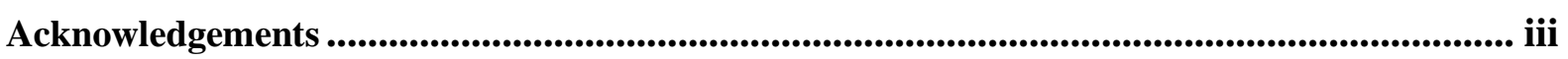

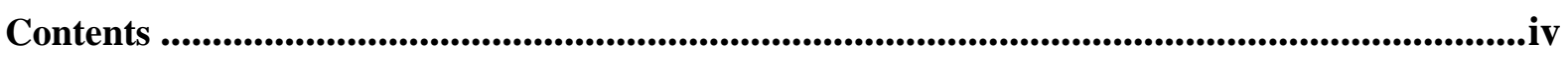

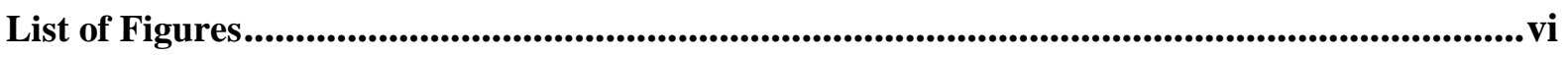

List of Tables ................................................................................................................................ viii

Chapter 1 : Introduction ............................................................................................................................ 1

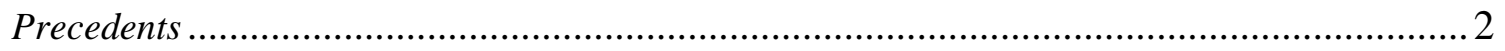

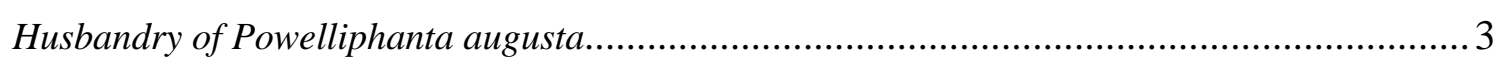

Chapter 2 : Biology and Husbandry of Stylommatophorans.......................................................4

Environmental control of activity and reproduction .............................................................. 4

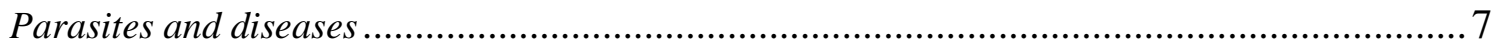

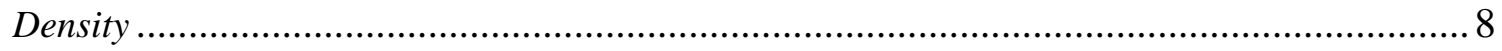

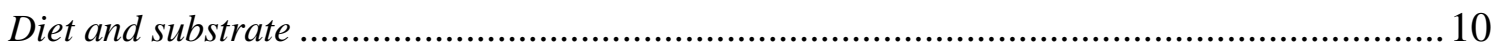

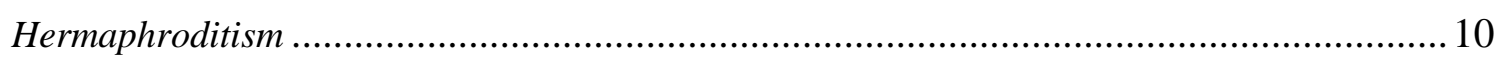

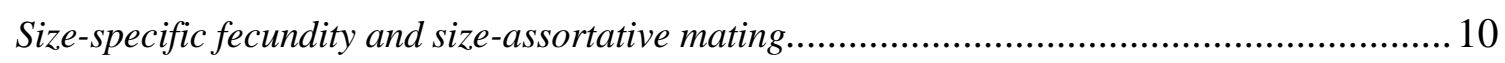

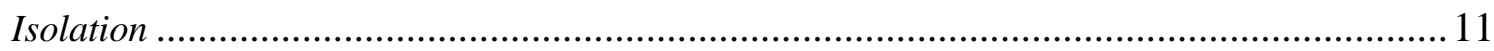

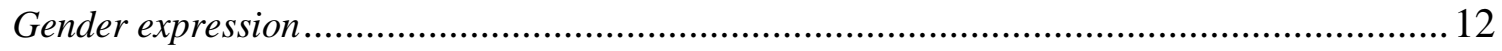

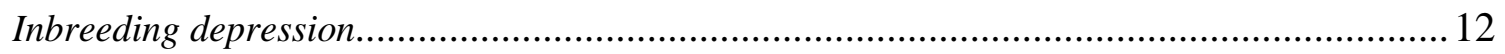

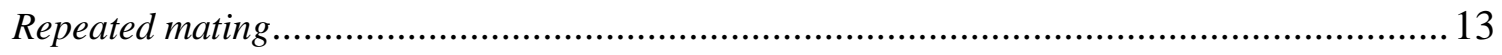

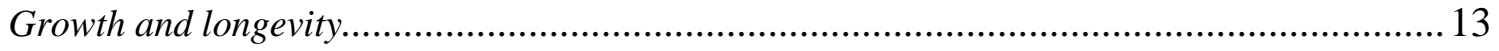

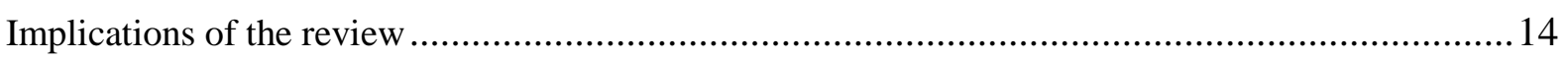

Chapter 3 : The Effect of Stocking Density on Survival and Well-being.......................................17

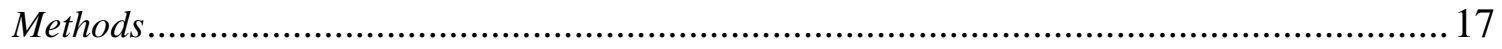

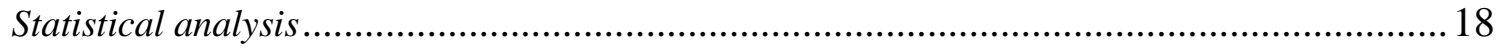

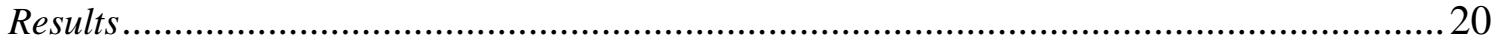

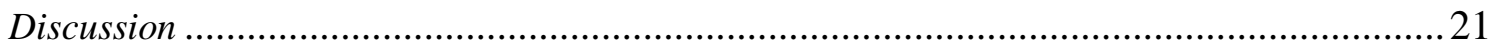

Chapter 4 : The Effect of Calcium Supplementation on Reproduction..........................................23

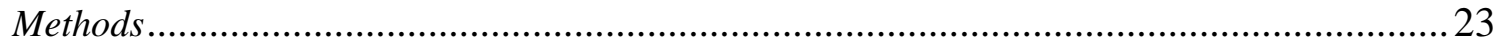

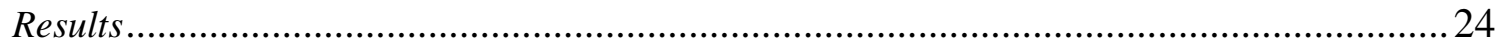

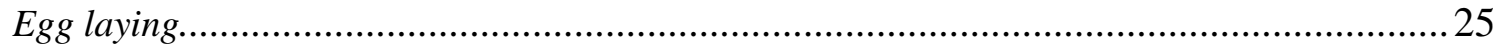

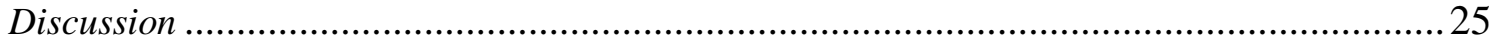

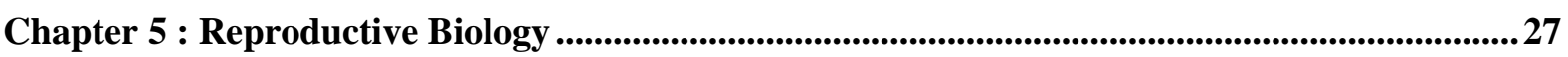

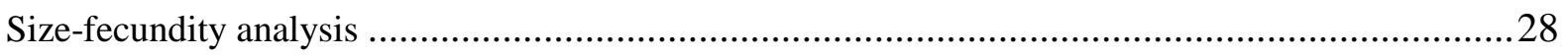

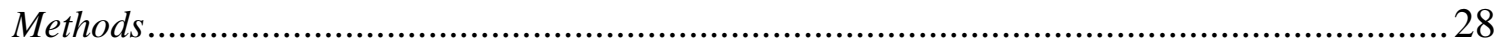

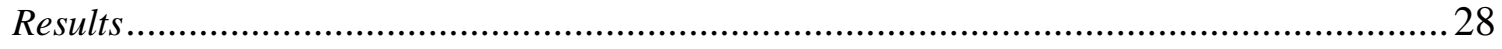

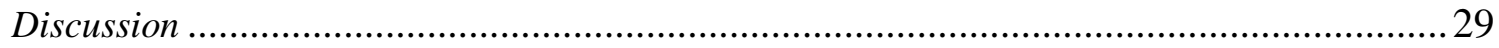


Size-assortative mating

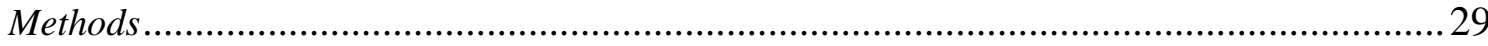

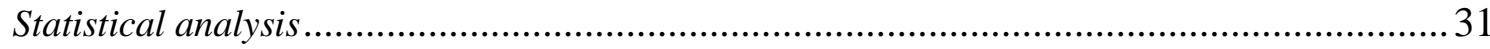

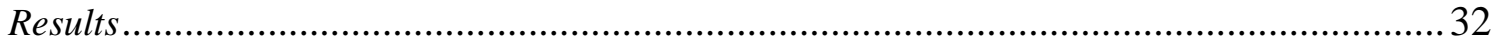

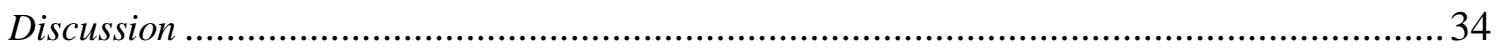

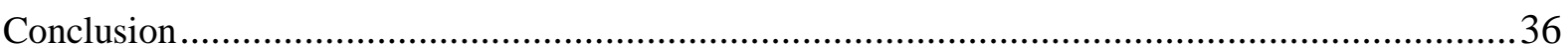

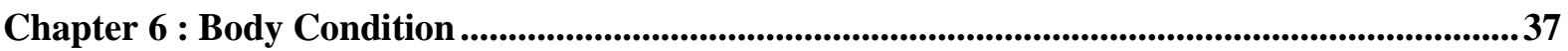

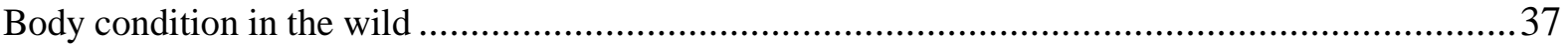

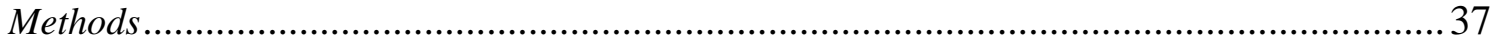

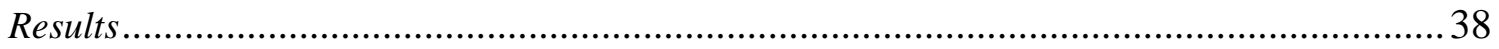

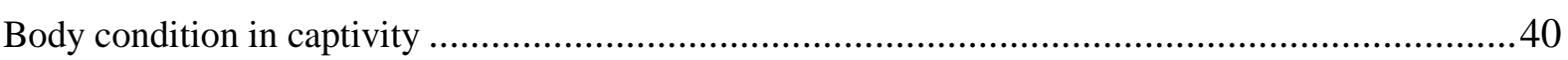

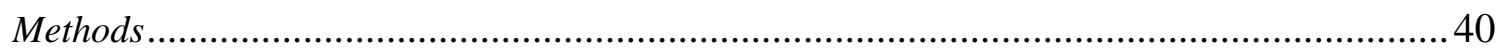

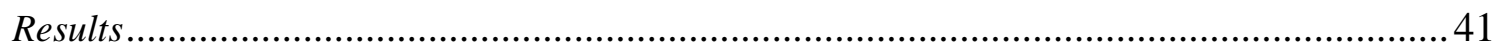

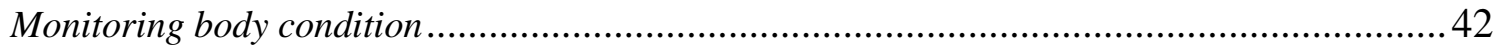

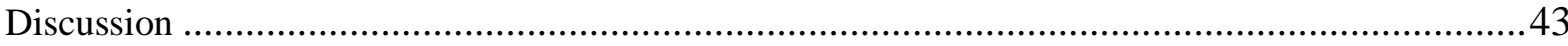

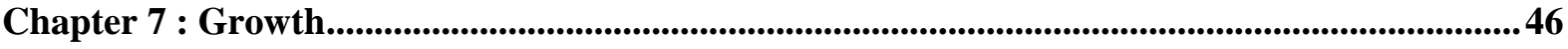

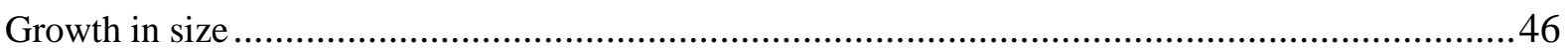

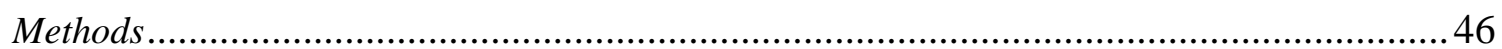

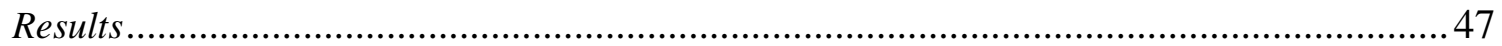

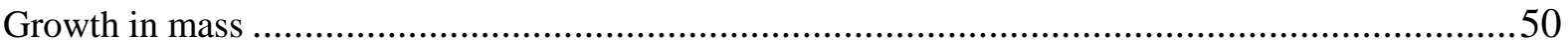

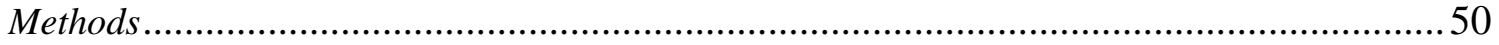

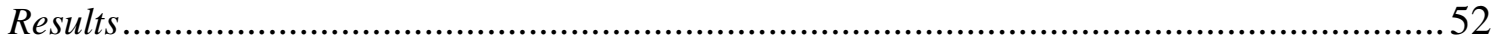

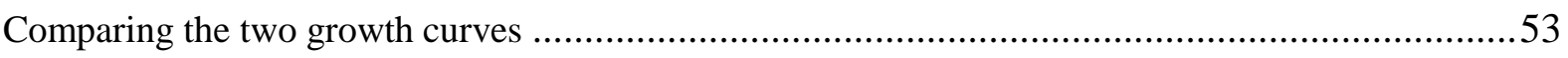

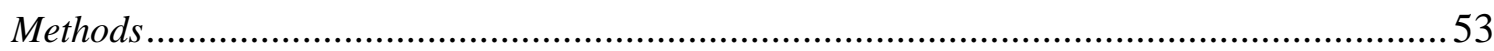

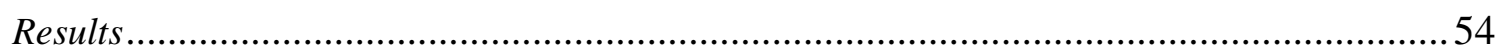

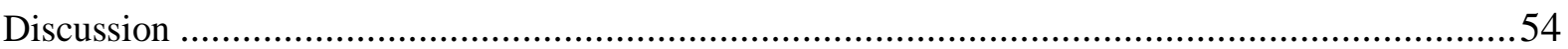

Chapter 8 : Research implications ........................................................................................................56

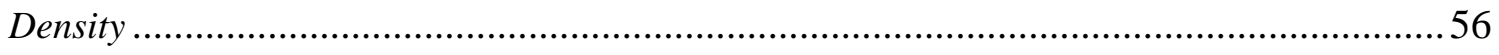

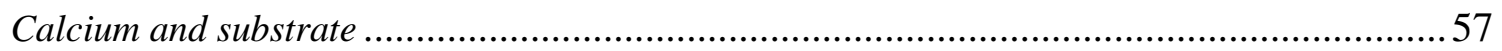

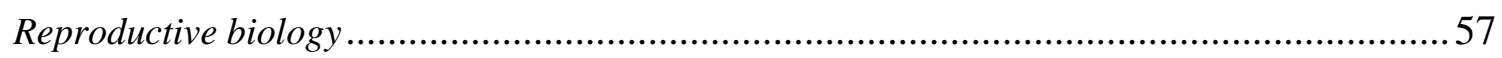

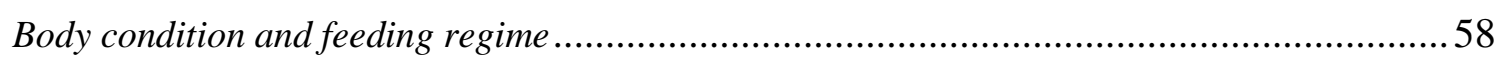

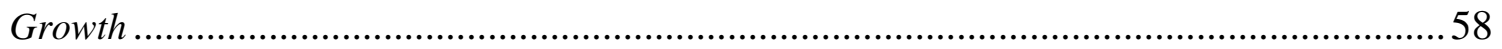

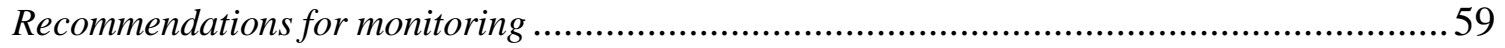

References ..............................................................................................................................................6 60

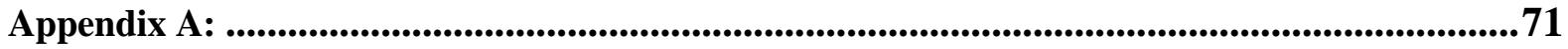

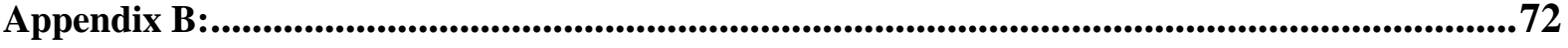




\section{List of Figures}

\section{Chapter 3}

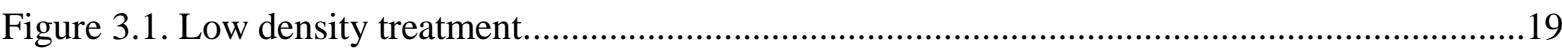

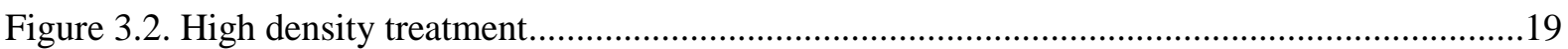

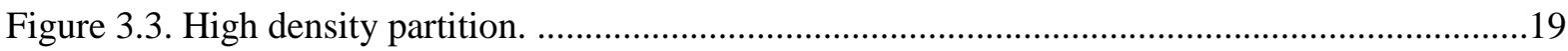

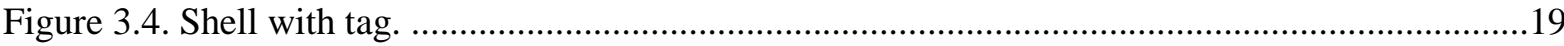

Figure 3.5. Digital scales with paper towel. ..................................................................................19

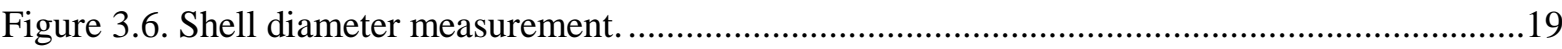

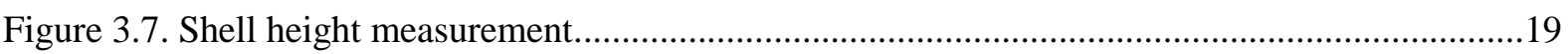

Figure 3.8. Containers in cool store

Figure 3.9. Proportion of groups remaining in the experiment (survival) ............................................20

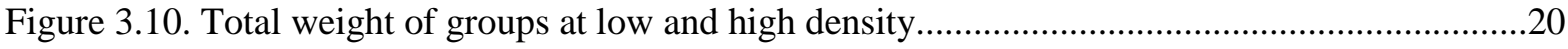

\section{Chapter 5}

Figure 5.1. Shell volume and size of first clutch produced in captivity ..............................................28

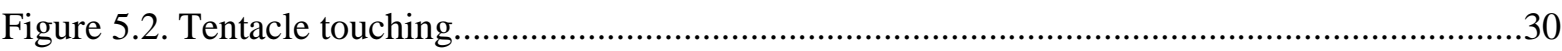

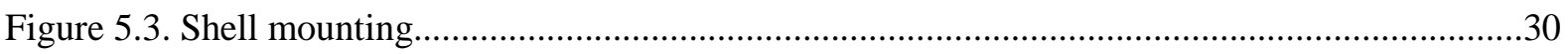

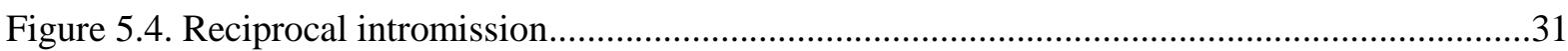

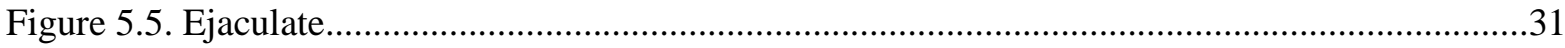

Figure 5.6. Body condition and the proportion of activity spent courting........................................33

\section{Chapter 6}

Figure 6.1. Mass vs. size for 5373 P. augusta at time of capture.......................................................38

Figure 6.2. Residuals from a mass/size regression of $P$. augusta at time of capture...........................39

Figure 6.3. Mass vs. size for $P$. augusta at time of capture, after the removal of two outliers............ .39

Figure 6.4. Residuals from a mass/size regression averaged by month of capture...............................40

Figure 6.5. Mass/size regression of P. augusta captured in December 2006 and January 2007..........41

Figure 6.6. Change in body condition over two years in 47 captive $P$. augusta .................................42

Figure 6.7. Temperature and rainfall recorded on Mt Augustus by a weather station..........................44 


\section{Chapter 7}

Figure 7.1. Growth rate vs. size for 204 captive $P$. augusta............................................................48

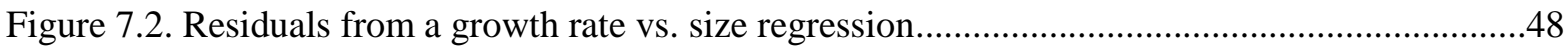

Figure 7.3. Residuals from a weighted least squares regression of growth rate vs. size......................49

Figure 7.4. Predicted growth in shell diameter from the age of one year............................................50

Figure 7.5. Growth rate vs. mass for 204 captive $P$. augusta ................................................................51

Figure 7.6. Residuals from a regression of growth rate vs. mass........................................................51

Figure 7.7. Residuals from a weighted least squares regression of growth rate vs. mass.....................52

Figure 7.8. Predicted growth in mass from the age of one year........................................................53 


\section{List of Tables}

\section{Chapter 2}

Table 2.1. Negative effects of density on laboratory snail populations.

\section{Chapter 4}

Table 4.1. Mortality amongst $P$. augusta kept on limestone chip and sphagnum moss .25

Table 4.2. Eggs laid by groups of $P$. augusta kept on limestone chip and sphagnum moss.

\section{Chapter 5}

Table 5.1. Failure to emerge and the frequency of copulation (L-L pairs) 32

Table 5.2. The activity of small and large $P$. augusta...... .33

Table 5.3. Copulations among pairs of small and large P. augusta. .34 


\section{Chapter 1: Introduction}

In this thesis I investigate some aspects of the captive husbandry of Powelliphanta augusta, a newly-described New Zealand land snail. Specifically, I address how they should be managed and fed to provide individuals for release back into the wild, and how a long-term captive population can be maintained as an insurance against extinction in the wild. This project arises from almost all members of this species having been brought into captivity due to their displacement in the wild by an opencast coalmine.

Powelliphanta (F: Rhytididae) is a genus of carnivorous snails, endemic to New Zealand. The most cited classification of Powelliphanta recognizes 10 species and 27 subspecies (Powell 1979). This taxonomy is contentious, however, (Climo 1978) and a number of undescribed taxa are recognised (Walker 2003). As well as its diversity, Powelliphanta is renowned for the large size of its members (up to 90mm diameter) and their attractively-patterned shells. Most taxa are threatened due to historical habitat loss, and predation by introduced mammalian predators (Meads et al. 1984), requiring their active management by New Zealand's Department of Conservation (DOC) under an extensive recovery plan (Walker 2003). All Powelliphanta are legally protected under schedule seven of the Wildlife Act 1953 (Mackenzie 2005).

In 1996 Powelliphanta shells were collected from Mt Augustus, on the South Island's West Coast Stockton plateau. These shells were initially thought to be of Powelliphanta patrickensis, a species previously known from the plateau. However, a reexamination in 2003 suggested they belonged to an undescribed taxon. In 2005, a genetic study confirmed the existence of a distinct lineage on Mt Augustus (Trewick et al. 2008) and this was later described as a new species, Powelliphanta augusta (Walker et al. 2008).

The Stockton Plateau is the site of a large open cast coalmine ( 2300 ha) operated by Solid Energy New Zealand Limited, a state-owned enterprise. By the time P. augusta was first recognized, most of its habitat had been destroyed through the mines' expansion, and only 5 ha of habitat remained on the ridgeline of Mt Augustus (Trewick et al. 2008). This remnant was also to be mined for the 2.5 million tonnes of premium coking coal lying beneath it. But before it could continue mining Solid Energy was required by the Minister of Conservation in 2006 to move the snails, and to formulate and fund a management plan to secure their long- 
term survival. Between July 2006 and June 2007, over 6000 snails and 1000 eggs were collected in the field and transferred to a specialist facility (laboratory) operated by DOC, at its West Coast Conservancy office in Hokitika, nearly 200km south of the mine.

\section{Precedents}

The propagation of snails for human consumption is well established and is supported by an extensive literature (Cooper and Knowler 1991; Dupont-Nivet et al. 2000; Flari and Lazaridoudimitriadou 1995; Jess and Marks 1995). But there have been very few captive breeding attempts or translocations of land snails for conservation purposes and much of the relevant literature is focused on two S-W Pacific genera Partula and Placostylus.

The conservation effort for Partula has included captive breeding since the early 1980s and 20 species from the tropical South Pacific have been maintained in universities and zoos throughout the world (Tonge and Bloxam 1991). At least 12 of these species are extinct in the wild (Cunningham and Daszak 1998). Captive populations have experienced periodic crashes, probably due to pathogens, and three species have become extinct in captivity (Cunningham and Daszak 1998).The major threat to Partula in the wild is the introduced carnivorous snail Euglandia rosea. As this threat remains, very few Partula reintroductions have been conducted. There has been one introduction of Partula taeniata into a patch of vegetation in the Royal Kew Botanic Gardens and although monitoring has been difficult, the introduction is thought to have been successful (Pearcekelly et al. 1995). A reintroduction into a predator-proof exclosure on the French Polynesian island of Moorea was unsuccessful, due to inadequate monitoring and maintenance (Coote et al. 2004). The snails did produce young that survived into adulthood, even after six generations in a highly artificial environment. However, these were eventually killed by E. rosea breaching the exclosure (Coote et al. 2004).

Placostylus has also been the focus of conservation efforts involving captive breeding and translocation. After initial difficulties, Placostylus fibratus have been successfully captivebred in large numbers in New Caledonia (Brescia et al. 2008; Salas et al. 1997). Large scale reintroductions of this species are planned, but still pending at time of publication (Brescia et al. 2008). Placostylus in New Zealand have in the past been transferred on a number of occasions, often by private individuals, but most of these are not well documented (Stringer and Parrish 2008). In more recent times, seven Placostylus ambagiosus paraspiritus were 
successfully reared in captivity and then released into outdoor cages, however, all died within a year from desiccation (Stringer and Parrish 2003). One Placostylus hongi, captive for 10 years, was transferred to a predator-free island in 2002 along with 10 truly captive-bred conspecifics (Stringer and Parrish 2008). Although there was evidence of growth and reproduction, all were found dead by 2004. Most were probably killed by unusually dry weather, with the cause of death for two snails unknown (Stringer and Parrish 2008). Both $P$. ambagiosus and $P$. hongi were successfully reared from eggs to adulthood in captivity (Stringer and Grant 2007).

\section{Husbandry of Powelliphanta augusta}

The husbandry of $P$. augusta has two purposes: short-term management of large numbers of snails before their translocation, and the long-term management (5-10 years) of a captive breeding colony. Powelliphanta have not been kept in captivity successfully before; in the 1980s Kath Walker kept several species in outdoor enclosures, but all snails were eventually killed by an unknown pathogen (K. Walker pers. comm.).

Upon initial field collection the snails were kept individually in 10 x $10 \mathrm{~cm}$ plastic containers on a substrate of sphagnum moss and housed in a cool store at a constant $7^{\circ} \mathrm{C}$ and without light. The cool stores rarely get above the set temperature, but in extremely cold weather it may drop below it by several degrees overnight. Every four weeks, the moss in the container is replaced and the snail is fed a single live earthworm, of the exotic species Eisenia andrei. The monitoring regime in captivity has varied, but most snails have been measured (shell diameter and height) and weighed at least every six months.

The use of environmental chambers is currently being trialed for the long term captive breeding colony. These chambers provide a programmable photoperiod, temperature control and water spray.

Although the largely improvised approach to short-term management seems to have been successful, there are a number of questions regarding the appropriateness of the regime, and its long-term impact on the snails. I commenced my study by conducting a literature review to refine husbandry methods and to assess the requirements for captive breeding (chapter 2). From this review I chose to investigate stocking densities (chapter 3), substrate (chapter 4), reproductive biology (chapter 5), body condition (chapter 6) and growth (chapter 7). 


\section{Chapter 2: Biology and Husbandry of Stylommatophorans}

The purpose of the review is to generate ideas to support the captive husbandry of Powelliphanta augusta in an artificial environment and to gain some expectations as to their likely response and amenability to captive breeding.

My review summarizes relevant knowledge on the biology of land snails and slugs (Gastropoda: Pulmonata: Stylommatophora), with some additional data from the aquatic snails (Gastropoda: Pulmonata: Basommatophora). It specifically concentrates on features of reproduction, and other aspects of their biology that are pertinent to captive breeding and husbandry.

\section{Environmental control of activity and reproduction}

The integument of snails is permeable to water, and water is also lost through the production of mucus, which is necessary for locomotion (Cook 2001). Hence, these animals are particularly prone to dehydration and this vulnerability explains much of their ecology.

To conserve water, snails are frequently nocturnal and more active during rainfall. For example, Helix aspersa is more active at night, but inactive altogether during dry spells (Bailey 1981), while Helix pomatia is active during the night and early morning in dry conditions, with periods of activity alternating with periods of rest (Lind 1988). In rainy conditions both species are active over 24 hrs (Attia 2004; Bailey 1981). Cepaea nemoralis is also most active during rain, especially when rain alternates with fine weather and conditions are warm and wet (Wolda and Kreulen 1973). Mesodon thyroidus held in enclosures in situ are predominantly nocturnal, but also crepuscular (Blinn 1963).

In the laboratory, land snails will remain active with the absence of rain if the air is sufficiently saturated and there is some interaction with temperature. Lazaridou-Dimitriadou and Saunders (1986) maintained Helix lucorum in treatments manipulating humidity, temperature and photoperiod, each at two levels. They found humidity to be the primary regulator of activity, although between $40 \%$ and $60 \%$ of snails died in the treatments at the highest temperature $\left(29^{\circ} \mathrm{C}\right)$. When kept at $5^{\circ} \mathrm{C}$ under a $15: 9$ (L: D) photoperiod, roughly $20 \%$ of adult snails were active at $30 \%$ relative humidity $(\mathrm{RH})$ and $50 \%$ were active at $80 \% \mathrm{RH}$. Placostylus fibrosus kept in the laboratory at $20^{\circ} \mathrm{C}$ are significantly more active at $95 \% \mathrm{RH}$ 
than $80 \% \mathrm{RH}$, but very few snails are active at $25^{\circ} \mathrm{C}$ and $30^{\circ} \mathrm{C}$, even at $95 \% \mathrm{RH}$ (Salas et al. 1997). Octala lactea are inactive below $58 \% \mathrm{RH}$, and the proportion of active snails increases with $\mathrm{RH}$ above this threshold, no snails are active above $30^{\circ} \mathrm{C}$ regardless of humidity (Herreid and Rokitka 1976). The desert snail Trichonephrus hautoni is only active when both the humidity is above $85 \% \mathrm{RH}$ and the temperature below $11^{\circ} \mathrm{C}$ (Dallas et al. 1991, in Cook 2001).

The fact that land snails are active over 24 hours during rain or high humidities suggests that their nocturnal behavior in the field is a response to the change in environmental moisture and not to time of day per se, and some laboratory observations support this. For example, $P$. fibrosus are nocturnal in the field, but in captivity activity is independent of photo phase (Salas et al. 1997). Furthermore, C. nemoralis, Cepaea hortensis and Arianta arbustorum demonstrate no behavioral rhythm at $0^{\circ} \mathrm{C}$, but are increasingly nocturnal with higher temperatures (Cameron 1970). However, in other experiments behaviour is influenced by photoperiod, as well as endogenous rhythms.

Bailey (1981) maintained $H$. aspersa under simulated summer and winter photoperiods, as well as 12:12 (L: D) and constant darkness. The temperature in all treatments varied little from $17.4^{\circ} \mathrm{C}$, and humidity was $95 \%$. Snails were mostly active two-three hours after the onset of darkness in the photoperiod treatments. In constant darkness there was a rhythm of 25.5 hours so that the peak in activity became progressively later each night. Slugs of the species Limax maximus and Limax fluvans showed $24 \mathrm{hr}$ activity cycles when kept under constant darkness (Beiswanger et al. 1981). Those kept under 16:8 (L: D) photoperiod showed a circadian rhythm, with a major peak in activity during the dark phase, and a smaller peak during the light phase. When this phase was shifted by 12 hours, the slugs showed no activity at all. Ogasawara and Tasaki (1990) maintained Achitina fulica at three photoperiods; 14:10, 12:12, 10:14 (L: D), with a constant temperature and humidity. Under all three regimes, activity began shortly before darkness and peaked at one to two hours after dark. There was another peak in activity six hours after dark.

$H$. lucorum may synchronise its activity to skeletal photoperiods consisting of only two onehour bursts of light within 24 hours (Flari and Lazaridou-Dimitriadou 1995). Limicolaria festiva are active during the early part of the dark period in photoperiods of 8:16, 12:12 and 
16:8 (L: D), and in constant darkness they show a similar behavioural rhythm, but with a period of 24.4 hrs (Elrayah et al. 1984).

As well as circadian rhythms, snails also display circannual rhythms. Reproduction is generally seasonal, and in all stylommatophorans studied the timing is influenced by photoperiod (Cook 2001).

Both $C$. nemoralis and H. pomatia mate in spring and produce eggs in summer (Pollard 1975; Wolda and Kreulen 1973). H. aspersa in the north of Spain also produce eggs in summer, but in the hotter south egg production is only in spring and autumn (Iglesias et al. 1996). New Zealand's Paryphanta busbyi mate in autumn to early winter (March-June), but oviposition peaks in both August/September and November/December (Stringer et al. 2003). In the closely related Powelliphanta the timing of mating is not known, but most species lay eggs from late October to early December (O'Connor 1945).

An increase in reproductive activity in some species is correlated with hotter, wetter weather (Iglesias et al. 1996; Wolda and Kreulen 1973). However, it is unclear whether this is the result of the adaptive timing of reproduction, or merely increased activity. In the field, high temperatures and rainfall stimulate mating in H. pomatia (Lind 1988; Pollard 1975), but in the laboratory there is no difference in mating frequency between $15^{\circ} \mathrm{C}$ and $20^{\circ} \mathrm{C}$ (Gomot 1990).

Experiments have confirmed the importance of photoperiod in reproduction, with temperature playing a minor role. H. aspersa kept at a constant temperature with a photoperiod simulating the seasons retained their natural circannual rhythm. Reproduction occurred at the usual time of year, while those kept under a 12:12 (L: D) photoperiod displayed a faster circannual rhythm, with a period of around eight-nine months (Bailey 1981). H. pomatia laid significantly more eggs under long photoperiods 18:6 (L: D), than under short photoperiods 8:16 (L: D) (Gomot 1990). Although there was no difference between two temperature regimes $\left(15^{\circ} \mathrm{C}\right.$ and $\left.20^{\circ} \mathrm{C}\right)$ under long photoperiods, significantly more eggs were laid at $20^{\circ} \mathrm{C}$ under short photoperiods (Gomot 1990). Mating was inhibited under short photoperiods, with no difference between temperatures. 
Photoperiod may also be important for sexual maturation; L. maximus slugs kept under short photoperiods remain immature indefinitely (Wayne 2001).

High temperatures hastened the start of oviposition in a natural population of $C$. nemoralis (Wolda and Kreulen 1973). The maturation of the ovotestis in this species is also influenced by temperature. In $C$. nemoralis kept at $0^{\circ} \mathrm{C}$ all gametogenesis is inhibited, at $6^{\circ} \mathrm{C}$ spermatogenesis is inhibited and oogenesis promoted, and at $23^{\circ} \mathrm{C}$ spermatogenesis is promoted and oogenesis is partially inhibited (Bouillon 1956).

\section{Parasites and diseases}

Mites of the genus Riccardoella parasitize a number of different species of land snails and slugs (Baur and Baur 2005). The mites may be transmitted during courtship and copulation, and the prevalence of infection may increase with host population density.

High stocking densities may increase the susceptibility to disease in farmed snails. The protozoan parasite Tetrahymena rostrata was found to be more abundant among intensively managed $H$. aspersa, then extensively managed (Segade et al. 2009).

Nematodes from a number of different genera infect snails, but their effects are not typically fatal (Cooper and Knowler 1991). Some nematodes may reduce the fecundity of their hosts, for instance, the number of Nemhelix bakeri infecting $H$. aspersa, is negatively correlated with egg production (Morand 1989, in Morand and Faliex 1994).

A significant study on snail pathology for conservation was conducted on the genus Partula in captivity (Cunningham and Daszak 1998). Pathological examinations were conducted on 37 dead snails from several species. Swabs and faecal samples were taken from 18 living controls. Bacteriological examination revealed dozens of species present (Cunningham et al. 1996), but no species was present significantly more on dead snails than on living snails. Four dead snails all from the same enclosure showed distinctive lesions associated with amoeboid structures, although the deaths could not be conclusively attributed to the protozoa. However, some previous mortality of snails had been associated with the growth of amoeba on food (Cunningham et al. 1996). Partula have remained vulnerable to disease even after years in captivity; a captive population of Partula turgida that had been increasing over five years, declined to extinction over 21 months (Cunningham and Daszak 1998). The disease 
responsible was later identified as a microsporidian from the genus Steinhausia. The disease may have possibly been introduced by another Partula species, although no microsporidia were found on those housed in the same room as P. turgida (Cunningham and Daszak 1998). The authors also speculated that the disease may have been pre-existing and an environmental change increased its virulence, although they did not explain what this change might have been.

The bacterial genera Aeromonas and Pseudomonas include pathogens of snails that may reduce activity and response to stimuli in infected individuals (Cooper and Knowler 1991; Kiebre-Toe et al. 2005; Kodjo et al. 1997). Both these genera are cosmopolitan (Pettibone 1998; Timmis 2002) and need not be brought into captivity with snails in order to infect them. Aeromonas hydrophila was associated with disease in Hawaiian populations of $A$. fulica (Dean et al. 1970) and a 1994 outbreak among farmed H. aspersa in France (Kodjo et al. 1997). This disease affects a wide range of vertebrate and invertebrate animals and outbreaks may result in 100\% mortality in gastropod populations (Raut 2004).

\section{Density}

There is an extensive literature on the effects of density on snail populations. The negative effects of density include; reduced growth rates, reduced adult size, reduced fecundity and reduced survival (Table 2.1).

Reduced growth rates have been consistently associated with increased density in a number of different species, but for reasons unknown. Some authors have suggested that pheromones in snail mucus retard growth directly, or indirectly by inhibiting feeding and activity (Cameron and Carter 1979; Dan and Bailey 1982).

Cameron and Carter (1979) pre-treated containers with mucus by allowing 10 snails to crawl around them for 2 hours. Two test snails were then placed in the containers, and their level of activity was compared with that of controls. Juveniles and adults of C. nemoralis, C. hortensis and H. aspersa were used, in different combinations of species and age-classes. No adult activity was inhibited, but the activity of juveniles was inhibited by the mucus of conspecific adults in $C$. nemoralis and $C$. hortensis. The mucus of adult $C$. nemoralis also inhibited the activity of juvenile $C$. hortensis. 
Table 2.1. Negative effects of density on laboratory snail populations.

\begin{tabular}{|l|l|l|}
\hline Species & Density negatively affects & References \\
\hline Arianta arbustorum & fecundity, hatching success & (Reichardt 1985) \\
\hline Balea perversa & $\begin{array}{l}\text { growth rates, adult size, } \\
\text { fecundity, survival }\end{array}$ & (Baur 1990; Baur and Baur 1990) \\
\hline Chondrina clienta & growth rates, adult size, survival & (Baur and Baur 1990) \\
\hline Cepaea hortensis & growth rates & (Cameron and Carter 1979) \\
\hline Cepaea nemoralis & growth rates, adult size & $\begin{array}{l}\text { (Oosterhoff 1977) } \\
\text { (Cameron and Carter 1979) }\end{array}$ \\
\hline Helix aspersa & $\begin{array}{l}\text { growth rates, adult size, } \\
\text { fecundity, survival }\end{array}$ & $\begin{array}{l}\text { (Cameron and Carter 1979; Dan and } \\
\text { Bailey 1982; Dupont-Nivet et al. } \\
\text { 2000; Jess and Marks 1995; } \\
\text { Lazaridou-Dimitriadou et al. 1998) }\end{array}$ \\
\hline Helisoma duryi & growth rates, fecundity & (Madsen et al. 1983) \\
\hline Helicella virgata & growth rates, fecundity & (Pomeroy 1969) \\
\hline Marisa cornuarietis & growth rates, fecundity & (Aufderheide et al. 2006) \\
\hline Mesodon normalis & survival & (Foster and Stiven 1996) \\
\hline
\end{tabular}

Dan and Bailey (1982) pre-treated containers with mucus by allowing a single adult $H$. aspersa to crawl around in them for 6 hours. The activity of juvenile $H$. aspersa was reduced after being placed in this container, but not that of adults. A similar mucus pre-treatment experiment was conducted with juvenile Balea perversa and Chondrina clienta, with growth rate as the response variable (Baur and Baur 1990), but there was no effect of mucus for either species. Bull et al. (1992) found no consistent inhibition of activity by mucus in the species Theba pisana and Cernuella virgata, but did observe inhibition by faeces pretreatment.

Survival may decline with increased stocking density (Baur and Baur 1990; Dan and Bailey 1982; Foster and Stiven 1996; Pomeroy 1969; Reichardt 1985), but again the mechanism remains obscure. Foster and Stiven (1996) tested the effects of density and food competition in a factorial experiment, with three levels of density (one, two and five snails per container) and three levels of feeding (once a day, twice a day and ad libitum). Although survival at the second level of density was greater than that at the highest density, it was independent of 
feeding level. Reichardt et al. (1985) also reported density-dependent survival with ab libitum feeding.

\section{Diet and substrate}

The Powelliphanta are a carnivorous group and their dietary requirements differ substantially from most snails. Earthworms are the major prey item of $P$. augusta (Walker et al. 2008), but the frequency of predation is unknown.

The eggs of 36 families of land snail contain calcium carbonate, including the Rhytididae (Tompa 1976). Adequate calcium is crucial to reproduction and snails deprived of it may produce no eggs at all (Egonmwan 2008). In addition to diet, snails may obtain calcium from the substrate by direct absorption through the sole of the foot. And calcium can be stored long-term in the shell, digestive gland and the connective calcium cells (Fournie and Chetail 1984). Forms of calcium supplementation given to snails include: chalk (Egonmwan 2008); cuttlebone (Tonge and Bloxam 1991); dolomite (Gardenfors 1992) and limestone (Ebenso 2003).

Vitamin E positively affects juvenile survival in captive Partula tohiveana (Tonge and Bloxam 1991). Biomphalaria glabrata initially denied vitamin E, did not produce eggs until after its introduction into the diet (Vieira 1967, in Morris 1991). Snails may obtain some nutrition from the substrate; $H$. aspersa reared on soil were significantly heavier than those raised on moist filter paper (Jess and Marks 1989).

\section{Hermaphroditism}

All pulmonates are hermaphrodites (Jordaens et al. 2007), but only 18 genera in the Stylommatophora are known to self-fertilize (Heller 1993). Sperm transfer may be simultaneously reciprocal or unilateral (Davison and Mordan 2007). Many snails have the ability to store sperm long-term, for between several months and several years (Jordaens et al. 2007). Partly to increase the viability of donated sperm, some snails may shoot calcareous 'love' darts into their mate. This trait is confined to three monophyletic groups, and the Rhytididae is not amongst them (Davison et al. 2005). 
Size-specific fecundity and size-assortative mating

Fecundity tends to increase with size in most pulmonates (Jordaens et al. 2007). Larger $C$. nemoralis produce bigger clutches more frequently (Wolda and Kreulen 1973). Egg numbers also increase with parental size in A. fulica and A. arbustorum, but so does the mass of each egg (Baur, 1988; Tomiyama and Miyashita 1992, in Tomiyama 1996). The greater mass of eggs may improve hatchling survivorship (Heller 2001).

If larger snails are more fecund, then they may be preferred as mates over smaller snails. Such a preference will result in size-assortative mating (Baur 1992) which, in Succinea putris, has been examined in a number of ways. Dillen et al. (2008) placed small and large snails in pairs of same-sized and mixed-sized individuals. They then compared the frequency of copulation between pair types, but this did not differ. In another experiment $S$. putris were offered a choice by placing two small and two large individuals together, but again no size preference was shown (Jordaens et al. 2005).

Two experiments similar to those with $S$. putris, were conducted with the pond snail Lymnaea stagnalis (Koene et al. 2007). Twelve pairs of two large, 14 pairs of one large and one small, and 14 pairs of two small snails were formed; 32 of the 40 pairs copulated, but there was no difference in pair type frequency. In the second experiment a focal individual which had been kept in isolation (to increase mating drive) was placed with one large and one small snail, but no size preference was shown.

Although size-assortative mating has not been demonstrated in controlled experiments, it has been observed in natural populations of H. pomatia (Baur 1992) and A. fulica (Tomiyama 1996). In A. fulica size discrimination occurs at two levels. This species is protandrous, producing sperm for three-six months before becoming fully sexually mature and simultaneously hermaphroditic (Tomiyama 1996). As a result, old adults are preferred as mates over young adults, but there is also size-assortative mating within old adults as fecundity increases with size. It has been suggested that the absence of size-assortative mating in land snails is the result of high search costs for mates, imposed by unfavorable environmental conditions and/or low population densities (Baur 1992; Jordaens et al. 2005), neither of these hypotheses has been explored in pulmonates. 


\section{Isolation}

Isolating individual snails may increase their drive to mate: $H$. aspersa isolated for one week showed more courtship behaviour than those having daily conspecific contact (Adamo and Chase 1990). Dillen et al. (2008) kept 220 S. putris in individual isolation, and another 225 in groups of 25 for two weeks. Pairs were then formed between either two isolated snails (IxI), two non-isolated snails $(\mathrm{N} \times \mathrm{N})$, or one from each treatment $(\mathrm{I} \times \mathrm{N})$. Significantly more copulations took place between $\mathrm{I} \times \mathrm{I}$ pairs $(47 / 60)$ than $\mathrm{I} \times \mathrm{N}$ pairs $(23 / 100)$, and between each of these and $\mathrm{N} \times \mathrm{N}$ pairs $(4 / 60)$. Isolated $S$. putris were more likely to take the active mating role (shell mounting) than snails kept in groups. Additionally, 100 S. putris were kept in isolation and 150 in groups of 15 for two weeks (Dillen et al. 2008). Isolated individuals had larger prostate glands and smaller albumen glands compared with controls, indicating a higher allocation of resources to the male function. Similarly, the prostate gland of the pond snail L. stagnalis shrinks with repeated mating (Koene et al. 2006).

\section{Gender expression}

Like isolation, body size can affect the allocation of resources between male and female function; large individuals are predicted to allocate more resources to female than male function, and the reverse is true for small individuals (Angeloni et al. 2002). In matings within the species of Physa acutsa, Physa gyrina and Physa heterostropha, the smaller partner is more likely to donate sperm (DeWitt 1996; Ohbayashi-Hodoki et al. 2004).

\section{Inbreeding depression}

Although all pulmonates are hermaphrodites, only a minority appear to self-fertilize (Heller 1993). Among those species that can self-fertilize, doing so may result in poorer reproductive success. Bulimulus tenuissimus raised in isolation took considerably longer to produce eggs than those raised in groups of seven (454 vs. 211 days) (Silva et al. 2008). Furthermore, isolated snails produced significantly fewer eggs and only $15.8 \%$ of these hatched compared to $39 \%$ of the grouped snail eggs. In the freshwater snail Lymnaea peregra the survival of hatchlings from selfing was significantly less than those from out-crossing (Jarne and Delay 1990). Habroconus semelini is a semelparous species and isolated snails were found to be more fecund than those kept in groups of 10 (Silva et al. 2009).

In addition to selfing, inbreeding depression may result from matings between closely related individuals. Chen (1993) formed pairs of A. arbustorum, where each individual was either 
from the same clutch or a different population entirely. Although there was no difference in the number of eggs produced, the hatching success of these was $\approx 50 \%$ in the outbred snails and $\approx 30 \%$ in the inbred snails. The survival of outbred hatchlings was also significantly greater over one year in a semi-natural setting.

As inbreeding may reduce fitness, inbreeding avoidance may occur in mate choice. $P$. acuta rejected potential mates from the same brood more frequently than non-kin, sympatric, or allopatric snails (Facon et al. 2006). A. arbustorum sampled from three populations preferred to mate with allopatric over sympatric partners (Baur and Baur 1992). In contrast, B. glabrata and Biomphalaria pfeifferi preferred to mate with sympatric over allopatric partners, but the performance of the progeny was not assessed (Rupp and Woolhouse 1999).

\section{Repeated mating}

Land snails may mate more than once in a reproductive season, even when a single copulation can fertilize all that seasons' eggs (Jordaens et al. 2007). Lind (1988) recorded the number of matings in a season by 127 frequently observed individuals; 29 did not mate, 60 mated once, 27 mated twice, ten mated three times and one mated four times. A. arbustorum mate at least twice in a reproductive season, but stored sperm is depleted over time (Baur 1994). The second mate will sire $34 \%$ of the offspring if the matings occur within 70 days of one another, or $76 \%$ if the second mating is over 70 days later (Baur 1994). Repeated mating promotes greater egg production in the pond snail L. stagnalis (Koene et al. 2006).

\section{Growth and longevity}

Life spans of terrestrial gastropods range from several months to 19 years (Heller 2001). The time between generations in Powelliphanta may exceed 15 years (Meads et al. 1984), which places them among the more long-lived species.

There is evidence to suggest this life-cycle could be accelerated in captivity. $C$. nemoralis in the laboratory take 18 months to mature (Wolda 1970) compared with three years in the field (Williamson 1976), although the factors responsible have not been identified. The juvenile periods of both Placostylus ambagiosus paraspiritus and Placostylus hongi were reduced in captivity because the snails could feed every night, whereas in the wild feeding is often interrupted by dry conditions (Stringer and Grant 2007). In captive New Caledonian 
Placostylus, accelerated growth rates have reduced the age at maturity from five to two years (Brescia et al. 2008).

Growth is generally not affected by photoperiod, but there are exceptions (Gomot 2001). For example, H. aspersa matured earlier, and had higher body weights under long days (18:6 or 24:0 L: D) than under short days (08:16 or 12:12 L: D) (Gomot et al. 1982; Gomot and Deray 1987 in, Gomot, 2001). In a separate experiment, snails of the same species were heavier at four months when reared at higher temperatures (Gomot 1994, in Gomot, 2001).

\section{Implications of the review}

This review has highlighted a number of potential challenges to both the captive maintenance and captive breeding of $P$. augusta.

1. Environmental control of activity. If the sphagnum moss on which P. augusta in short-term management are held is kept moist, the snails should be adequately hydrated, and regular weighing will indicate if this is not the case. $P$. augusta may well retain their behavioural rhythms without light, or with only a brief exposure during the day, and a simple $\log$ of activity could evaluate this. However, photoperiod is an important reproductive cue for land snails and those $P$. augusta in short-term management cannot be expected to mate and produce eggs in any great number. When environmental chambers become available, the combination of photoperiod and temperature under which $P$. augusta is most fecund, could be tested in a factorial experiment.

2. Parasites and diseases. Invertebrate pathology is not well developed and to establish what pathogens are a threat to $P$. augusta presents difficulties. To identify disease as a cause of mortality would require a number of samples from both dead snails and living controls. Even if a disease responsible for mortality is identified, it does not mean it can be eradicated. Prevention is the best way to mitigate the effects of disease through regular cleaning of housing and equipment, and the use of modest stocking densities.

3. Density. Density is obviously not an issue for those snails kept individually in shortterm management. However, snails in long-term management will need to be kept in groups for the purposes of breeding and an appropriate density for these must be established. High stocking densities can result in slower growth rates, reduced adult size and reduced fecundity, 
but the most serious consequence is reduced survival. A suitable stocking density for groups of snails should be determined experimentally, whilst minimizing mortality.

4. Diet and reproduction. Powelliphanta should be expected to have a high demand for calcium, given their heavily calcified eggs and $P$. augusta in their natural environment may have the opportunity to absorb calcium directly from the substrate. Calcium supplementation should be given to some captive snails and their reproductive output compared with that of controls. Limestone is the cheapest and most readily available supplement obtainable.

5. Size-specific fecundity and size-assortative mating. There is considerable variation in the size of reproductively mature $P$. augusta. Snails which have produced eggs in captivity range from $30 \mathrm{~mm}$ to $40 \mathrm{~mm}$ in diameter. An analysis of the records of reproduction in captivity should be conducted to test for size-specific fecundity. If this is present in this species, then mating between individuals divergent in size may not occur. Size-assortative mating should be investigated through the use of mate choice experiments.

6. Diet and feeding regime. The natural rate of earthworm predation by P. augusta would, ideally, determine their captive feeding regime. As this rate is unknown, an alternative approach is to adjust feeding so that the body condition (weight in relation to size) of captive snails resembles their natural state. The weight and size of each snail was measured at the time of capture and this data could be used to assess and monitor body condition in captivity.

7. Growth and maturity. The time until maturity for P. augusta potentially exceeds a decade. Estimates of growth rates in captivity need to be made to inform plans for captive breeding. The effort required for breeding will be highly dependent on the time between generations.

I will now present the results of research which addresses the issues and questions generated by this review. I start in chapter three with an experiment to determine the optimal stocking density for captive $P$. augusta. 


\section{Chapter 3: The Effect of Stocking Density on Survival and Well-being.}

During the transitional management, Powelliphanta augusta snails have been kept individually, but captive breeding requires snails to be kept in groups. The appropriate stocking density for these groups requires some consideration. Density can negatively affect life-history traits such as growth, size at maturity, fecundity and most significantly, survival (Baur 1990; Baur and Baur 1990). Its effect on P. augusta cannot easily be ascertained from the wild where its habitat is extremely patchy and its distribution likewise (Walker et al. 2008). Therefore, I compared snails kept at two essentially arbitrary densities and evaluated the effect of density on survival, and well-being; as expressed through weight gain.

\section{Methods}

I first selected a container that was of large, but manageable size $\left(1440 \mathrm{~cm}^{2}\right)$; this was $48 \mathrm{~cm}$ in length, $30 \mathrm{~cm}$ in width and $12 \mathrm{~cm}$ in height. In a low density treatment six snails were cohoused in the container (Fig. 3.1). In a high density treatment the container was partitioned down the middle and six snails were placed in each half, so that two groups were in a single container (Fig. 3.2). The partition consisted of a thick piece of plastic cut to the shape of the container, which was sealed and held in place by weather stripping (Fig. 3.3). The rim of the container was also sealed with weather stripping to prevent worms fed to the snails, from taking refuge in the space between the container and the lid. Each container held $2 \mathrm{~kg}$ of damp sphagnum moss, $1 \mathrm{~kg}$ in each half for the high density containers. The areas available to the low and high density groups were $1440 \mathrm{~cm}^{2}$ and $720 \mathrm{~cm}^{2}$, respectively.

To monitor individuals, each snail was tagged with a number printed on water-proof paper, which was attached with Selleys $®$ Supa glue to the shell (Fig. 3.4). Snails were weighed at the beginning of the experiment and when the groups were re-housed every four weeks (Fig. 3.5). At the beginning and the end of the experiment only, the shell maximum diameter (Fig. 3.6) and shell height (Fig. 3.7) were measured with digital callipers, although the shell height was not subsequently used in this experiment. The containers were kept in an industrial coolstore set at a constant $7^{\circ} \mathrm{C}$ (Fig. 3.8). At re-housing the containers were rotated through their positions on the shelves to control for any temperature variation with height.

When re-housed the containers were washed with hot water and detergent and the substrate replaced with fresh moss, six worms were placed in the container after the snails had been 
returned to it, i.e., the snails competed for food. To avoid cross-contamination between groups, a fresh piece of paper towel was placed on the scales when groups were weighed and hands were washed between the handling of groups.

Every two weeks the groups were checked for mortalities and dead snails were removed. If a death occurred, the surviving members were re-housed individually to check the spread of any possible infection, and they were no longer part of the experiment.

A single replicate consists of one whole container holding a low density group and one half of a container holding a high density group. 24 replicates were made; 24 containers holding low density groups and 12 containers holding high density groups. Replicates 1-12 were created during the week beginning June 22008 and replicates 13-24 the week beginning June 16 2008. The experiment lasted 52 weeks with the last re-housing of replicates 1-12 during the week beginning June 12009 and replicates 13-24 the week beginning June 152009.

\section{Statistical analysis}

As a group had to be removed from the experiment when a death occurred, the group forms the experimental unit. Survival in each group was modelled using the Kaplan-Meier estimator, and the null hypothesis that the survival distributions for each treatment are identical, was tested with the Log-rank test.

As a measure of well-being, I examined the change during the experiment in the combined weight of each group. I tested whether this differed between the beginning and end of experiment, as well as between densities.

As I expected some weight loss associated with a period of adjustment, I used the weights at week four for a 'pre-treatment' weight measure. I used a mixed-design repeated-measures ANOVA, with density as the between-subjects variable and time as the within-subjects variable (Quinn and Keough 2002). A significant interaction between time and density would indicate an effect of density on weight change.

Because growth in diameter at this size is very slight, I did not expect any difference in final size. However, to be certain, I tested the final group diameter at the end of the experiment using an independent samples $t$-test. 


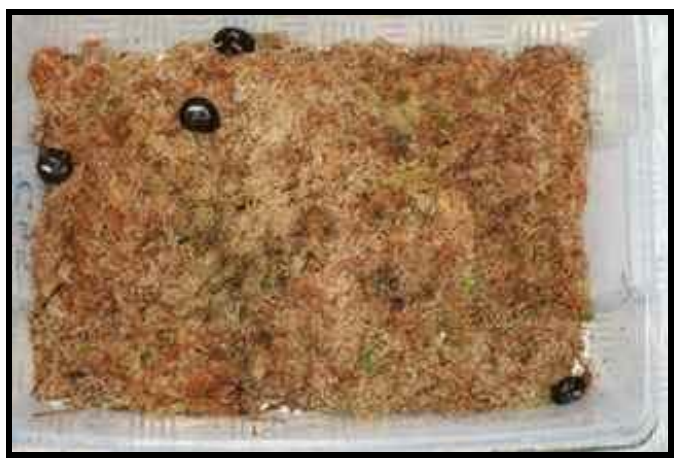

Figure 3.1. Low density treatment.

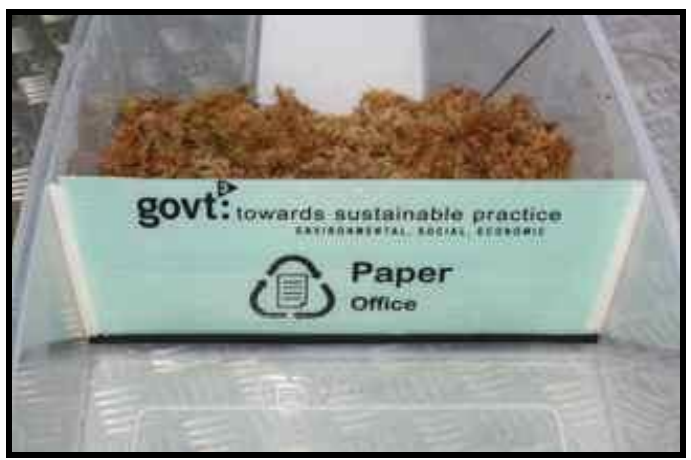

Figure 3.3. High density partition.

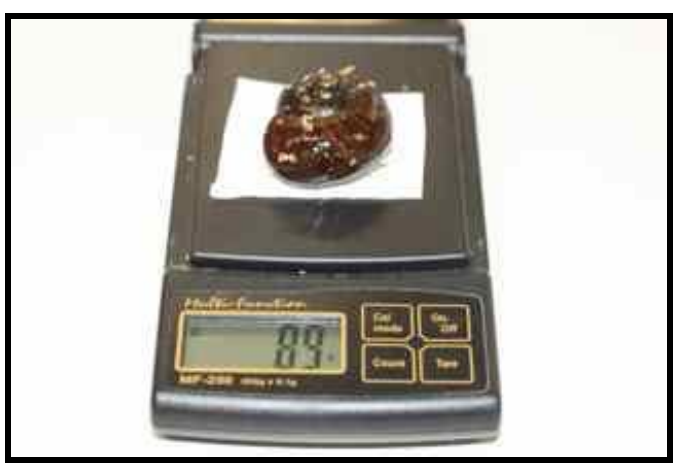

Figure 3.5. Digital scales with paper towel.

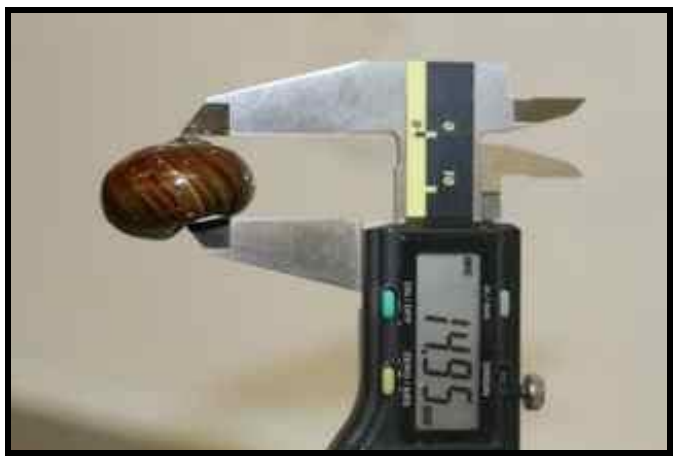

Figure 3.7. Shell height measurement.

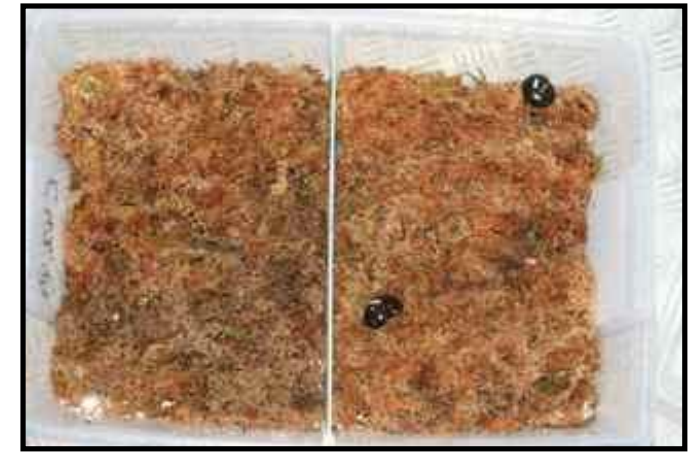

Figure 3.2. High density treatment.

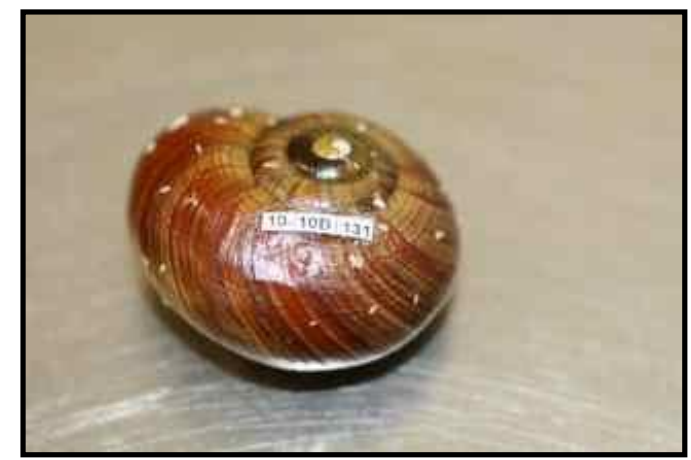

Figure 3.4. Shell with tag.

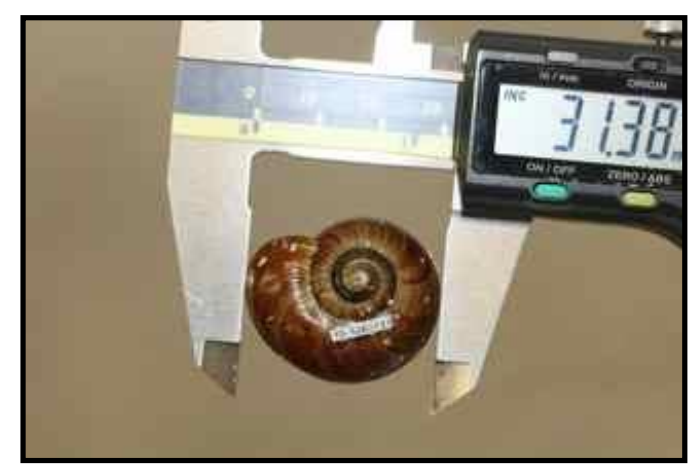

Figure 3.6. Shell diameter measurement.

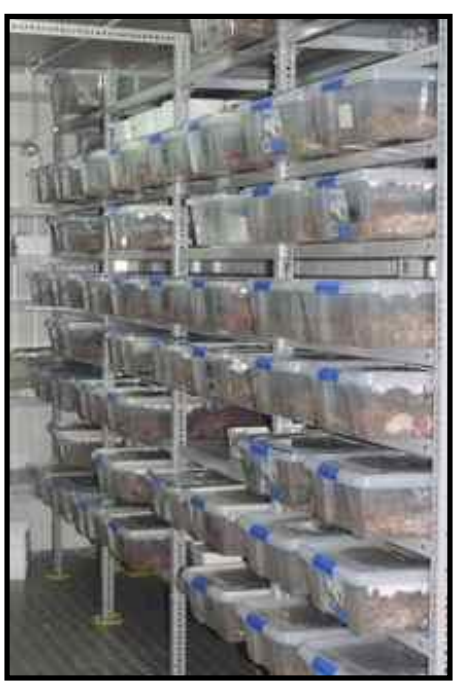

Figure 3.8. Containers in cool store. 


\section{Results}

At the conclusion of the experiment, 23 out of 24 groups $(95.9 \%)$ in the low density treatment and 16 out of 24 groups $(66.7 \%)$ in the high density treatment had no deaths among members. There were no censored observations, and the survival distributions of each treatment were significantly different (Log-rank test: $\chi^{2}{ }_{1}=6.908, N=48, P=0.009$ ).

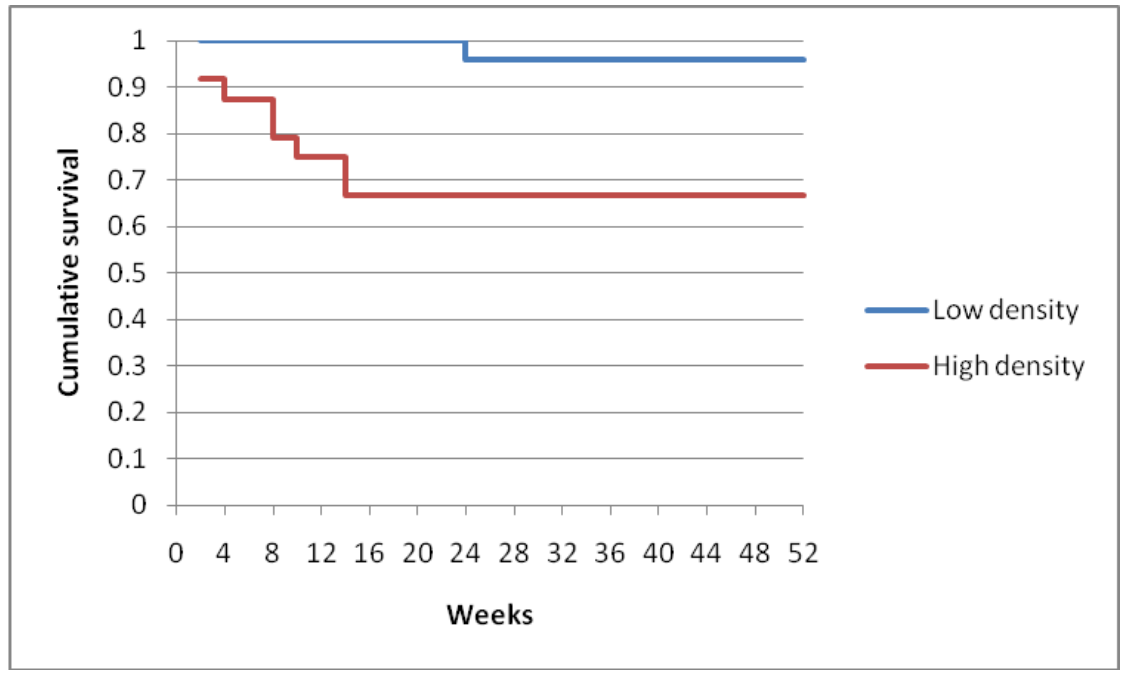

Figure 3.9. Proportion of groups remaining in the experiment (survival).

There was a significant decline in the total weight of each group, from week four to week 52 (ANOVA: $F_{1,37}=21.136, P<0.001$ ). The magnitude of change was the same in each treatment, as indicated by a lack of interaction between time and density (ANOVA: $F_{1,37}=$ $0.068, P=0.795)$. There was no difference between treatments in the total group diameter at the end of the experiment $\left(t_{37}=0.771, P=0.445\right)$.

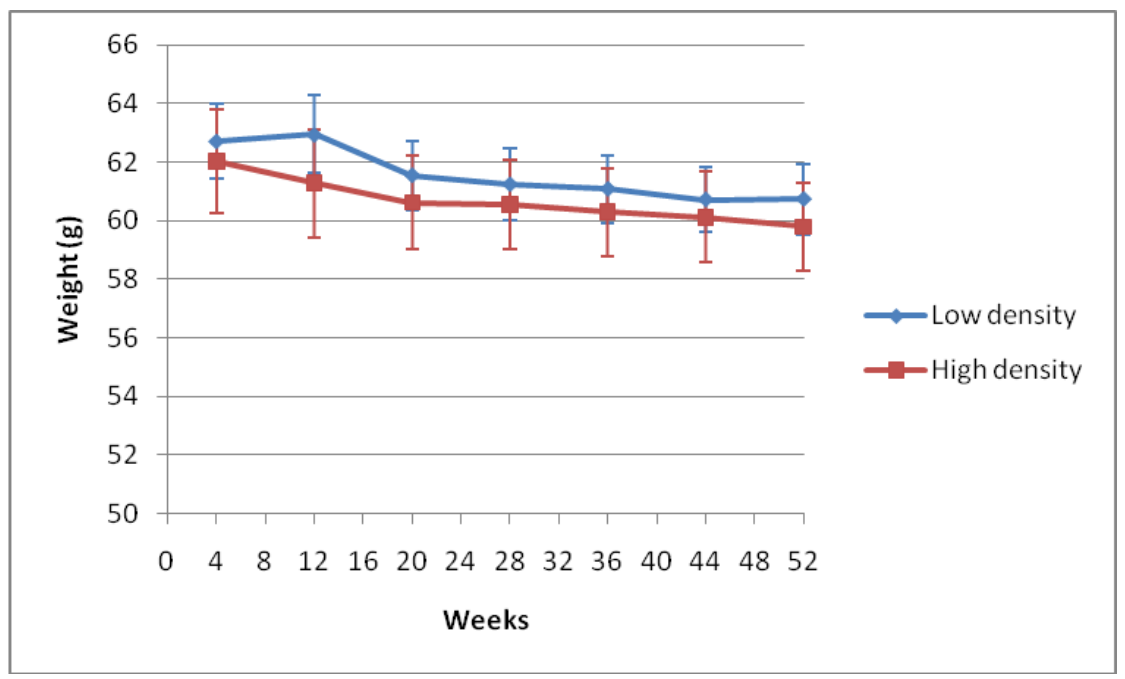

Figure 3.10. Total weight of groups at low $(n=23)$ and high $(n=16)$ density (mean \pm SE). 


\section{Discussion}

This experiment clearly demonstrated reduced survival with increased density in groups of $P$. augusta. Although all snails lost weight during the experiment, there was no difference in weight loss between treatments.

As the experiment was the first time that captive $P$. augusta had been kept in groups, there was some concern about the level of mortality that could result. For this reason, the experimental design included removing a group from the trial when a death occurred within it, as opposed to replacing the dead individual with a new snail. This precautionary measure was to mitigate the effects of potential pathogens and to limit the total number of deaths which could occur in the experiment. However, if the dead snail was replaced as might occur during captive breeding, more deaths could have occurred within a group.

All deaths in the high density treatment occurred inside 14 weeks, and this possibly represents a period of adjustment for the snails, although one without consequence at the low density. Changes in the captive conditions of Partula snails have caused temporary episodes of mortality. For instance, mortality was associated with a minor change in diet, a change to UV lighting and a change in daily temperature (Tonge and Bloxam 1991).

Controlled experiments have repeatedly shown reduced survival with increased density in land snails (Baur and Baur 1990; Dan and Bailey 1982; Foster and Stiven 1996; LazaridouDimitriadou et al. 1998). However, the mechanism responsible remains obscure. Both Foster and Stiven (1996) and Reichardt et al. (1985) recorded density-dependent survival with ad libitum feeding. Indicating reduced survival was not the result of food competition. $P$. augusta did compete for food, but the number of competitors (six) was the same in each treatment. Although there is some evidence that pheromones in snail mucus suppress growth rates (Baur and Baur 1990; Dan and Bailey 1982), reduced survival rates have not been demonstrated.

There is some evidence for a link between density and disease in land snail populations, and this may explain the link between density and mortality. For instance, density is known to increase the prevalence of the Protozoan parasite Tetrahymena rostrata in farmed populations of Helix aspersa (Segade et al. 2009), as well as the intensity of Ricardoella mite infestation in Arianta arbustorum (Baur and Baur 2005). Further studies with A. arbustorum and 
Ricardoella have provided evidence for threshold host population densities, below which the parasite cannot persist, as encounters between snails are too infrequent (Schupbach and Baur 2010).

Density is known to compound the effects of disease in a diverse range of captive animals (Ford et al. 2002; Kautsky et al. 2000; Maes et al. 2008; Noble and Summerfelt 1996; Shoemaker et al. 2000; Solorio-Rivera et al. 1999). This may result because density increases the rate of exposure to pathogens (Kautsky et al. 2000; Maes et al. 2008; Shoemaker et al. 2000; Solorio-Rivera et al. 1999), or increases susceptibility through elevated stress levels (Iguchi et al. 2003; Kautsky et al. 2000; Maes et al. 2008; Noble and Summerfelt 1996).

A decline in weight with density was observed in Cepaea nemoralis and Cepaea hortensis (Cameron and Carter 1979), but there was no such effect in P. augusta. Although all snails lost weight during the experiment, this did not differ between treatments. Without matchedcontrols of individual snails it is difficult to attribute the weight loss to group living. However, kept individually, most snails have put on weight while in captivity and then remained stable (see chapter six). Group living may cause snails to lose weight because of competition for food, or increased stress. Obvious declines in weight were observed before the deaths of several snails in the experiment (Appendix A), and monitoring weight could identify individuals at risk.

High densities may be lethal to P. augusta and modest stocking densities should be used. Survival rates in the low density of this treatment were high, but above this density survival may rapidly decline. The weight of snails maintained in groups should be continually monitored to ensure their well-being. 


\section{Chapter 4: The Effect of Calcium Supplementation on Reproduction}

The ecology of land snails is, in general, closely linked to the availability of calcium (Hotopp 2002). Their high demand for calcium, relative to other nutrients, is primarily for the construction of the shell and the production of eggs (Fournie and Chetail 1984).

The shells of Powelliphanta augusta are very thin compared to those of its congeners, probably due to the paucity of calcium in their habitat (Walker et al. 2008). However, its eggs are highly calcified and very brittle. Although the actual demand for calcium has not been quantified for this species, the fact that there is no calcium available in the intended substrate of their captive containers, sphagnum moss, leaves open the possibility that their reproduction will be calcium-limited in captivity. An experiment was therefore required to test the effect of calcium supplementation (in the form of limestone) on the egg production of $P$. augusta. The following hypotheses were tested:

$H_{0}$ : The number of eggs laid by snails kept on sphagnum moss and limestone, and snails kept on sphagnum moss only, are the same.

$H_{1}$ : The number of eggs laid by snails kept on sphagnum moss and limestone, exceeds that of snails kept on sphagnum moss only.

\section{Methods}

Snails were placed in groups of six in plastic containers $48 \mathrm{~cm}$ in length, $30 \mathrm{~cm}$ in width and $12 \mathrm{~cm}$ in height. The bottom of each plastic container in the calcium supplementation treatment was covered with a layer of limestone chip, from the Ross lime works (30km south of Hokitika). The limestone from this area is comprised mostly of calcite crystals and the calcium carbonate in it exceeds $80 \%$ (Christie et al. 2001). On top of the limestone was placed $1 \mathrm{~kg}$ of damp sphagnum moss. The containers in the control contained $1 \mathrm{~kg}$ of damp sphagnum moss only.

In both treatments, the rim on the container was lined with a length of weather stripping, to prevent worms fed to the snails from taking refuge in the space between 
the container and its lid. Each snail was tagged with a number printed on waterproof paper that was attached to shell with Selleys ${ }^{\circledR}$ Supa glue (Fig. 3.4). Every four weeks the snails were removed and the containers were washed in hot water and detergent and had fresh sphagnum moss and limestone placed in them.

The maximum shell diameter (Fig. 3.6) was measured with digital calipers at the beginning of the experiment. The snails were weighed at the beginning of the experiment and every four weeks at re-housing (Fig. 3.5). The containers were placed on shelving in an industrial cool store set to a constant $7^{\circ} \mathrm{C}$ (Fig. 3.8).

The experiment was replicated eight times: matching pairs of containers of six cohoused snails, one with moss + limestone (experimental) and one moss only (control) being considered a replicate. Replicate one was formed on May 8 2008, and replicates two-eight were formed on May 13 2008. The experiment was planned to run for 52 weeks.

\section{Results}

This experiment was halted after a number of deaths occurred. One death in the control group occurred in October 2008, and one death in the experimental treatment in November 2008. A further six deaths occurred in the experimental treatment; three in January 2009 and three in February 2009. All the 2009 experimental treatment deaths were from the same group. There was concern that the limestone might be the cause of death, and an analysis of mortality was made. The analysis of data before the conclusion of an experiment is generally undesirable, as multiple tests can inflate the type one error rate (Todd et al. 2001). However, it was felt the deaths justified such a move.

Using Fisher's exact test, I examined the association of death with substrate treatment. Although the 2009 deaths all occurred in one group, for the analysis I treated these deaths as independent. Rejection of the null hypothesis would result in the termination of the experiment. 
Table 4.1. Mortality amongst $P$. augusta kept on limestone chip and sphagnum moss (experimental treatment), or sphagnum moss only (control), for eight months.

\begin{tabular}{|lll|}
\hline & Alive & Dead \\
\hline & & \\
Control & 47 & 1 \\
Exp. treatment & 41 & 7 \\
\hline
\end{tabular}

The probability of death was significantly greater when limestone was present in the substrate (Fisher's exact test, one-tailed: $N=96, P=0.029$; Table 4.1). The experiment was aborted and the snails were put back into individual containers, with sphagnum moss only.

\section{Egg laying}

In the eight-month duration of this experiment only three groups produced eggs (Table 4.2). All three clutches were found in September 2008.

Table 4.2. Eggs laid by groups of $P$. augusta kept on limestone chip and sphagnum moss (experimental treatment), or sphagnum moss only (control).

\begin{tabular}{|llll|}
\hline & $\begin{array}{l}\text { Date when eggs } \\
\text { found }\end{array}$ & No. of eggs & Group \\
\hline Control & $2 / 9 / 08$ & 2 & 2 \\
Exp. Treatment & $30 / 9 / 08$ & 3 & 4 \\
Control & $30 / 9 / 08$ & 1 & 6 \\
\hline
\end{tabular}

\section{Discussion}

This experiment was aborted due to concerns that the limestone treatment was fatal to snails. However, if the experiment had run its intended course it is unlikely to have yielded any useful results, given that only three groups produced eggs in eight months. This was probably due to a lack of environmental cues for breeding in the captive environment, such as photoperiod (Gomot 2001; see chapter two). Although the importance of photoperiod to reproduction was known at the beginning of the experiment, it was hoped that enough eggs would be produced to assess the effect of treatment. 
Calcium can be extremely disruptive to cellular processes and consequently the ion is carefully regulated by organisms, to between $10^{-6}$ and $10^{-7}$ mol.1 1 (Simkiss 1977). It is not clear just how much land snails can control the intake of calcium from the substrate. Simkiss (1977) proposed that calcium in mollusks is regulated by excretion, through the formation of renal concretions that convert soluble calcium into an insoluble and harmless form. However, Beeby and Richmond (1988) proposed that the function of these concretions was to remove heavy metals and thus provided evidence that Helix aspersa could control the assimilation rate of calcium. The uptake of calcium through the foot by Euhadra nipponensis involves active transport (Kado 1960 in, Fournie and Chetail 1984), although the degree of regulation is uncertain.

Although the excess of calcium, hypercalcemia, has been well-documented in vertebrates (Messinger et al. 2009), there is very little experimental evidence of the condition in invertebrates. Ireland (1991) observed an anomalous response to the highest of seven dietary calcium treatments fed to Achatina fulica. These snails exhibited slower growth rates than a large proportion of the treatments given less calcium. The author suggested that excessive calcium might have had toxic effects, or interfered with the uptake of other nutrients. A. fulica were provided calcium in the diet and not in the substrate. Those snails in a parallel experiment that were able to choose the amount of calcium they consumed, did not exhibit ill effects.

It is possible that reduced amounts of limestone chip may still have a beneficial effect on the reproduction of $P$. augusta, but it would be imprudent to use this as a supplement again. Another source of calcium that snails could regulate the intake of by rasping, such as cuttlebone, may prove beneficial. But if reproductive output is to be assessed in $P$. augusta again, a photoperiod will need to be provided. 


\section{Chapter 5: Reproductive Biology}

Fecundity typically increases with size amongst land snail species (Jordaens et al. 2007). For this reason, land snails may prefer large individuals as mates resulting in size-assortative mating (Tomiyama 1996). Size-specific fecundity and size-assortative mating are relevant to the husbandry of Powelliphanta augusta because they may affect the reproductive output of the captive breeding population. For instance, if larger P. augusta are more fecund, then these should be preferentially retained for breeding. And if mate discrimination by size does occur, then similar-sized individuals should be co-housed, as matings among these will be more frequent than in groups of dissimilar-sized individuals.

Based on the literature, I predicted that larger P. augusta would be more fecund. I analyzed data on reproduction in captivity, using clutch size as a measure of fecundity. I tested the hypothesis that the number of eggs in a clutch increases with the shell volume of the parent.

Secondly, I tested for size-assortative mating by splitting adults into two size-classes; small and large, and forming pairs of similar- and dissimilar-sized individuals. If sizeassortative mating is occurring, then copulations should be less frequent among dissimilar-sized pairs. However, if there are other behavioural differences between size-classes, then these might also affect the frequency of copulation. Specifically, if one size-class is less active than the other, spending more time withdrawn in the shell and stationary, then they may copulate less as a result of reduced encounters. Or if one size-class courts more than the other, then they may copulate more frequently as a result of increased eagerness to mate, rather than reduced discrimination. Because of these potential behavioural differences, I observed pairs for four hours and recorded the time spent active, as well as the time spent courting, and analyzed these by sizeclass.

Body condition may also affect reproductive behaviour in invertebrates (Lomborg \& Toft 2009). I predicted those snails in better body condition would spend more time courting, as they have surplus resources to invest in reproduction. 


\section{Size-fecundity analysis}

\section{Methods}

I reviewed the records of those clutches where the size of the parent was recorded at the time the clutch was produced. I used only one clutch from each snail, the first produced in captivity. The shell maximum diameter (Fig 3.6) and shell height (Fig 3.7) had been measured with digital calipers, and I calculated the shell volume following Rensch (1932, in Baur 1992):

Shell volume $\left(\mathrm{mm}^{3}\right)=$ Shell diameter ${ }^{2}(\mathrm{~mm}) \times$ height $(\mathrm{mm}) / 2$

Data was available for 57 clutches; 22 of these had only one egg, while 20 clutches had two eggs, and 15 clutches had three eggs. Because clutch size is a count variable, and small values were more common than large, I used Poisson regression to analyze the trend between shell volume and clutch size in the R statistical software package (Crawley 2005).

\section{Results}

Parent shell volume ranged from $5668-18204 \mathrm{~mm}^{3}$. The size of the clutch increased significantly with parent shell volume (Poisson regression: coefficient $=0.0000882, Z$ $=2.215, P=0.027$ ). The equation relating shell volume and clutch size was: $\ln$ (clutch size $)=0.000088 \times$ shell volume -0.58 .

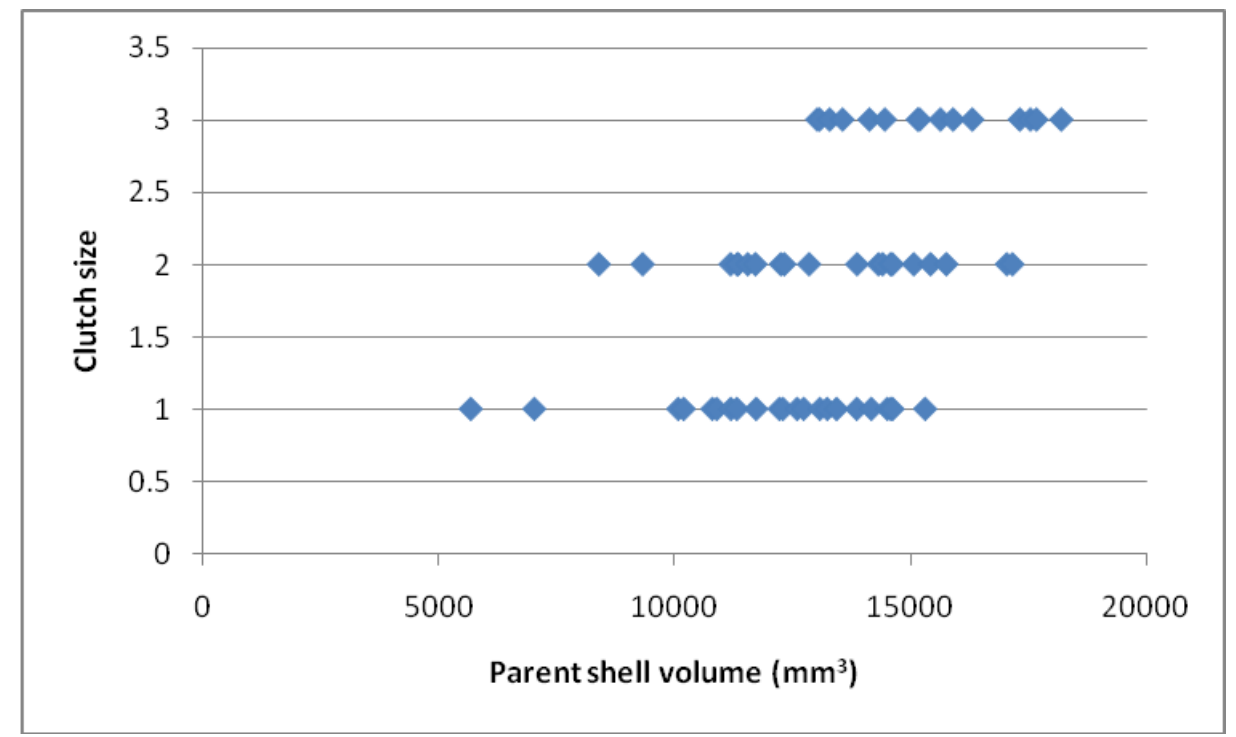

Figure 5.1. Shell volume and size of first clutch produced in captivity for 57 P. augusta. 


\section{Discussion}

There was a clear trend of increasing clutch size with parental shell size, supporting the hypothesis of size-dependent fecundity in P. augusta. It was not possible to evaluate the rate at which clutches are produced, and smaller snails may well compensate for reduced clutch size by producing them with greater frequency. Because $P$. augusta were isolated after capture, any effects of size on clutch frequency would be confounded by the capacity to store sperm. Although fecundity generally increases with size in land snails (Jordaens et al. 2007), this may vary intraand inter-specifically as a function of clutch size and/or clutch frequency (Heller 2001)

\section{Size-assortative mating}

\section{Methods}

From the records of reproduction in captivity, it appears that most snails with a shell diameter exceeding $30 \mathrm{~mm}$ are reproductively mature. Although there are morphological features in the shell associated with maturity (Walker et al. 2008), their absence does not denote immaturity, and I classified adults on the basis of size. I compiled a list of all captive snails over $30 \mathrm{~mm}$ in diameter that were not currently or previously involved in experiments, measured their shell diameter again with digital calipers (Fig. 3.6), as well as the shell height (Fig. 3.7), and calculated the shell volume (eq.1).

The snails were sorted into two size- classes based on volume: small $(8,000-$ $\left.11,000 \mathrm{~mm}^{3}\right)$ and large $\left(>11,000 \mathrm{~mm}^{3}\right)$. These were complied in Microsoft $\circledast$ Excel (2004) and using the random number function, a snail was selected and then its partner. If the second snail was in the same size-class, then the difference in volume could not exceed $10 \%$ (based on size of smallest snail). If the second snail was in a different size-class then the difference had to exceed $25 \%$. This process was iterated until there were 20 pairs of each possible pair-type; small-small (S-S); small-large (SL) and large-large (L-L). Closer to the time of the trial in which they were to be used (one to seven days), the pairs were measured again to make sure their classification was still valid. 
After being weighed, and sprayed 16 times with a water mister to ensure hydration, each partner was placed approximately $10 \mathrm{~cm}$ apart in a transparent plastic container $48 \mathrm{~cm}$ in length, $30 \mathrm{~cm}$ in width and $12 \mathrm{~cm}$ in height. The bottom of the container was covered with a thin layer of sodden sphagnum moss and the lid was placed on the container, but without being latched so as to minimize disturbance. Two pairs in two containers were observed simultaneously during each evening, in a darkened room with just enough light from an adjoining room to allow observation. The temperature in the room was kept stable at around $18^{\circ} \mathrm{C}$ by a heat pump. I did not place thermometers in the containers, because snails interacted with them in pilot trials, but the container was much colder then the room due to the wet moss. The trials were started at $1700 \mathrm{hrs}$ and finished at $2100 \mathrm{hrs}$. Every 15 minutes the activity of each snail was recorded as one of five behavioural states:

- Withdrawn: no part of the soft body out of the shell.

- Emerged: some part of the soft body out of the shell, but snail stationary.

- Mobile: moving around the container.

- Courting: touching the other snail, scored as reciprocal if both emerged, unilateral if one withdrawn.

- Copulating: intromission occurring.

Courtship typically began with tentacle touching followed by touching of the soft parts of the body (Fig. 5.2). Then one of the snails or both in turn, would mount the shell of the other and crawl right over it (Fig. 5.3). P. augusta would always mate side-by-side, never while shell-mounted, and all observed copulations involved reciprocal intromission (Fig. 5.4).

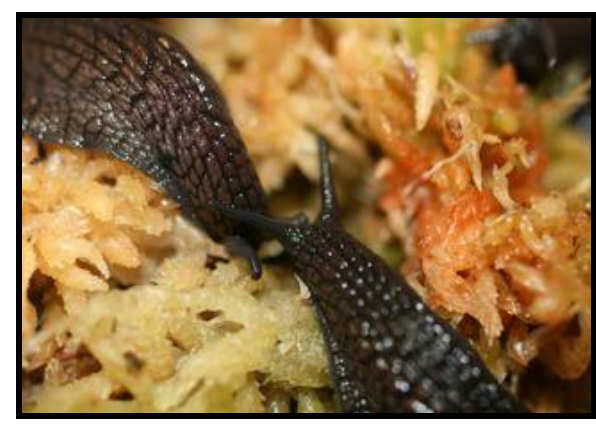

Figure 5.2. Tentacle touching.

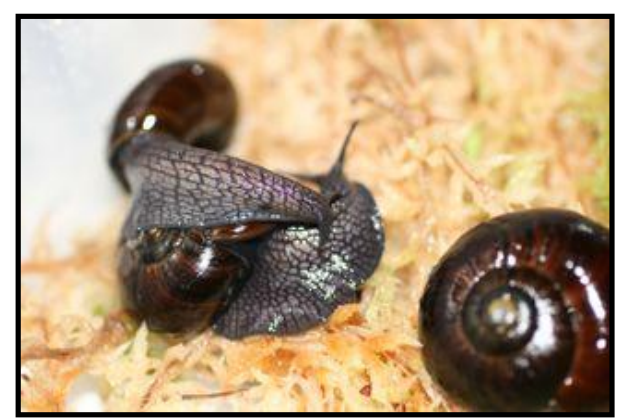

Figure 5.3. Shell mounting. 


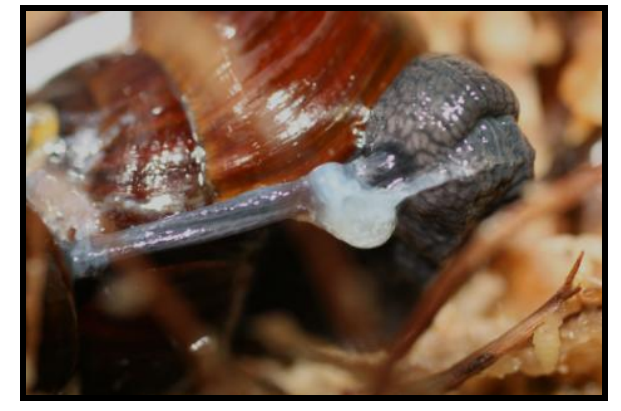

Figure 5.4. Reciprocal intromission.

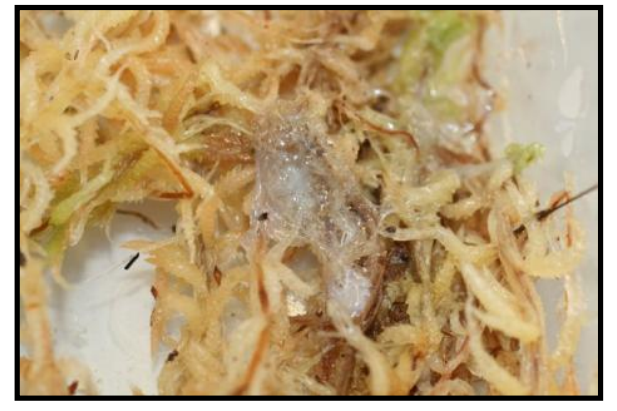

Figure 5.5. Ejaculate.

At the end of the trial the pairs were kept together and placed in a cool store set to a constant $7^{\circ} \mathrm{C}$. Copulating snails produced conspicuous ejaculate (Fig. 5.5), and if this was found at $1500 \mathrm{hrs}$ the following day, the pair was recorded as copulating. The trials took place over 30 evenings between May 62009 and July 222009.

\section{Statistical analysis}

I compared between size-classes the number failing to emerge during the observation period and the association between failure to emerge and copulation frequency, both using Fisher's exact test. Also between size-classes, I compared the time taken to emerge from the shell (i.e., the time spent withdrawn at the beginning of the observation), and the time spent in each of the five behavioural states, using an independent samples $t$-test. Time was analyzed as the mean number of 15 -minute observation intervals. From the behavioural data I calculated the proportion of time after emergence spent active (i.e., not withdrawn or stationary) and the proportion of activity (mobile, courting or mating) spent courting (or mating) and compared these between size-classes using a $t$-test.

From the weight measured at the beginning of the trial, and the diameter already recorded shortly before the trial, I calculated the body condition for each snail (eq. 2; chapter six), and analyzed the relationship between body condition and the proportion of time spent courting using linear regression, after the arcsine square-root transformation of the dependent variable (Zar 1974) (diagnostic plots in Appendix B). My expectation was that those snails in better body condition would devote a greater proportion of their activity to courtship and I tested the hypothesis that the slope of the regression line was greater than zero (ANOVA, one-tailed test). 
Finally, I tested the association of pair-type and copulation frequency using Pearson's chi-square test. The null and alternative hypotheses were:

$H_{0}$ : Pair-type and copulation are independent.

$H_{1}$ : Pair-type and copulation are not independent.

Means \pm SE are presented and all tests are two tailed unless stated otherwise.

Results

Large snails were significantly less likely to emerge during the observation period, with 15 large, and three small failing to emerge (Fisher's exact test: $N=116, P=$ 0.004). This resulted in $12 \mathrm{~L}-\mathrm{L}$, four L-S and two S-S pairs where at least one of the partners failed to emerge. Amongst L-L pairs, I found no association between one or more partner(s) failing to emerge and the frequency of copulation (Fisher's exact test: $N=20, P=0.10$; Table 5.1). The behavioural data for two trials (both $\mathrm{S}-\mathrm{S}$ ) was lost.

Table 5.1. Failure to emerge by one or both partner(s) during a four hr observation period and the frequency of copulation (L-L pairs).

\begin{tabular}{|llll|}
\hline & Copulated & Did not copulate & Total \\
\hline Emerged & 8 & & \\
Did not emerge & 3 & 3 & 11 \\
Total & 11 & 6 & 9 \\
\hline
\end{tabular}

For those snails that did emerge, there was no difference in the time taken to do so between size-class, or the time spent withdrawn, stationary, mobile, courting or mating (Table 5.2). There was no difference between size-classes in the proportion of time spent active, or in the proportion of activity spent courting (Table 5.2). 
Table 5.2. The activity of small $(n=53)$ and large $(n=45) P$. augusta, expressed as the number of 15 -minute observation intervals (mean $\pm \mathrm{SE}$ ).

\begin{tabular}{|lllllllll|}
\hline & $\begin{array}{l}\text { Emergence } \\
\text { time }\end{array}$ & Withdrawn & Stationary & Mobile & Courting & Mating & $\begin{array}{l}\text { Proportion } \\
\text { active }\end{array}$ & $\begin{array}{l}\text { Proportion } \\
\text { courting }\end{array}$ \\
\hline Small & $2.40 \pm 0.34$ & $0.36 \pm 0.18$ & $3.08 \pm 0.51$ & $9.23 \pm 0.62$ & $0.72 \pm 0.16$ & $0.23 \pm 0.21$ & $0.74 \pm 0.04$ & $0.08 \pm 0.02$ \\
Large & $3.13 \pm 0.45$ & $0.07 \pm 0.07$ & $3.40 \pm 0.62$ & $8.47 \pm 0.67$ & $0.53 \pm 0.15$ & $0.40 \pm 0.26$ & $0.72 \pm 0.05$ & $0.10 \pm 0.03$ \\
$t$ & -1.33 & 1.45 & -0.41 & 0.83 & 0.70 & -0.53 & 0.44 & -0.66 \\
$d f$ & 96 & 96 & 96 & 96 & 96 & 96 & 96 & 91 \\
$P$ & 0.19 & 0.15 & 0.68 & 0.41 & 0.48 & 0.60 & 0.67 & 0.51 \\
& & & & & & & & \\
\hline
\end{tabular}

There was a very weak correlation between body condition and the proportion of activity spent courting (linear regression: $F_{1,91}=2.780, r^{2}=0.03, P=0.05$; Fig. 5.6).

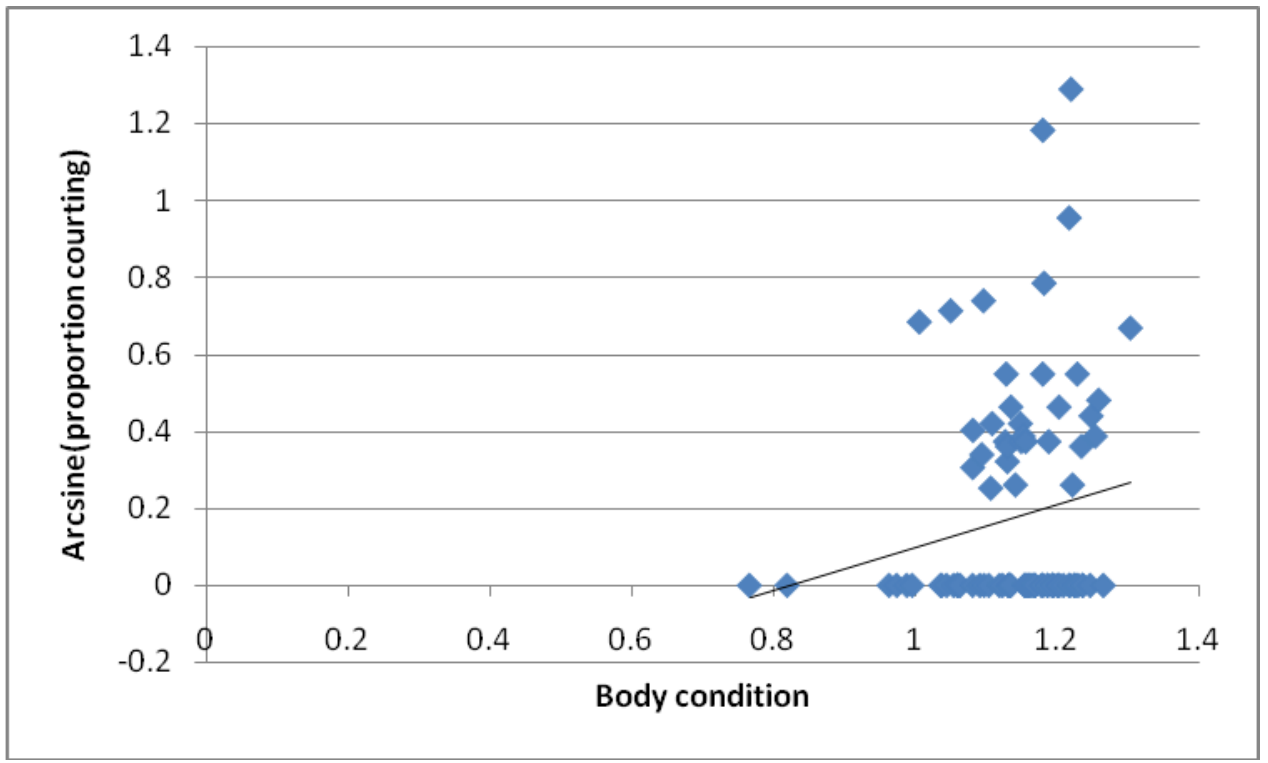

Figure 5.6. Body condition and the proportion of activity spent courting by $P$. augusta, during four hrs of observation $(N=93)$.

Snails mated in 33/60 trials (55\%) and the frequency of copulation was independent of pair-type (Pearson's chi-square test: $\chi^{2}{ }_{1}=0.404, N=60, P=0.817$; Table 5.3). 
Table 5.3. Copulations among pairs of small (shell volume: $8,000-11,000 \mathrm{~mm}^{3}$ ) and large (shell volume $>11,000 \mathrm{~mm}^{3}$ ) P. augusta.

\begin{tabular}{|lllll|}
\hline & Small-Small & Small-Large & Large-Large & Total \\
\hline Copulation & 11 & 10 & 12 & 33 \\
No copulation & 9 & 10 & 8 & 27 \\
Total & 20 & 20 & 20 & 60 \\
\hline
\end{tabular}

Copulation began within the observation period on three occasions, and on two of these I was able to continue observations without disturbance, after transfer to the cool store. I made observations every 15 minutes, and the length of both copulations was three hrs.

\section{Discussion}

Aspects of courtship in P. augusta are similar to those in Helix aspersa and Helix pomatia (Adamo and Chase 1990; Lind 1976). Specifically the 'introductory behaviour' characterized by the repeated touching of the tentacles and soft body parts. Shell-mounting is also seen in other land snail species, but these tend to mate in this position also (Davison et al. 2005), whereas $P$. augusta was only observed to mate side-by-side. Shell-mounting would allow P. augusta to assess partner body size, as appears to be the function of this behaviour in Succinea putris (Dillen et al. 2008).

Large snails were less active than small snails, in that significantly more failed to emerge during the experimental observation period. However, after this time the pairs were co-housed for a further $18 \mathrm{hrs}$ and failure to emerge during the observation period did not affect the likelihood of copulation. When large snails did emerge during the observation period they were as active as small, spending no more time stationary or withdrawn. Both size-classes spent an equal proportion of their activity courting, which suggests an equal propensity to mate. There are size-related differences in reproductive behaviour in other species of land snail. For instance, mating propensity increases with size in H. aspersa (Fearnley 1993, in Fearnley 1996), while smaller $S$. putris are the more active during courtship (Jordaens et al. 2005). 
As body condition increases, so should the resources available for reproduction and the eagerness to mate. For instance, body condition affects 'courtship intensity,' (the time spent courting divided by the observation period), in male spiders (Pardosa prativaga) (Lomborg \& Toft 2009). There was an extremely weak correlation between body condition and courtship in P. augusta, and the two snails with the lowest body condition, appear to have large leverage on the regression line (Fig. 5.6). The body condition in the sample of snails was rather homogenous $(1.14 \pm 0.01)$, and greater variation may have revealed a stronger pattern.

Matings between small and large snails were no less frequent than in same-sized pairs, indicating that mating is random with respect to size in P. augusta. It could be proposed that size-discrimination is more likely to occur when there is a choice between potential partners. However, many mate-choice experiments with snails have failed to demonstrate size-assortative mating (Baur 1992; Koene et al. 2007; Ohbayashi-Hodoki et al. 2004). During preliminary trials, mate-choice experiments with $P$. augusta in trios were also unsuccessful. Using timed observations, it was difficult to establish whether all three snails had made contact with one another, before copulation occurred. And the long latency until copulation (typically $>10 \mathrm{hrs}$ ) made it impractical to observe continuously. Therefore, I placed snails in pairs after Dillen et al. (2008), and inferred the act of copulation based on the presence of ejaculate.

Many observations of mating snails before the experiment confirmed the reliability of ejaculate as evidence of copulation. Single snails sometimes leave mucus on the substrate, but this is distinctive from the deposits left by copulating snails. It is thus unlikely that the number of copulations was over-estimated. Although all searches were thorough, it is conceivable that the number was underestimated. But any underestimation should not have affected the main outcome of the experiment.

The snails used in this experiment had been isolated, and this may have increased their drive to mate and decreased their choosiness. Isolation increased the drive to mate in $H$. aspersa and $S$. putris, after only one and two weeks, respectively (Adamo \& Chase 1990; Dillen et al. 2008). In the present study, P. augusta had been isolated for between 24 and 32 months. 
Controlled experiments have largely failed to detect size-assortative mating (Baur 1992; Dillen et al. 2008; Jordaens et al. 2005; Koene et al. 2007), although it has been observed in natural populations (Baur 1992; Tomiyama 1996). One difficulty with the experimental design is choosing a meaningful difference between size-classes. Here I followed the precedent of Baur (1992) and Dillen et al. (2008) and fixed a minimum difference of $25 \%$ between dissimilar-sized individuals. It is possible that a larger difference between size-classes could result in size-discrimination.

\section{Conclusion}

As size has no effect on the mate-choice of $P$. augusta, differences in the size of individuals co-housed for breeding should not affect their mating frequency.

Large snails may be preferred for breeding as fecundity increases with size. If clutch size is a reliable indicator of fecundity, then the reproductive output of the largest adult snails is potentially three times that of the smallest. 


\section{Chapter 6: Body Condition}

The rate at which Powelliphanta augusta consume their earthworm prey in the wild is unknown, and this makes it difficult to determine an appropriate feeding regime that maximizes both survival and reproductive output. One solution is to adjust feeding so that the "relative weight" of captive snails is close to that in the wild. Relative weight is loosely defined as weight in relation to size, and is also known as body condition, a representation of the nutritional state or "fatness" of an animal (Jakob et al. 1996).

The simplest way to measure body condition is with the ratio index; the body mass of an animal divided by some measure of size (Jakob et al. 1996). A limitation of this method, however, is that condition correlates with body size, and animals that differ greatly in size cannot be compared (Jakob et al. 1996). One way to control for absolute body size is to regress mass against size and use the residuals from this regression as the measure of condition, a method also known as the residual index (Jakob et al. 1996). The regression may involve the population of interest directly, or it may be used as a reference with which to assess another population, in which case it becomes the slope-adjusted ratio index (Jakob et al. 1996).

My aim was to create a reference equation based on the relationship between mass and size of $P$. augusta in the wild, and use this to assess and monitor the body condition of captive snails. Both survival and fecundity should increase with body condition (Moya-Larano et al. 2008), but over-feeding could pose some health risks. Therefore, the peak of condition in the wild should be an appropriate standard for condition in captivity.

\section{Body condition in the wild}

\section{Methods}

The weight and shell diameter of most snails were measured at the time of capture on the Stockton plateau. The capture of snails began on July 252006 and continued until May 30 2007. Collecting occurred on 206 out of 310 days, pausing on irregular days off and during extreme weather. The only systematic break in collecting was 12 days from December 222006 to January 3 2007. As soon as a snail was found the weight 
was measured with digital scales and its maximum diameter was measured with digital calipers (same dimension as Fig. 3.6).

Records where the weight or diameter measurement was missing were excluded, as were measurements that were only recorded as being greater or less than a certain value. Only diameter measurements between $5 \mathrm{~mm}$ and $50 \mathrm{~mm}$ were included, as no snails in captivity were known to be outside of this range. The total number of excluded entries was 120, leaving $N=5373$. Diagnostic plots for all regressions are available in Appendix B, if not presented here.

\section{Results}

A plot of the raw data (Fig. 6.1) suggested a power relationship between size and mass. To allow analysis with linear regression, the weights were converted from grams to milligrams and both variables were transformed with the natural logarithm. The regression of $\ln$ (weight) against $\ln$ (diameter) showed a clear linear relationship (linear regression: $F_{1,5371}=112525.619, R^{2}=0.954, P<0.001$ ), with a slope of $2.630 \pm 0.008($ mean $\pm \mathrm{SE})$.

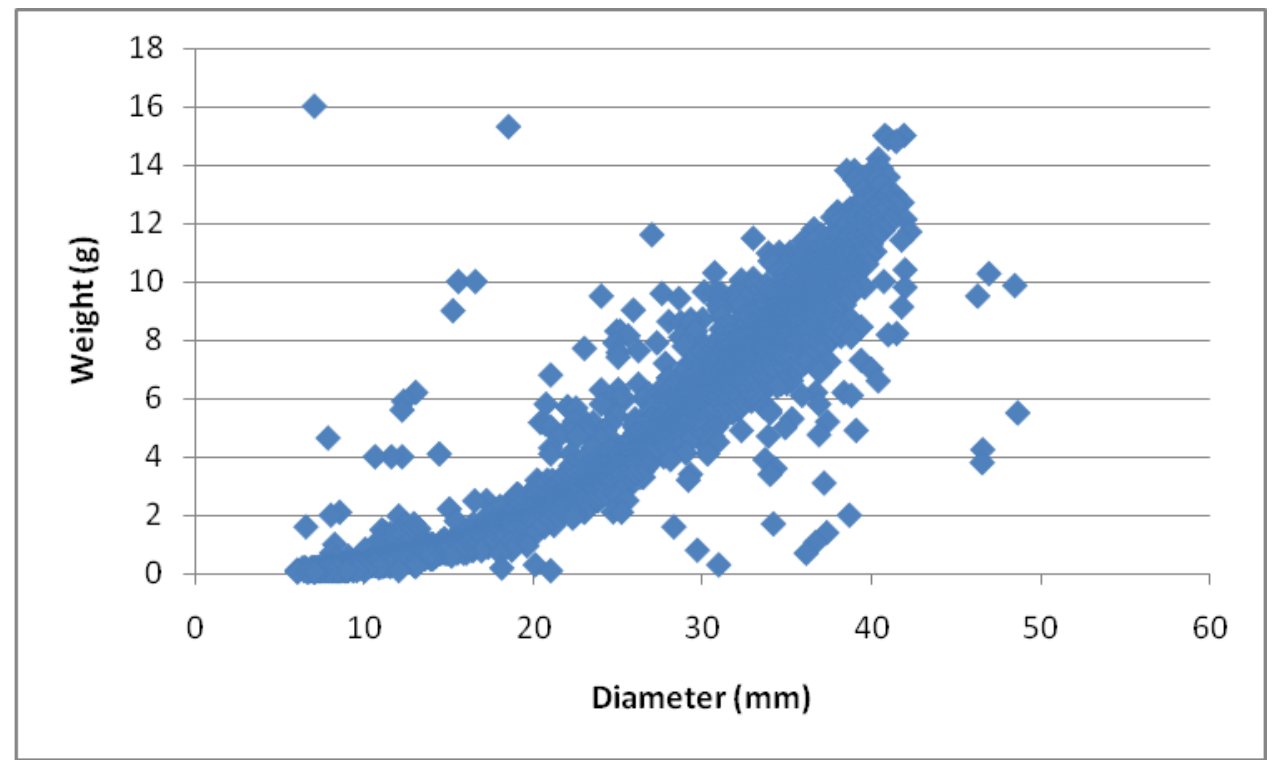

Figure 6.1. Mass vs. size for 5373 P. augusta at time of capture.

To check the assumption of homogeneity of variance, I plotted the residuals from the mass/size regression against $\ln$ (diameter) (Fig. 6.2). After inspecting the outliers, I concluded that the two most extreme (both $>3$; Fig. 6.2) were the result of weights 
improbably large for the diameter. I interpreted these two records as mistakes and deleted them. Although other values seemed improbable, I was not confident enough to delete them. With the removal of the two outliers, I re-ran the regression and there was a slight increase in the $R^{2}$ value (linear regression: $F_{1,5369}=125563.486, R^{2}=$ $0.959, P<0.001$; Fig. 6.3 ), but very little change in the slope; $2.638 \pm 0.007$ (mean \pm $\mathrm{SE})$. Although a number of extreme values remained their influence was small, with a maximum Cook's distance of 0.120 (Chatterjee and Hadi 2006).

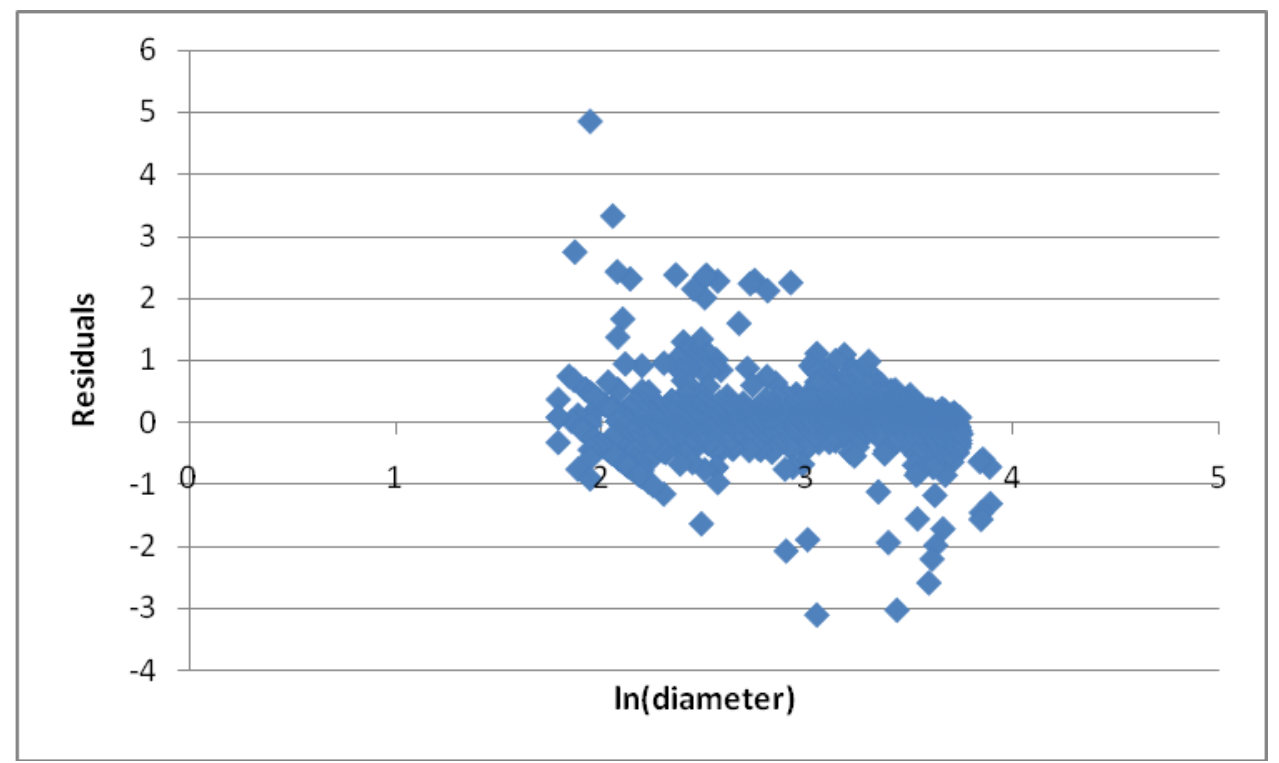

Figure 6.2. Residuals from a mass/size regression of 5373 P. augusta at time of capture.

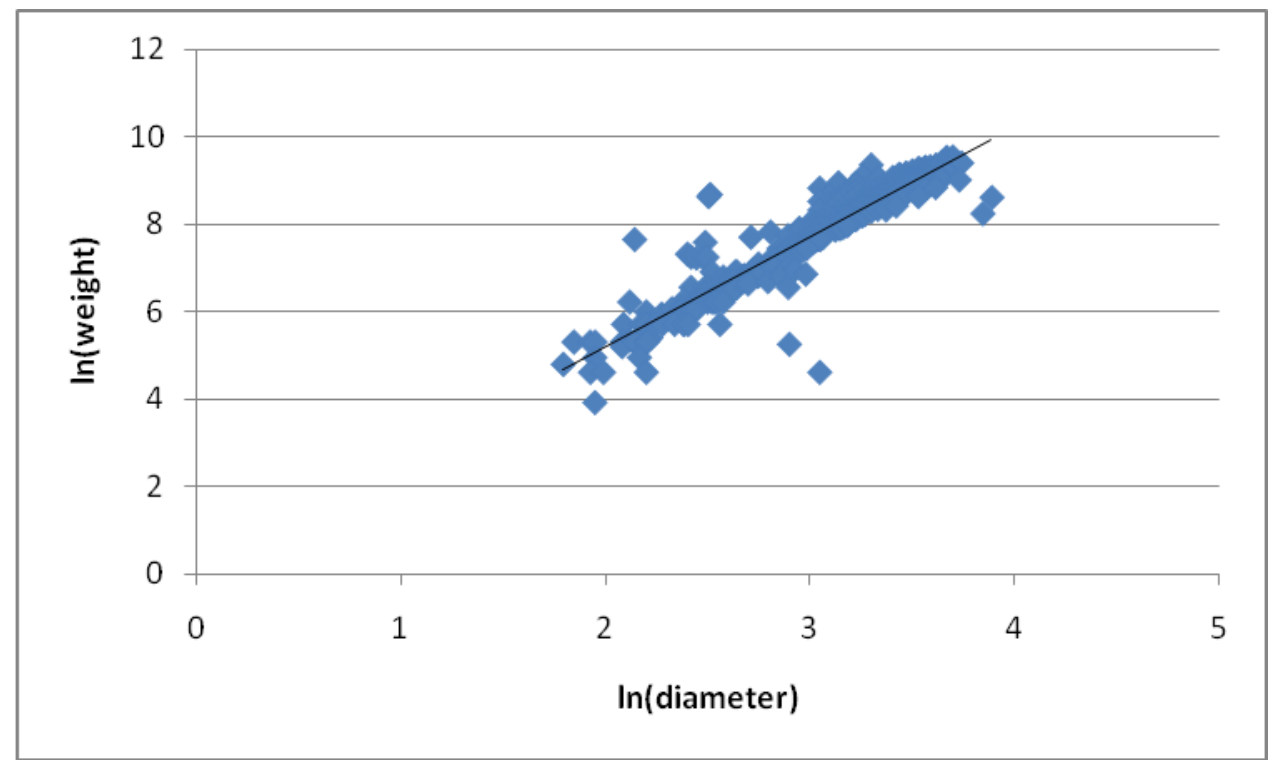

Figure 6.3. Mass vs. size for $P$. augusta at time of capture, after the removal of two outliers $(N=5371)$. 
To determine the time of year when the snails were in best condition, I calculated the mean value of the residuals from the mass/size regression, in each month. Only 10 snails were collected in July 2006 and these were pooled with the August data.

The mean residual value differed significantly by month (ANOVA: $F_{9,5358}=28.37, P$ $<0.001$; Fig. 6.4). Pair wise comparisons of means divided the months into five homogenous groups, and the group with the highest means contained December and January (Tukey multiple comparison test: $P<0.05$ ).

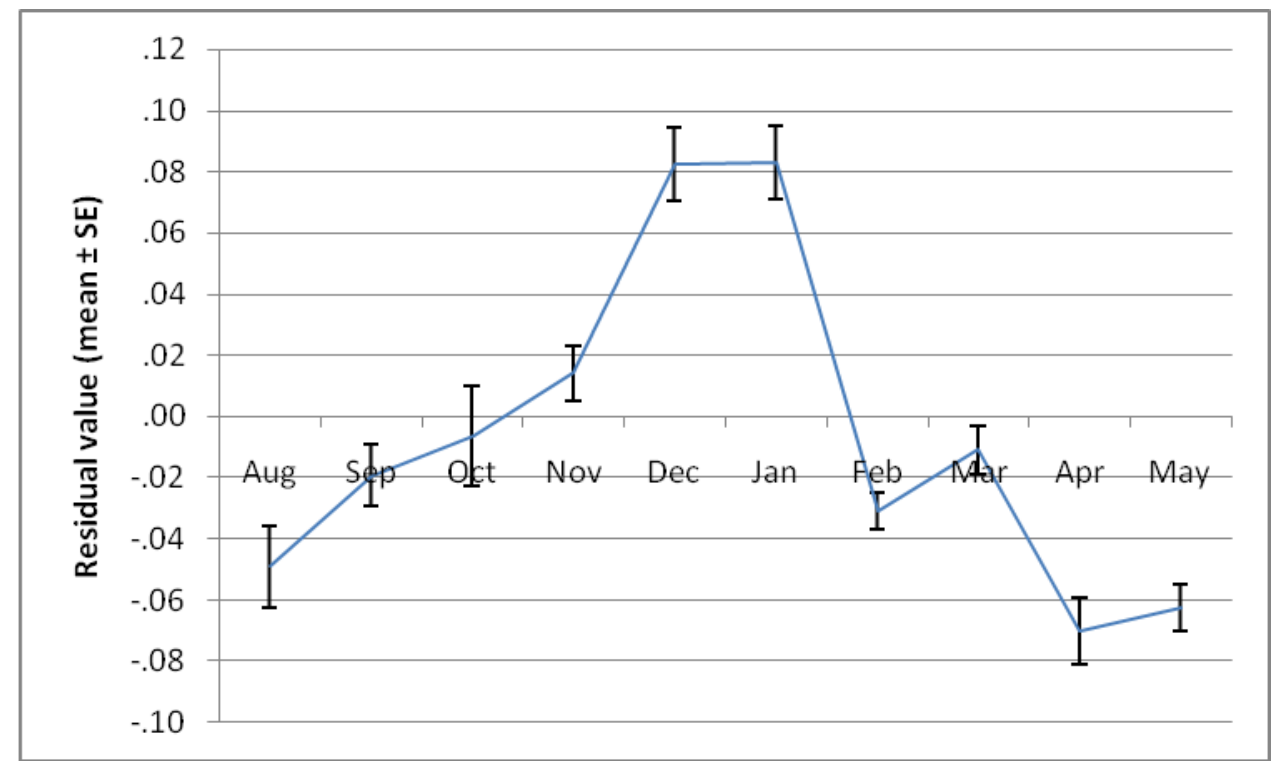

Figure 6.4. Residuals from a mass/size regression of 5371 P. augusta at time of capture, averaged by month of capture.

\section{Body condition in captivity}

\section{Methods}

To set a standard for body condition in captivity, I regressed $\ln$ (weight) against $\ln$ (diameter) using the capture data from December and January only (linear regression: $F_{1,1226}=18392.3, R^{2}=0.938, P<0.001$ : Fig. 6.5). Again, extreme values were present, but their influence was slight, with a maximum Cook's distance of 0.290 (Chatterjee and Hadi 2006). I used the regression parameters to generate a reference equation (eq.2), and assessed the body condition of captive snails as the quotient of the observed weight over the expected weight (Watson 1990).

Expected weight $(\mathrm{mg})=e^{(2.573 \times \ln \text { diameter }(\mathrm{mm})-0.023)}$ 


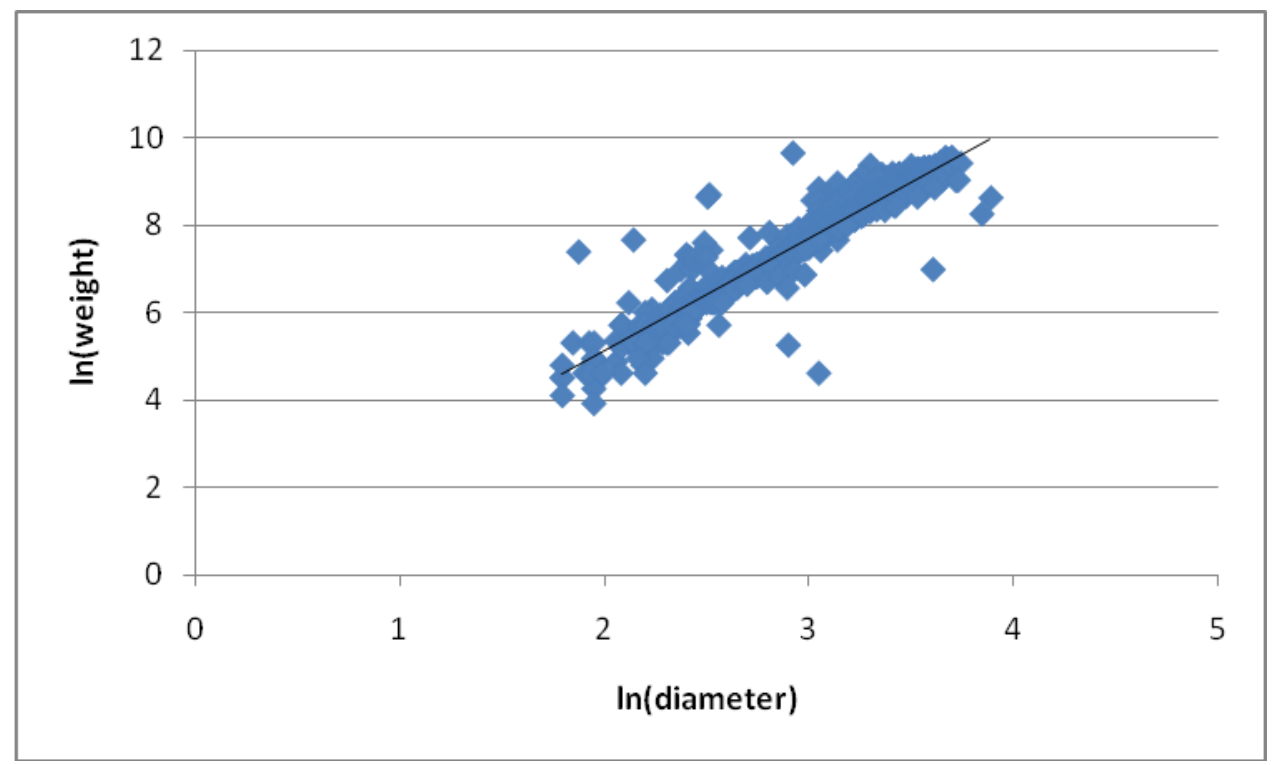

Figure 6.5. Mass/size regression of 1228 P. augusta captured in December 2006 and January 2007.

I reviewed the records of 47 P. augusta collected in May 2007, and measured again in May 2008 and May 2009. I evaluated the hypothesis that body condition has increased with time in captivity, by comparing the means of 2008 and 2009, each to 2007, and the hypothesis that body condition has stabilized in captivity by comparing the means of 2008 and 2009. I conducted an overall repeated measures ANOVA and then made pair wise comparisons of means using matched-pairs $t$-tests, with the Bonferroni adjustment to control the type one error rate $(P=0.05 / 3=0.017)$. I also contrasted the body condition of captive snails with the peak of condition in the wild; comparing the mean condition in 2009 to the hypothesized mean of one using an independent one-sample $t$-test.

\section{Results}

The assumption of sphericity required for the repeated measures ANOVA was not met (Mauchly's test: $\chi^{2}{ }_{2}=12.4, P=0.002$ ) and the degrees of freedom were corrected using Huynh-Fledt estimates of sphericity $(\varepsilon=0.83)$ (Quinn and Keough 2002). There was a significant difference in means between years (repeated measures ANOVA: $\left.F_{1.66,76.4}=91.5, P<0.001\right)$, and the mean body condition in 2007 differed significantly from 2008 (matched-pairs $t$-test: $t_{46}=-9.805, P<0.001$ ) and 2009 (matched-pairs $t$-test: $t_{46}=-11.301, P<0.001$ ). There was no change in mean 
condition from 2008 to 2009 (matched-pairs $t$-test: $t_{46}=-0.955, P=0.344$ ), and mean body condition in 2009 did not significantly differ from one (one-sample $t$-test: $t_{46}=$ $-0.565, P=0.575)$.

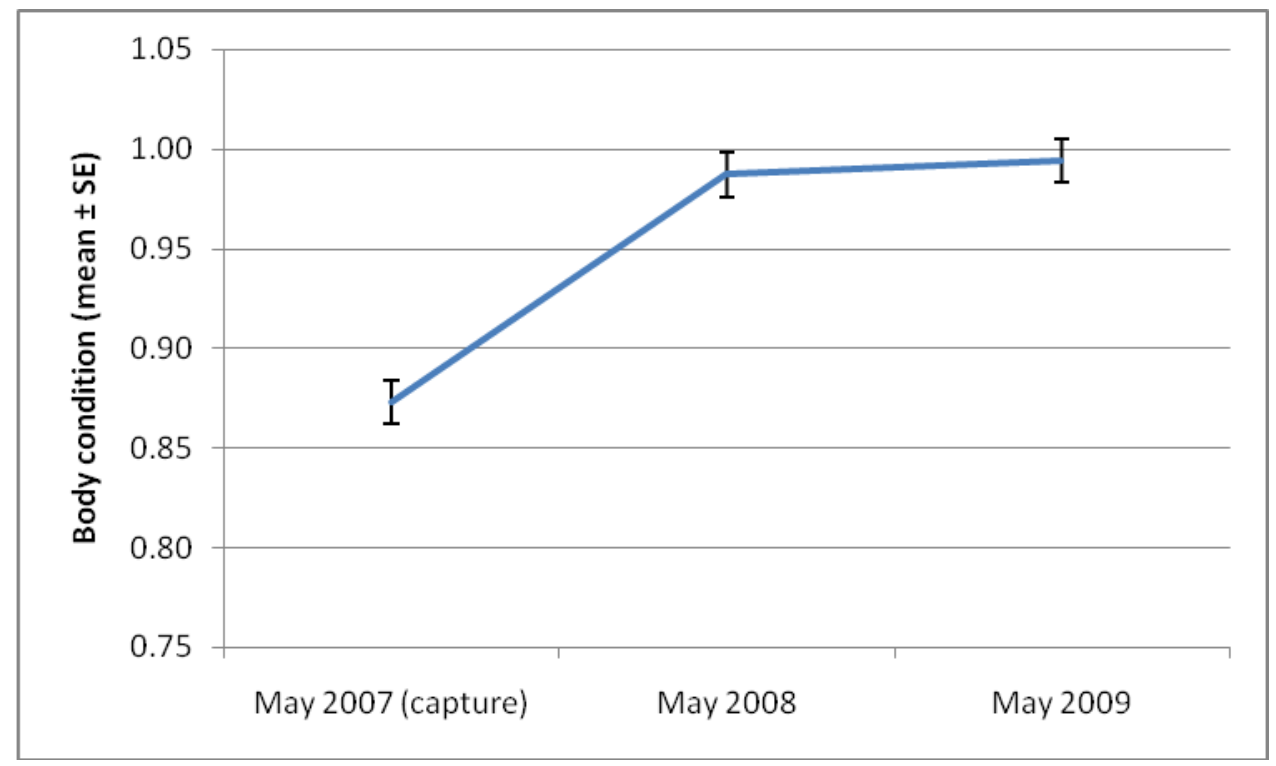

Figure 6.6. Change in body condition over two years in 47 captive $P$. augusta.

\section{Monitoring body condition}

To effectively monitor the body condition of captive snails, a significant departure from a mean condition score of one must be detected. This can be done using a onesample $t$-test. The sample size required for a two-tailed test with alpha level 0.05 and approximate power of 0.80 is:

$n=8 \times s^{2} / d^{2} \quad($ Lehr 1992)

Where $n$ is the sample size, $s^{2}$ is population variance estimate and $d$ is the difference to be detected.

Using the sample variance from the body condition analysis to estimate the population variance, the sample size required to detect a $5 \%$ difference from a mean score of one is:

$$
\begin{aligned}
n & =8 \times 0.06 / 0.05^{2} \\
& =19.2
\end{aligned}
$$


To detect a 5\% departure from a mean condition score of one in the captive population, 20 snails would need to be monitored.

If the body condition of two groups is to be contrasted, say when two feeding regimes are being compared, then the formula needs only slight modification:

$n=16 \times s^{2} / d^{2} \quad($ Lehr 1992)

Where $n=$ the sample size in each group.

\section{Discussion}

The use of residuals from an ordinary least squares mass/size regression as an index of body condition, is both wide and controversial (Green 2001). Criticisms have been addressed by Schulte-Hostedde et al. (2005). However, one criticized assumption of this method is that variation in residuals necessarily represents variation in energy stores. In actual fact this variation will also be due to other body constituents such as protein and water (Schulte-Hostedde et al. 2005). Water forms a large percentage of weight in land snails (Baur 1992) and it is important that they are not in a dehydrated state when their body condition is assessed. As P. augusta were measured immediately after capture, we can safely assume that this represents their natural state of hydration. To determine the relationship between weight and true condition (i.e., fat stores) in P. augusta would require destructive sampling, which was not possible in this imperiled species.

Despite assessing body condition in the wild using the residual index, I used a variant of the slope-adjusted ratio index used by Watson (1991), to assess body condition in captivity. Although there are advantages of the residual index over this type of index (Jakob et al. 1996), it is more suitable for daily use in the laboratory. Condition in captivity may be understood intuitively, as a factor of peak condition in the wild.

The body condition of $P$. augusta as expressed through the residual index, showed considerable variation throughout the 10 months of collection. The original habitat on the Stockton plateau is a semi-alpine environment, and in the winter months the 
ground is often frozen by frost, and occasionally snow (Walker et al. 2008). During these conditions the snails are immobile, taking refuge in the bases of tussock bushes, or buried up to $5 \mathrm{~cm}$ underground (Walker et al. 2008). Such a restraint on feeding would explain why body condition was most depressed during the coldest months of collection.

Although low in winter, body condition is equally depressed in February at the height of summer. During this month body condition plummets from its peak in December and January and this appears coincident with a rise in daily temperatures and a decline in rainfall (Fig. 6.7). The weather is warm and wet during January, but conditions are less ideal during December, and the snails collected in this month are possibly still showing the benefits of extremely wet weather in November (Fig. 6.7).

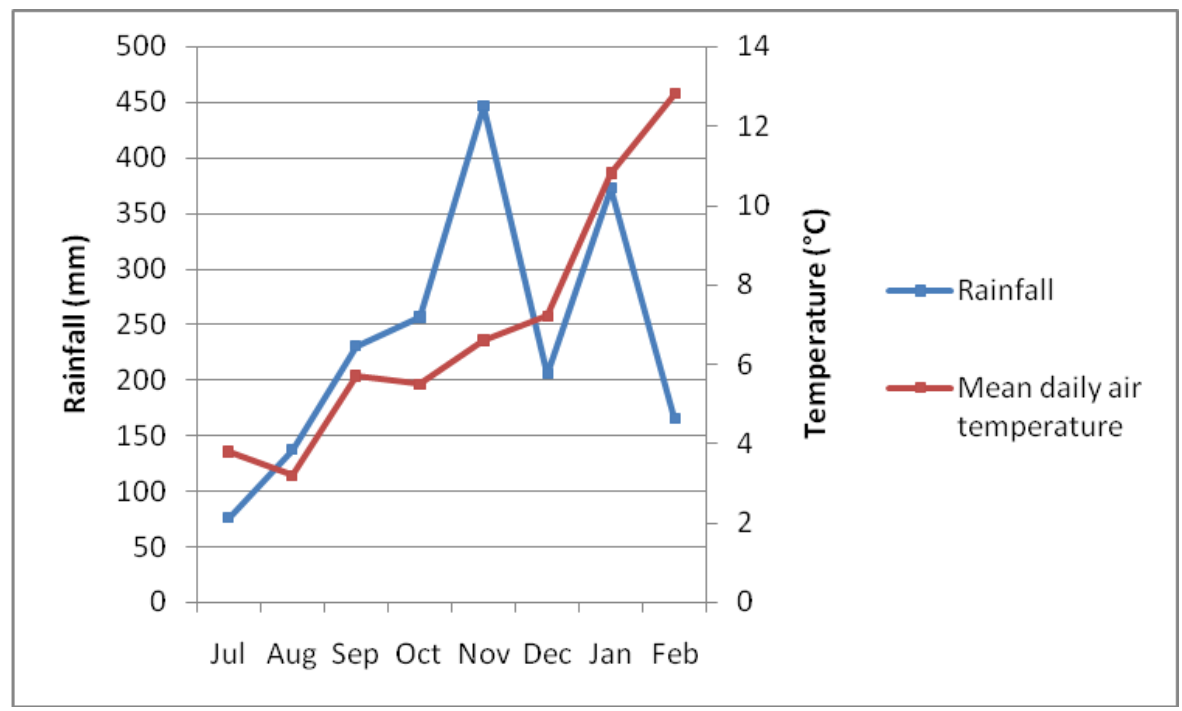

Figure 6.7. Temperature and rainfall recorded on Mt Augustus by a weather station, from July 2006 to February 2007. From Walker et al. (2008).

As the captive snails examined were captured in May, their body condition is low upon entry into the laboratory. But condition increases in captivity, and after one year is comparable to the peak in the wild. Interestingly, it does not continue to increase but stabilizes at this level.

It seems unlikely that the rather arbitrary feeding regime of one earthworm a month is, by chance, equivalent to the rate of consumption in the wild during December and January. Rather, food is probably being provided in excess and the surplus is either 
not being consumed, or invested in growth. Fortuitously, it would seem that the captive snails are maintaining themselves in optimal body condition and this may not be compromised by a reduction in feeding. 


\section{Chapter 7: Growth}

The effort required for captive breeding of Powelliphanta augusta will be highly dependent on the time between generations, and an estimate of this time would be extremely valuable. Assuming that a $30 \mathrm{~mm}$ shell diameter is a reliable reproductive indicator, the predicted time to reach this size can be used as a proxy for time until maturity. Therefore, to predict when snails hatching in captivity would become mature, I constructed a model of growth for P. augusta.

Growth can be measured as change in size, or change in mass. There are many different linear measures of size, but the most common used for land snails is shell diameter (Goodfriend 1986). I assessed whether shell diameter or weight would be more appropriate for monitoring growth in P. augusta. I directly compared the performance of these two metrics over the same period of time.

\section{Growth in size}

\section{Methods}

Using the technique of Kaufmann (1981), I described the growth of $P$. augusta using a Gompertz curve, which has the following form:

$S=S_{\infty} \exp \left[-\exp -a\left(t+t_{0}\right)\right]$

Where $S=$ size at time $t ; S_{\infty}=$ asymptotic size; $-a=$ constant of proportionality; $t_{0}=$ constant of integration.

Determining the parameters of this curve first involves estimating the specific growth rate $(G)$ to understand how the rate of growth of an organism changes with size. This is done using cross-sectional (mark recapture) data, which is a record of growth for many individuals of different sizes, over short periods. Each individual is measured at two points in time $\left(S_{1}\right.$ and $\left.S_{2}\right)$ and the specific growth rate during this period is estimated as:

$G=\left(\ln S_{2^{-}} \ln S_{1}\right) / \Delta t$ 
The specific growth rate is then regressed against the log of the geometric mean of $S_{1}$ and $S_{2}$. The slope of this regression is the estimate of a, and with the intercept b, can be used to predict the asymptotic size:

$S_{\infty}=\exp (b / a)$

Finally, using an individual of known age and size, values of $S$ and $t$ are inserted into the Gompertz equation, and the equation is solved for $t_{0}$.

From the monitoring records, I selected all snails whose diameters had been measured eight weeks either side of July 12008 . This measurement, and the one made when the snail was first brought into the laboratory, defined the growth interval. I regressed the specific growth rate in this interval against $\ln ($ geometric mean size). Diagnostic plots for all regressions are available in Appendix B. Snails which had hatched in captivity were not included in the dataset, as the measurement error at this small size was too great. The model only applies over the age of one year.

\section{Results}

There was a significant linear relationship between size and growth rate (linear regression: $F_{1,202}=617.053, R^{2}=0.753, P<0.001$; Fig 7.1), and the slope of the line was $-0.000533 \pm 0.000021$ (mean $\pm \mathrm{SE}$ ). However, the variance appeared nonconstant and a plot of the residuals against the predicted values confirmed increasing variance with growth rate (Fig. 7.2). 


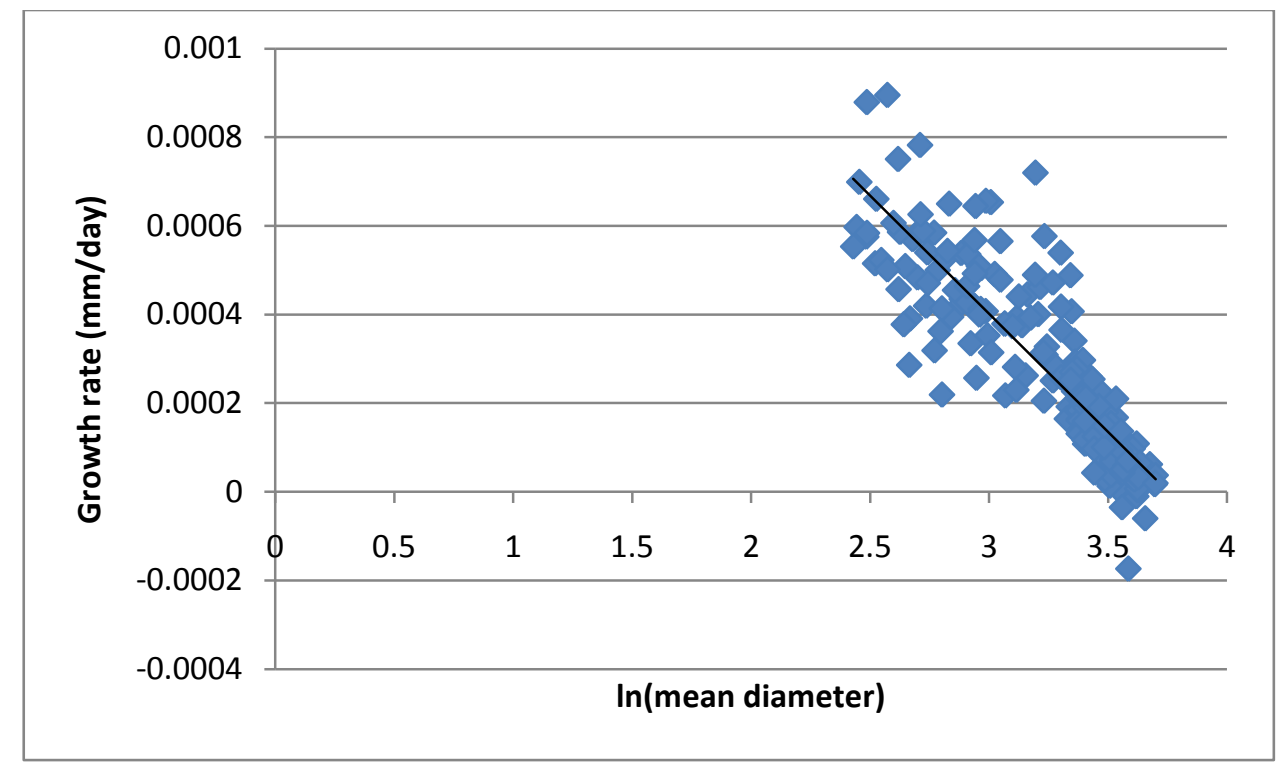

Figure 7.1. Growth rate vs. size for 204 captive P. augusta.

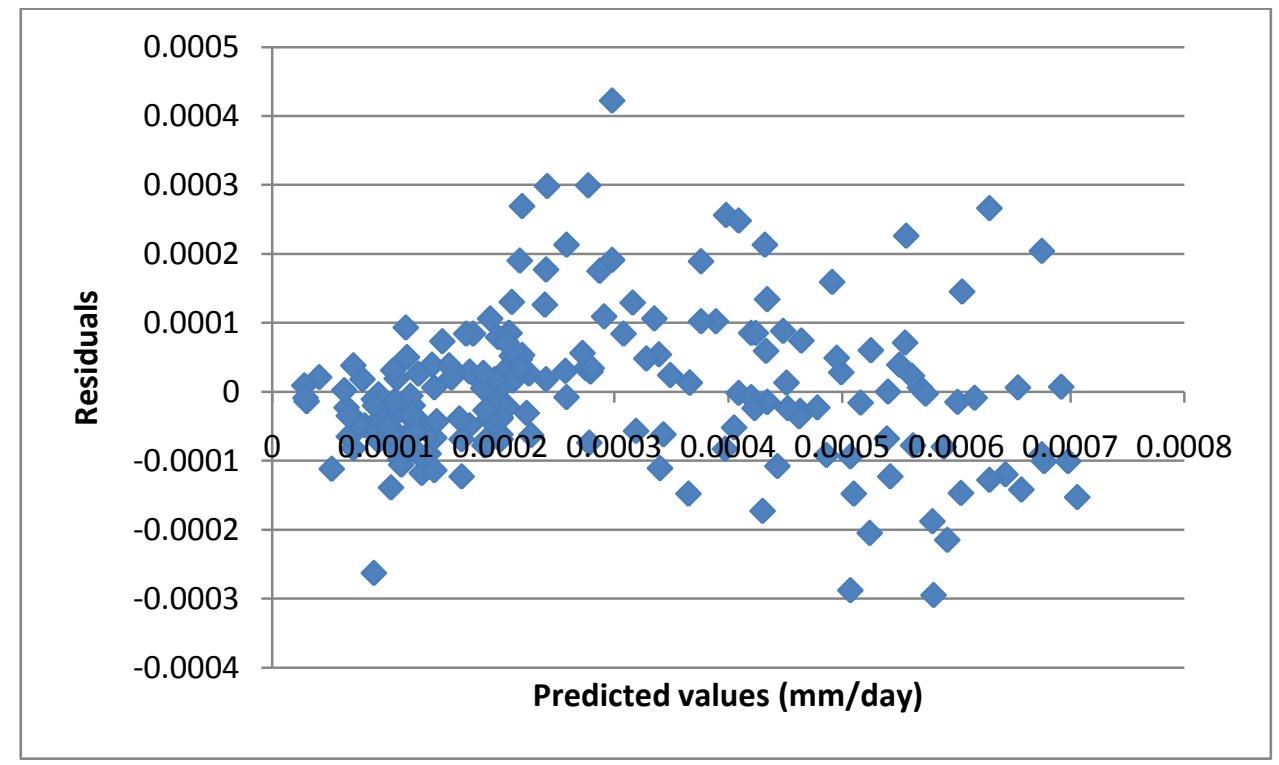

Figure 7.2. Residuals from a growth rate vs. size regression showing increasing variance with growth rate.

To accommodate the large heterogeneity of variance, I used weighted least squares regression (Quinn and Keough 2002). I used the absolute value of the residuals and regressed these against $\ln ($ mean diameter). The inverse square of the predicted values were used to weight each observation, and I re-ran the original regression using the weighted least squares procedure in SPSS 16. 
The slope of the new regression was: $-0.000582 \pm 0.00023$ (mean \pm SE) (linear regression: $\left.F_{1,202}=638.965, R^{2}=0.760, P<0.001\right)$ There was some improvement in the spread of the residuals (Fig 7.3).

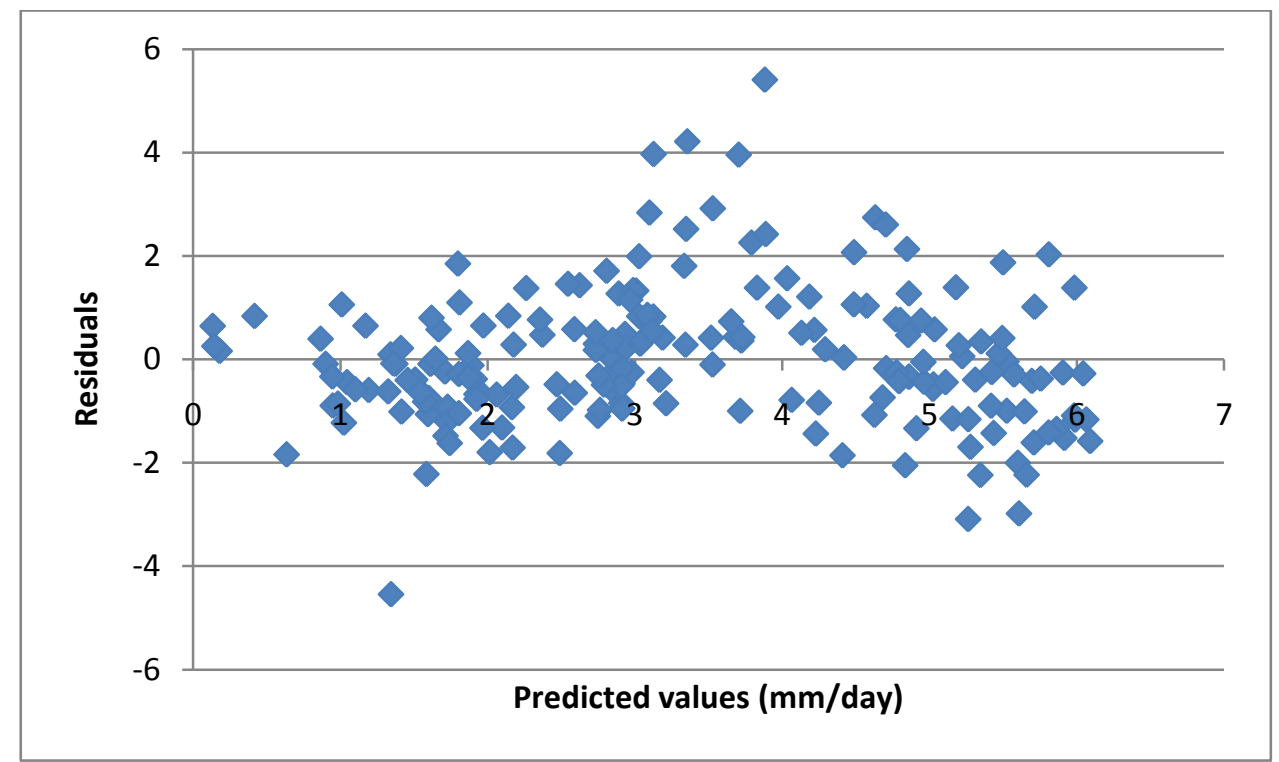

Figure 7.3. Residuals from a weighted least squares regression of growth rate vs. size for 204 captive $P$. augusta.

From the weighted least squares regression I obtained estimates of $a(-0.000582)$ and $b$ (0.002162), which I used to calculate the asymptotic size:

$S_{\infty}=\exp (b / a)=\exp (0.002162 /-0.000582)=41.049 \mathrm{~mm}$

The mean diameter after approximately one year (365 days), for eight snails hatched in captivity was used to find $t_{0}$. This was $8.818 \mathrm{~mm} \pm 0.095$ (mean $\pm \mathrm{SE}$ ).

$S=S_{\infty} \exp \left[-\exp -a\left(t+t_{0}\right)\right]$

$8.818=41.049 \exp \left[-\exp -0.000582\left(365+t_{0}\right)\right]$

$t_{0}=-1106.911$ 
The full Gompertz equation was:

$S=41.049 \exp [-\exp -0.000582(t-1106.911)]$

This equation describes the change in size of a snail that will occur with time in captivity. If the age of a snail is known, such as when it hatches in captivity, then the equation can relate size to age and this is shown in figure 7.4.

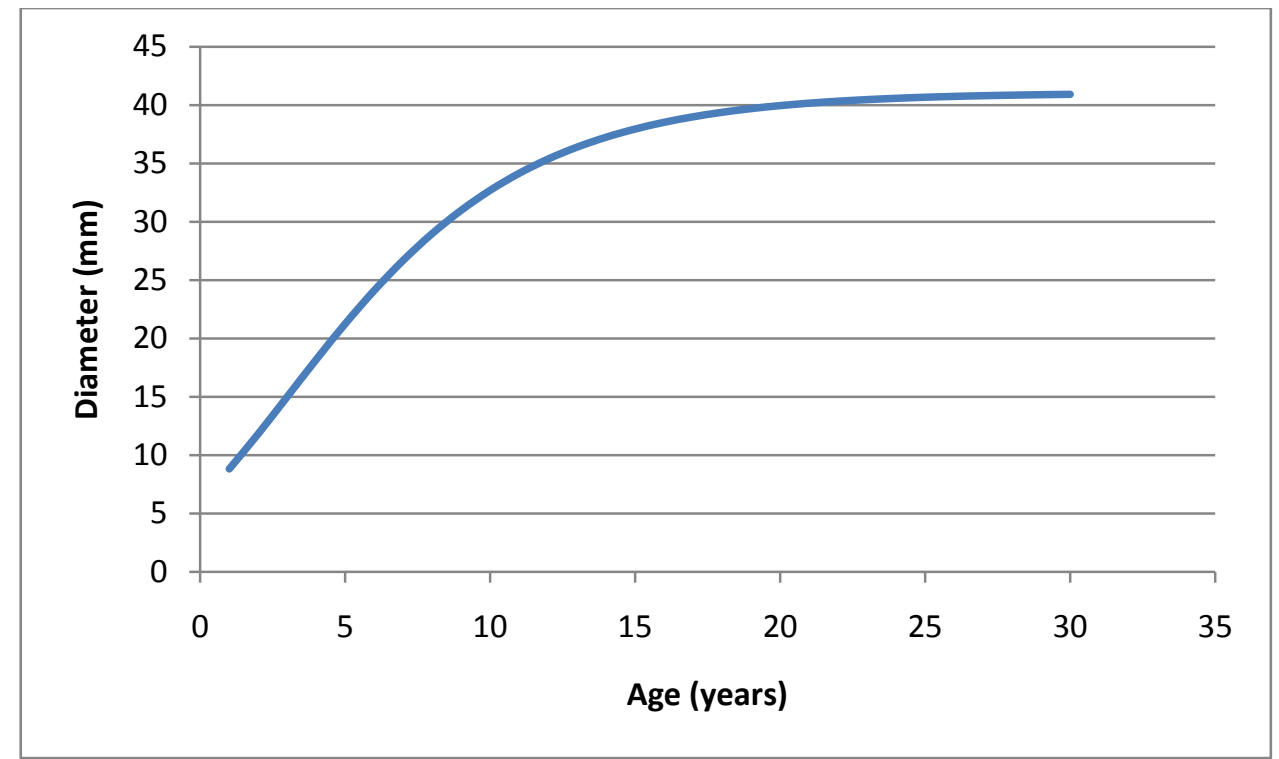

Figure 7.4. Predicted growth in shell diameter from the age of one year, for $P$. augusta hatching in captivity.

\section{Growth in mass}

\section{Methods}

To describe growth in mass in $P$. augusta I used the weights measured at the same time as the diameters. There was a linear relationship between $\ln$ (mean weight) and growth rate (linear regression: $F_{1,202}=583.711, R^{2}=0.743, P<0.001 ;$ Fig 7.5 ), and the slope of the line was $-0.000566 \pm 0.000023$ (mean \pm SE). But again there was heterogeneity of variance, as verified by a plot of the residuals against the predicted values (Figure 7.6). 


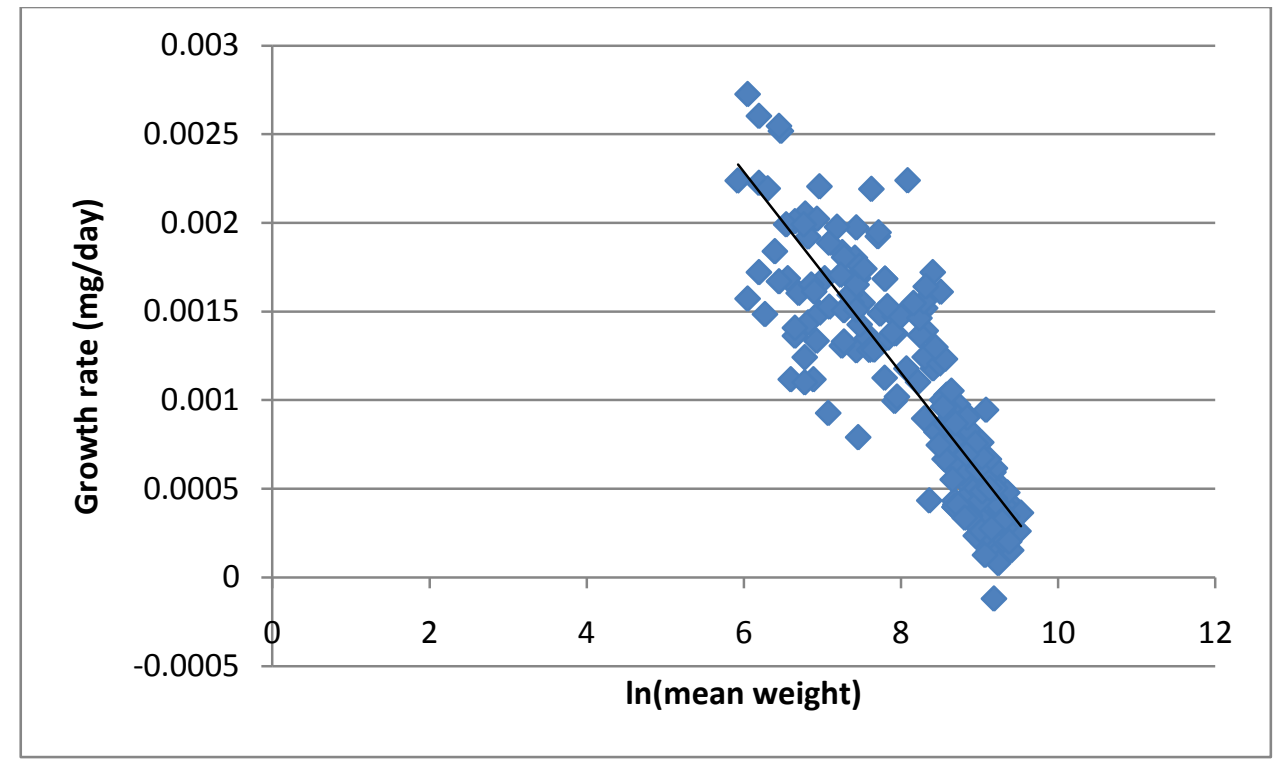

Figure 7.5. Growth rate vs. mass for 204 captive P. augusta.

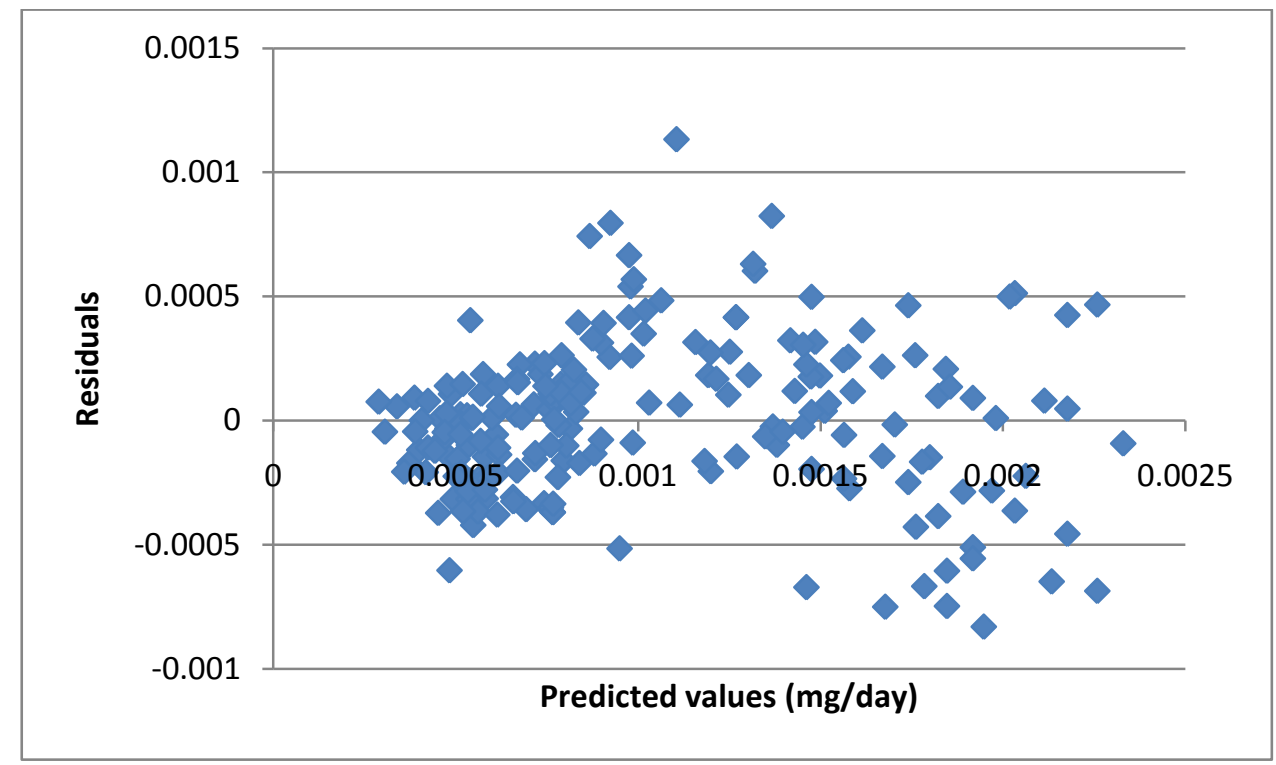

Figure 7.6. Residuals from a regression of growth rate vs. mass $(N=204)$.

I used the same weighted least squares procedure used for diameter growth (linear regression: $\left.F_{1,202}=590.227, R^{2}=0.745, P<0.001\right)$. Again there was an improvement in the stability of the variance (Figure 7.7). 


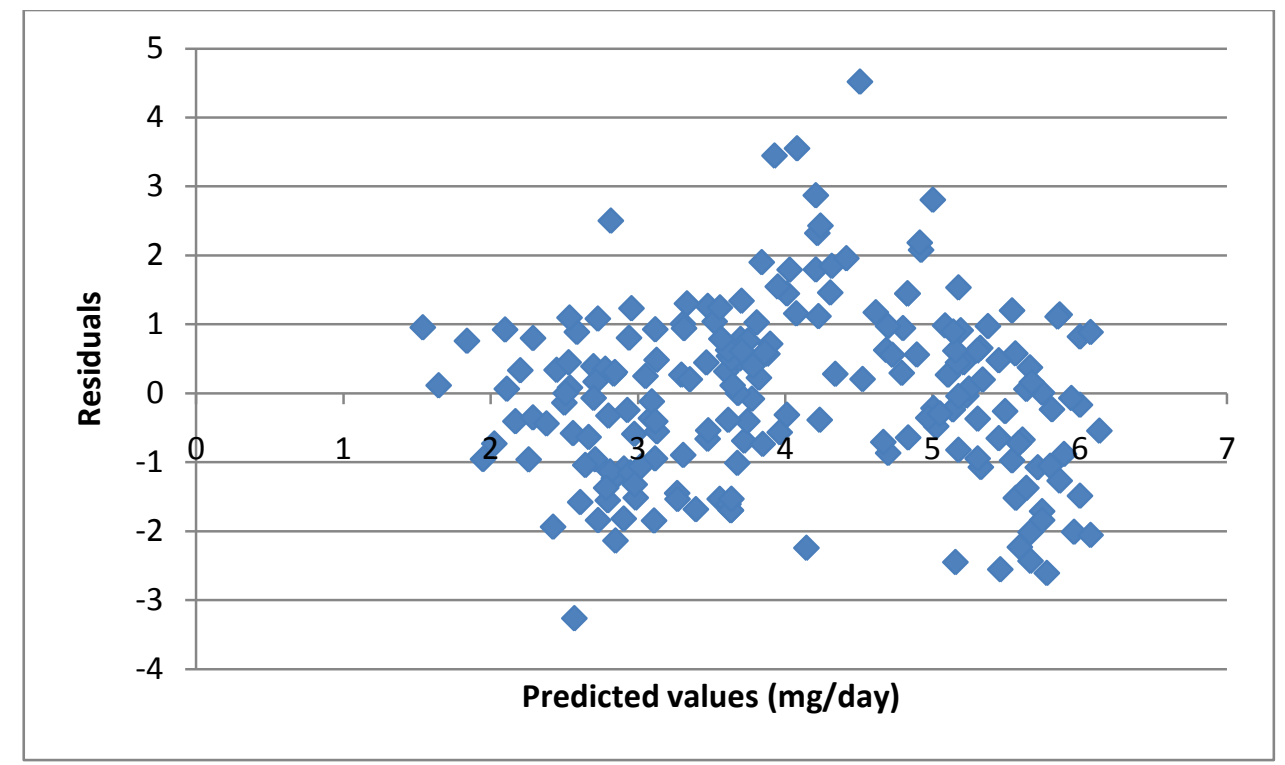

Figure 7.7. Residuals from a weighted least squares regression of growth rate vs. mass $(N=$ 204).

To find the constant of proportionality, I used the mean weight after one year for the same eight snails used for diameter growth, which was $163.750 \pm 8.647$ (mean \pm SE).

\section{Results}

The estimates of the parameters were:

$a=-0.000619$

$b=0.006122$

$S_{\infty}=19734.929$

$t_{0}=-2895.838$

And the equation relating time and mass was:

$S=19734.929 \exp [-\exp -0.000619(t-2895.838)]$

Figure 7.8 shows the predicted relationship between age and mass, for those snails hatching in captivity. 


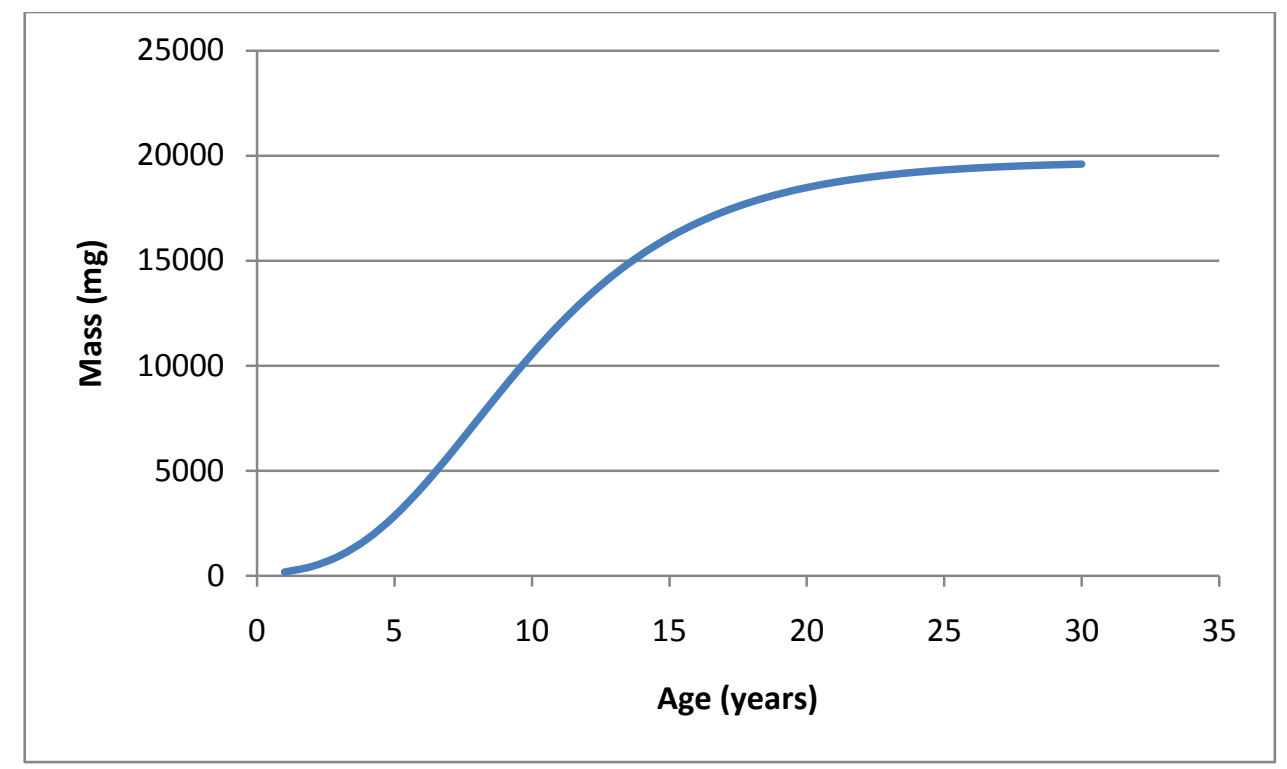

Figure 7.8. Predicted growth in mass from the age of one year, for P. augusta hatching in captivity.

\section{Comparing the two growth curves}

\section{Methods}

To compare the performance of the two growth curves, I tested the hypotheses of equal correlation coefficients and equal regression slopes using the methods of Zar (1974). The correlation coefficients were $r=0.872$ for size, and $r=0.863$ for mass. I first transformed the correlation coefficients to make them approximately normally distributed:

$z=0.5 \ln (1+r / 1-r)$

And then computed the $\mathrm{z}$ statistic:

$Z=\left(z_{1}-z_{2}\right) / \sigma_{z 1}-\sigma_{z 2}$

The $t$ statistic was used to compare the regression slopes, which is calculated as the difference between the slopes divided by the difference between the standard errors of the slopes, on $(N-4)$ degrees of freedom (Zar 1974):

$t=\left(b_{1}-b_{2}\right) / S_{b 1-b 2}$ 
$d f=408-4=404$

Results

There was no difference between the correlation coefficients of the regressions describing growth in size and growth in mass $(z=0.371, P=0.711)$. There was also no difference in the slopes of the two regression lines $\left(t_{404}=1.089, P=0.277\right)$.

\section{Discussion}

A number of different curves have been fitted to the growth of snail species. The most common are the exponential (Gimbert et al. 2008; Hadfield et al. 1993); Von Bertalanffy (Fernandez and Esch 1991; Plorin and Gilbertson 1984; Stiven and Walton 1967); logistic (Dybdahl and Kane 2005; Fernandez and Esch 1991; Garcia et al. 2006; Plorin and Gilbertson 1984) and Gompertz (Fernandez and Esch 1991; Gimbert et al. 2008; Hadfield et al. 1993). Gimbert et al. (2008) found the Gompertz the best fit to the growth of Helix aspersa, compared with the exponential, logistic and Von Bertalanffy. While the logistic curve was superior to the exponential, Von Bertalanffy and Gompertz in describing the growth of Achatinella mustelina (Hadfield et al. 1993). The Gompertz curve, compared with the logistic, shows faster initial growth, but a slower approach to the asymptote (Karkach 2006). The Gompertz curve is appealing because the same type of curve can be used to describe growth in length, volume or mass (Kaufmann 1981).

I was interested in whether weight or shell diameter would prove more suitable for monitoring the growth of $P$. augusta. The strength of the linear relationship between growth rate and size, was the same as that between growth rate and mass, as indicated by equal correlation coefficients. The regression slopes for weight and shell diameter were also identical; meaning the rate of growth was similar for both mass and size. However, there was an important biological difference in the asymptotes predicted by each regression. The asymptotic size was approximately $41 \mathrm{~mm}$ in diameter, around the size of the largest individuals in the dataset. But the asymptotic mass was over 19 grams, and the heaviest individual in the dataset was only 15 grams. Furthermore, there are no records of any snail approaching this weight. Both size and mass have merits as indicators of growth. Weighing may be preferable to measuring when the 
snails are very small, and the shell is both delicate and difficult to measure accurately. Growth in mass may also continue, when growth in some linear measurement of size all but ceases (Stringer and Grant 2007).

On the other hand, the true growth in mass of snails may be confounded by changes in water content (Baur 1992), or fat content (Karkach 2006). For these reasons, as well as the anomalous asymptotic weight, shell diameter is more appropriate for monitoring the growth of $P$. augusta. Weight might still be more suitable for measuring the growth of newly-hatched snails with delicate shells.

Because the size-age curve (Fig 7.4) for P. augusta is based on growth in captivity, there are important limits to its application. The curve can only relate size to age if an initial age is known, such as when a snail has hatched in captivity. Furthermore, it cannot be used for snails less than one year-old. However, if reproductive maturity is achieved at a $30 \mathrm{~mm}$ shell diameter, then the curve predicts snails hatching in captivity to take approximately eight years to mature. 


\section{Chapter 8: Research Implications}

The success of land snail translocations for conservation has been mixed (Coote et al. 2004; Pearcekelly et al. 1995; Stringer and Parrish 2003; Stringer and Parrish 2008) and failures may well occur before $P$. augusta is successfully re-settled in the wild. If the snails cannot only be maintained in captivity but bred in large numbers, then the buffer to extinction would be considerably enlarged. Captive maintenance and breeding is thus a vital part of the conservation strategy for P. augusta and I will now outline the implications of my research for its success. I discuss the most important problems and propose solutions.

\section{Density}

The experiment with stocking densities of $P$. augusta was possibly one of the most crucial of the study. It clearly demonstrated a potent effect of density on the survival of this snail. Although the agent responsible was not identified, previous studies on other snail species implicate disease (Segade et al. 2009). This may have been a novel infection, or one already present in the population, but previously innocuous.

It is difficult to overstate the threat of disease to the captive population. Disease is responsible for massive episodes of mortality among edible snail cultures (Kodjo et al. 1997), the extinction of at least one species of endangered Partula snails (Cunningham and Daszak 1998), as well as the failure of a previous attempt to maintain Powelliphanta in captivity (Kath Walker pers. comm.). The risk of disease will always be present, and need not come from pathogens brought into captivity with the snails. For example, the bacteria Pseudomonas infects not only snails, but other animal taxa, as well as living freely in water and soil (Timmis 2002).

The most effective disease counter-measures are modest stocking densities and hygiene. If groups of snails are held under the conditions of the lowest experimental stocking density, then no more than $5 \%$ of these groups should be affected by mortality annually. Hence, the group number should not exceed six, and each individual should have at least $240 \mathrm{~cm}^{2}$ of space. However, even if baseline mortality is acceptably low, holding snails in groups rather than individually will increase both 
the likelihood and severity of disease outbreaks, and this risk will increase with stocking density.

Disease will also be inhibited by regular cleaning of the laboratory, cool store and equipment. Detergent, thoroughly rinsed off, is best for cleaning and the use of stronger chemicals should be avoided (Tonge and Bloxam 1991).

The snails in the density experiment lost weight, and this decline did not plateau over 52 weeks of observation. This may have been the result of stress, food competition, or the same disease presumed to have killed snails. Re-housing snails individually could potentially remedy all three of these problems. Ideally, all snails held in groups should be weighed monthly. Those exhibiting a loss of more than $10 \%$ should be segregated until they recover weight. Weight-loss could also identify those individuals at risk of death, as the deaths of several snails in the experiment were preceded by obvious declines in weight (Appendix A).

\section{Calcium and substrate}

A benefit of calcium to the reproduction of P.augusta could not be established, as an experimental treatment appeared to have lethal effects. The limestone used as a supplement may have been provided in excess. The more limited use of limestone, or the use of an alternative supplement, may well bolster egg production and further investigation is warranted. Future experiments will require a change in environmental conditions, as the experimental snails kept in cool stores did not produce eggs, likely due to the lack of photoperiod (Gomot 2001).

\section{Reproductive biology}

There is large variation in both the size of adult $P$. augusta and their reproductive output. The largest reproductively mature snails are more than three times the size of the smallest, and the difference in clutch size may also be threefold. It was only possible in this study to assess fecundity in terms of clutch size. The isolation of captive snails and their inability to mate, precluded any assessment of clutch frequency. An assessment using both measures would more accurately quantify the strength of size-specific fecundity when snails have access to mates. 
Regardless of any reassessment, however, the largest individuals will still be the most fecund and should be preferentially retained for breeding.

An experiment determined that mating is random with respect to shell size in $P$. augusta. The experiment also confirmed the use of a 30mm shell diameter as a reasonable reproductive indicator. Many matings took place in the cool store which suggests that environmental cues like photoperiod are not necessary for copulation, although apparently important for egg production.

\section{Body condition and feeding regime}

The body condition of captive snails appears satisfactory, being stable at a level equivalent to the peak of condition in the wild. Most likely, body condition is stable because the snails are being fed in excess, and the surplus is either not being consumed, or invested in growth.

This analysis needs to be updated, as the most recent data examined was collected in May 2009. The formula for expected weight in chapter six should be used to assess body condition exclusively. If the weight/diameter ratio is used instead, the result will vary with the mean body size of the sample examined. If a re-analysis finds body condition to have remained stable, then feeding could potentially be reduced, without a reduction in condition.

\section{Growth}

As with the body condition analysis, the analysis of growth in captivity requires updating, the data spanning from the collection period (July 2006-May 2007) to the middle of 2008. If the rate of growth has changed since that time then the estimate for age at maturity needs to be modified accordingly.

Furthermore, recent data for comparison would allow any change in captive growth rates to be ascertained. There is a possibility that growth in captivity has slowed due to low temperatures (Gomot 2001), or accelerated due to increased feeding frequency, relative to the wild (Stringer and Grant 2007). 
If growth rates have increased in captivity, then the generation time could possibly be reduced from the predicted eight years. Accelerated growth rates in captive New Caledonian Placostylus have significantly reduced the time until maturity (Brescia et al. 2008).

\section{Recommendations for monitoring}

Because snails in groups compete for food and are susceptible to stress and disease, they should be closely monitored. Weighing should be monthly, but the growth of adult snails is so slight that the shell diameter need only be measured biannually, or even annually. These measurements are to identify individuals at risk and need not be statistically analyzed. If the population housed in groups is to be periodically assessed as a whole, then a subsample of this data could be analyzed. For instance, 50 randomly chosen individuals, or every sixth snail, etc.

A minimum sample size of 20 snails is required to detect a change in mean body condition of $5 \%$. Monitoring snails of all sizes is advisable, as there may be differences in the response to feeding, between juveniles and adults. For example, 20 individuals could be monitored, in each of four size-classes.

Finally, in addition to the specific recommendations made here, it is suggested that links be established with other snail conservation programs elsewhere. Specifically, the captive breeding program for Placostylus in New Caledonia (Brescia et al. 2008) and that for Partula; which is worldwide, but headquartered at London Zoo (Cunningham and Daszak, 1998). As the case will be with $P$. augusta, the obstacles faced by these two genera have been numerous, but not insurmountable. 


\section{References}

Adamo, S. A. and Chase, R. 1990. Dissociation of Sexual Arousal and Sexual Proclivity in the Garden Snail, Helix aspersa. Behavioral and Neural Biology, 54, 115-130.

Angeloni, L., Bradbury, J. W. and Charnov, E. L. 2002. Body Size and Sex Allocation in Simultaneously Hermaphroditic Animals. Behavioral Ecology, 13, 419426.

Attia, J. 2004. Behavioural Rhythms of Land Snails in the Field. Biological Rhythm Research, 35, 35-41.

Aufderheide, J., Warbritton, R., Pounds, N., File-Emperador, S., Staples, C., Caspers, N. and Forbes, V. 2006. Effects of Husbandry Parameters on the LifeHistory Traits of the Apple Snail, Marisa cornuarietis: Effects of Temperature, Photoperiod, and Population Density. Invertebrate Biology, 125, 9-20.

Bailey, S. E. R. 1981. Circannual and Circadian Rhythms in the Snail Helix aspersa and the Photoperiodic Control of Annual Activity and Reproduction. Journal of Comparative Physiology A: Sensory Neural and Behavioral Physiology, 142, 88-94. Baur, A. 1990. Intra- and Interspecific Influences on Age at First Reproduction and Fecundity in the Land Snail Balea perversa. Oikos, 57, 333-337.

Baur, A. and Baur, B. 2005. Interpopulation Variation in the Prevalence and Intensity of Parasitic Mite Infection in the Land Snail Arianta arbustorum. Invertebrate Biology, 124, 194-201.

Baur, B. 1994. Multiple Paternity and Individual Variation in Sperm Precedence in the Simultaneously Hermaphroditic Land Snail Arianta arbustorum. Behavioral Ecology and Sociobiology, 35, 413-421.

Baur, B. 1992. Random Mating by Size in the Simultaneously Hermaphroditic Land Snail Arianta arbustorum - Experiments and an Explanation. Animal Behaviour, 43, 511-518.

Baur, B. and Baur, A. 1990. Experimental Evidence for Intraspecific and Interspecific Competition in 2 Species of Rock-Dwelling Land Snails. Journal of Animal Ecology, 59, 301-315.

Baur, B. and Baur, A. 1992. Reduced Reproductive Compatibility in Arianta arbustorum (Gastropoda) from Distant Populations. Heredity, 69, 65-72. 
Beiswanger, C. M., Sokolove, P. G. and Prior, D. J. 1981. Extra-Ocular Photoentrainment of the Circadian Locomotor Rhythm of the Garden Slug Limax. Journal of Experimental Zoology, 216, 13-23.

Blinn, W. C. 1963. Ecology of Land Snails Mesodon thyroidus and Allogona profunda. Ecology, 44, 498-505.

Bouillon, J. 1956. Influence of Temperature on the Histological Evolution of the Ovotestis of Cepea nemoralis. Nature, 177, 142-143.

Brescia, F. M., Pollabauer, C. M., Potter, M. A. and Robertson, A. W. 2008. A Review of the Ecology and Conservation of Placostylus (Mollusca: Gastropoda: Bulimulidae) in New Caledonia. Molluscan Research, 28, 111-122.

Bull, C. M., Baker, G. H., Lawson, L. M. and Steed, M. A. 1992. Investigations of the Role of Mucus and Feces in Interspecific Interactions of 2 Land Snails. Journal of Molluscan Studies, 58, 433-441.

Cameron, R. A. D. 1970. The Effect of Temperature on the Activity of Three Species of Helicid Snail (Mollusca: Gastropoda). Journal of Zoology, 162, 303-315.

Cameron, R. A. D. and Carter, M. A. 1979. Intraspecific and Interspecific Effects of Population-Density on Growth and Activity in Some Helicid Land Snails (Gastropoda, Pulmonata). Journal of Animal Ecology, 48, 237-246.

Chatterjee, S. and Hadi, A. S. 2006. Regression Analysis by Example, Fourth edn. Hoboken: John Wiley \& Sons.

Christie, B., Thompson, B. and Brathwaite, B. 2001. Mineral Commodity Report 21: Limestone, Marble and Dolomite. Institute of Geological and Nuclear Sciences New Zealand ltd.

Climo, F. M. 1978. Powelliphanta-gilliesi-traversi-hochstetteri-rossiana-lignariasuperba Ring Species (Mollusca-Pulmonata). New Zealand Journal of Zoology, 5, 289-294.

Cook, A. 2001. Behavioural Ecology: On Doing the Right Thing, in the Right Place at the Right Time. In: The Biology of Terrestrial Molluscs (Ed. by Barker, G. M.), pp. 447-487. New York: CAB International.

Cooper, J. E. and Knowler, C. 1991. Snails and Snail Farming - an Introduction for the Veterinary Profession. Veterinary Record, 129, 541-549.

Coote, T., Clarke, D., Hickman, C. J. S., Murray, J. and Pearce-Kelly, P. 2004. Experimental Release of Endemic Partula Species, Extinct in the Wild, into a Protected Area of Natural Habitat on Moorea. Pacific Science, 58, 429-434. 
Crawley, M. J. 2005. Statistics: An Introduction Using R. Chichester: J. Wiley.

Cunningham, A. A. and Daszak, P. 1998. Extinction of a Species of Land Snail Due to Infection with a Microsporidian Parasite. Conservation Biology, 12, 1139-1141.

Cunningham, A. A., Daszak, P., Macgregor, S. K., Foster, I., Clarke, D. and

PearceKelly, P. 1996. Mortality of Endangered Snails of the Genus Partula:

Preliminary Results of Pathologic Investigations. Journal of Zoo and Wildlife Medicine, 27, 19-27.

Dan, N. and Bailey, S. E. R. 1982. Growth, Mortality, and Feeding Rates of the Snail Helix aspersa at Different Population-Densities in the Laboratory, and the Depression of Activity of Helicid Snails by Other Individuals, or their Mucus. Journal of Molluscan Studies, 48, 257-265.

Davison, A. and Mordan, P. 2007. A Literature Database on the Mating Behavior of Stylommatophoran Land Snails and Slugs. American Malacological Bulletin, 23, 173181.

Davison, A., Wade, C. M., Mordan, P. B. and Chiba, S. 2005. Sex and Darts in Slugs and Snails (Mollusca : Gastropoda : Stylommatophora). Journal of Zoology, 267, 329-338.

Dean, W. W., Mead, A. R. and Northey, W. T. 1970. Aeromonas liquefaciens in the Giant African Snail, Achatina fulica. Journal of Invertebrate Pathology, 16, 346-351.

DeWitt, T. J. 1996. Gender Contests in a Simultaneous Hermaphrodite Snail: A SizeAdvantage Model for Behaviour. Animal Behaviour, 51, 345-351.

Dillen, L., Jordaens, K., Dieleman, W. and Backeljau, T. 2008. Effects of Isolation and Body Size on the Mating Behaviour of the Hermaphroditic Land Snail Succinea putris. Animal Behaviour, 75, 1401-1411.

Dupont-Nivet, M., Coste, V., Coinon, P., Bonnet, J. C. and Blanc, J. M. 2000. Rearing Density Effect on the Production Performance of the Edible Snail Helix aspersa Muller in Indoor Rearing. Annales De Zootechnie, 49, 447-456.

Dybdahl, M. F. and Kane, S. L. 2005. Adaptation vs. Phenotypic Plasticity in the Success of a Clonal Invader. Ecology, 86, 1592-1601.

Ebenso, I. E. 2003. Dietary Calcium Supplement for Edible Tropical Land Snails Archachatina marginata in Niger Delta, Nigeria. Livestock Research for Rural Development, 15 , article 6. 
Egonmwan, R. I. 2008. Effects of Dietary Calcium on Growth and Oviposition of the African Land Snail Limicolaria flammea (Pulmonata : Achatinidae). Revista De Biologia Tropical, 56, 333-343.

EIrayah, E., Constantinou, C. and Cloudsleythompson, J. L. 1984. Environmental Adaptations of the African Snail Limicolaria festiva martens. International Journal of Biometeorology, 28, 327-331.

Facon, B., Ravigne, V. and Goudet, J. 2006. Experimental Evidence of Inbreeding Avoidance in the Hermaphroditic Snail Physa acuta. Evolutionary Ecology, 20, 395406.

Fearnley, R. H. 1996. Heterogenic Copulatory Behaviour Produces Non-Random Mating in Laboratory Trials in the Land Snail Helix aspersa Muller. Journal of Molluscan Studies, 62, 159-164.

Fernandez, J. and Esch, G. W. 1991. Effect of Parasitism on the Growth-Rate of the Pulmonate Snail Helisoma anceps. Journal of Parasitology, 77, 937-944.

Flari, V. and Lazaridoudimitriadou, M. 1995. The Locomotor-Activity Rhythm of the Edible Snail, Helix Lucorum L, in Symmetrical Skeleton Photoperiod Regimes. Animal Behaviour, 50, 635-644.

Ford, S. E., Kraeuter, J. N., Barber, R. D. and Mathis, G. 2002. AquacultureAssociated Factors in Qpx Disease of Hard Clams: Density and Seed Source. Aquaculture, 208, 23-38.

Foster, B. A. and Stiven, A. E. 1996. Experimental Effects of Density and Food on Growth and Mortality of the Southern Appalachian Land Gastropod, Mesodon normalis (Pilsbry). American Midland Naturalist, 136, 300-314.

Fournie, J. and Chetail, M. 1984. Calcium Dynamics in Land Gastropods. American Zoologist, 24, 857-870.

Garcia, A., Perea, J. M., Mayoral, A., Acero, R., Martos, J., Gomez, G. and Pena, F. 2006. Laboratory Rearing Conditions for Improved Growth of Juvenile Helix aspersa Muller Snails. Laboratory Animals, 40, 309-316.

Gardenfors, U. 1992. Effects of Artificial Liming on Land Snail Populations. Journal of Applied Ecology, 29, 50-54.

Gimbert, F., de Vaufleury, A., Douay, F., Coeurdassier, M., Scheifler, R. and

Badot, P. M. 2008. Long-Term Responses of Snails Exposed to CadmiumContaminated Soils in a Partial Life-Cycle Experiment. Ecotoxicology and Environmental Safety, 70, 138-146. 
Gomot De Vaufleury, A. 1990. Photoperiod and Temperature Interaction in the Determination of Reproduction of the Edible Snail, Helix pomatia. Journal of Reproduction and Fertility, 90, 581-585.

Gomot De Vaufleiry, A. 2001. Regulation of Growth and Reproduction. In: The Biology of Terrestrial Molluscs (Ed. by Barker, G. M.), pp. 331-355. New York: CAB International.

Goodfriend, G. A. 1986. Variation in Land-Snail Shell Form and Size and Its Causes - a Review. Systematic Zoology, 35, 204-223.

Green, A. J. 2001. Mass/Length Residuals: Measures of Body Condition or Generators of Spurious Results? Ecology, 82, 1473-1483.

Hadfield, M. G., Miller, S. E. and Carwile, A. H. 1993. The Decimation of Endemic Hawaiian Tree Snails by Alien Predators. American Zoologist, 33, 610-622.

Heller, J. 1993. Hermaphroditism in Mollusks. Biological Journal of the Linnean Society, 48, 19-42.

Heller, J. 2001. Life History Strategies. In: The Biology of Terrestrial Molluscs (Ed. by Barker, G. M.), pp. 413-445. New York: CAB International.

Herreid, C. F. and Rokitka, M. A. 1976. Environmental Stimuli for Arousal from Dormancy in Land Snail Otala lactea (Muller). Physiological Zoology, 49, 181-190.

Hotopp, K. P. 2002. Land Snails and Soil Calcium in Central Appalachian Mountain Forest. Southeastern Naturalist, 1, 27-44.

Iglesias, J., Santos, M. and Castillejo, J. 1996. Annual Activity Cycles of the Land Snail Helix aspersa Muller in Natural Populations in North-Western Spain. Journal of Molluscan Studies, 62, 495-505.

Iguchi, K., Ogawa, K., Nagae, M. and Ito, F. 2003. The Influence of Rearing Density on Stress Response and Disease Susceptibility of Ayu (Plecoglossus altivelis). Aquaculture, 220, 515-523.

Ireland, M. P. 1991. The Effect of Dietary Calcium on Growth, Shell Thickness and Tissue Calcium Distribution in the Snail Achatina fulica. Comparative Biochemistry and Physiology A: Physiology, 98, 111-116.

Jakob, E. M., Marshall, S. D. and Uetz, G. W. 1996. Estimating Fitness: A Comparison of Body Condition Indices. Oikos, 77, 61-67.

Jarne, P. and Delay, B. 1990. Inbreeding Depression and Self-Fertilization in Lymnaea peregra (Gastropoda, Pulmonata). Heredity, 64, 169-175. 
Jess, S. and Marks, R. J. 1989. The Interaction of Diet and Substrate on the Growth of Helix aspersa var. maxima. Henderson, I. (Ed.). British Crop Protection Council Monograph, No. 41. Slugs and Snails in World Agriculture; Symposium, Surrey, England, Uk, April 10-12, 1989, 311-318.

Jess, S. and Marks, R. J. 1995. Population-Density Effects on Growth in Culture of the Edible Snail Helix aspersa Var Maxima. Journal of Molluscan Studies, 61, 313323.

Jordaens, K., Dillen, L. and Backeljau, T. 2007. Effects of Mating, Breeding System and Parasites on Reproduction in Hermaphrodites: Pulmonate Gastropods (Mollusca). Animal Biology, 57, 137-195.

Jordaens, K., Pinceel, J. and Backeljau, T. 2005. Mate Choice in the Hermaphroditic Land Snail Succinea putris (Stylommatophora: Succineidae). Animal Behaviour, 70, 329-337.

Karkach, A. S. 2006. Trajectories and Models of Individual Growth. Demographic Research, 15, 348-400.

Kaufmann, K. W. 1981. Fitting and Using Growth-Curves. Oecologia, 49, 293-299. Kautsky, N., Ronnback, P., Tedengren, M. and Troell, M. 2000. Ecosystem Perspectives on Management of Disease in Shrimp Pond Farming. Aquaculture, 191, $145-161$.

Kiebre-Toe, M. B., Lacheretz, A., Villard, L., Richard, Y. and Kodjo, A. 2005. Pulsed-Field Gel Electrophoresis Profiles of Aeromonads Isolated from Healthy and Diseased Helix aspersa from French Snail Farms. Canadian Journal of Microbiology, $51,817-820$.

Kodjo, A., Haond, F. and Richard, Y. 1997. Molecular and Phenotypic Features of Aeromonads Isolated from Snails (Helix aspersa) Affected with a New Summer Disease. Journal of Veterinary Medicine Series B-Infectious Diseases and Veterinary Public Health, 44, 245-252.

Koene, J. M., Montagne-Wajer, K. and Ter Maat, A. 2007. Aspects of Body Size and Mate Choice in the Simultaneously Hermaphroditic Pond Snail Lymnaea stagnalis. Animal Biology, 57, 247-259.

Koene, J. M., Montagne-Wajer, K. and Ter Maat, A. 2006. Effects of Frequent Mating on Sex Allocation in the Simultaneously Hermaphroditic Great Pond Snail (Lymnaea stagnalis). Behavioral Ecology and Sociobiology, 60, 332-338. 
Lazaridou-Dimitriadou, M., Alpoyanni, E., Baka, M., Brouziotis, T., Kifonidis, N., Mihaloudi, E., Sioula, D. and Vellis, G. 1998. Growth, Mortality and Fecundity in Successive Generations of Helix aspersa Muller Cultured Indoors and Crowding Effects on Fast-, Medium- and Slow-Growing Snails of the Same Clutch. Journal of Molluscan Studies, 64, 67-74.

Lazaridou-Dimitriadou, M. and Saunders, D. S. 1986. The Influence of Humidity, Photoperiod and Temperature on the Activity and Dormancy of Helix lucorum (Gastropoda, Pulmonata). Journal of Molluscan Studies, 52, 180-189.

Lehr, R. 1992. 16 S-Squared over D-Squared - a Relation for Crude Sample-Size Estimates. Statistics in Medicine, 11, 1099-1102.

Lind, H. 1988. The Behaviour of Helix pomatia L. Gastropoda Pulmonata in a Natural Habitat. Videnskabelige Meddelelser fra Dansk Naturhistorisk Forening, 6792.

Lind, H. 1976. Causal and Functional Organization of Mating-Behavior Sequence in Helix pomatia (Pulmonata, Gastropoda). Behaviour, 59, 162-202.

Lomborg, J. P. and Toft, S. 2009. Nutritional Enrichment Increases Courtship Intensity and Improves Mating Success in Male Spiders. Behavioral Ecology, 20, 700-708.

Mackenzie, J. 2005. Judgement in the High Court: Royal Forest and Bird Protection Society of New Zealand Inc vs. Minister of Conservation, Civ-2005-4852419. Wellington, New Zealand.

Madsen, H., Thiongo, F. W. and Ouma, J. H. 1983. Egg-Laying and Growth in Helisoma duryi (Wetherby) (Pulmonata, Planorbidae) - Effect of Population-Density and Mode of Fertilization. Hydrobiologia, 106, 185-191.

Maes, D., Segales, J., Meyns, T., Sibila, M., Pieters, M. and Haesebrouck, F. 2008. Control of Mycoplasma hyopneumoniae Infections in Pigs. Veterinary Microbiology, 126, 297-309.

Meads, M. J., Walker, K. J. and Elliott, G. P. 1984. Status, Conservation, and Management of the Land Snails of the Genus Powelliphanta (Mollusca, Pulmonata). New Zealand Journal of Zoology, 11, 277-306.

Messinger, J. S., Windham, W. R. and Ward, C. R. 2009. Ionized Hypercalcemia in Dogs: A Retrospective Study of 109 Cases (1998-2003). Journal of Veterinary Internal Medicine, 23, 514-519. 
Moya-Larano, J., Macias-Ordonez, R., Blanckenhorn, W. U. and Fernandez-

Montraveta, C. 2008. Analysing Body Condition: Mass, Volume or Density?

Journal of Animal Ecology, 77, 1099-1108.

Morand, S. and Faliex, E. 1994. Study on the Life-Cycle of a Sexually-Transmitted Nematode Parasite of a Terrestrial Snail. Journal of Parasitology, 80, 1049-1052.

Noble, A. C. and Summerfelt, S. T. 1996. Diseases Countered in Rainbow Trout Cultured in Recirculating Systems. Annual Review of Fish Diseases, 6, 65-92.

O'Connor, A. C. 1945. Notes on the Eggs of New Zealand Paryphantidae, with Description of a New Subgenus. Trans and Proc Roy Soc New Zealand, 75, 54-56.

Ohbayashi-Hodoki, K., Ishihama, F. and Shimada, M. 2004. Body Size-

Dependent Gender Role in a Simultaneous Hermaphrodite Freshwater Snail, Physa acuta. Behavioral Ecology, 15, 976-981.

Oosterhoff, L. M. 1977. Variation in Growth Rate as an Ecological Factor in the Land Snail Cepaea nemoralis. Netherlands Journal of Zoology, 27, 1-132.

Pearcekelly, P., Mace, G. M. and Clarke, D. 1995. The Release of Captive Bred Snails (Partula taeniata) into a Seminatural Environment. Biodiversity and Conservation, 4, 645-663.

Pettibone, G. W. 1998. Population Dynamics of Aeromonas Spp. In an Urban River Watershed. Journal of Applied Microbiology, 85, 723-730.

Plorin, G. G. and Gilbertson, D. E. 1984. Equations for Describing Growth of the Schistosome Host Snail Biomphalaria glabrata. Journal of Parasitology, 70, 43-47.

Pollard, E. 1975. Aspects of the Ecology of Helix pomatia L. Journal of Animal Ecology, 44, 305-329.

Pomeroy, D. E. 1969. Some Aspects of the Ecology of the Land Snail Helicella virgata in South Australia. Australian Journal of Zoology, 17, 495-514.

Powell, A. W. B. 1979. New Zealand Mollusca. Marine, Land and Freshwater Shells. Auckland: Collins.

Quinn, G. P. and Keough, M. J. 2002. Experimental Design and Data Analysis for Biologists, First edn. Cambridge: Cambridge University Press.

Raut, S. K. 2004. Bacterial and Non-Microbial Diseases in Terrestrial Gastropods. In: Natural Enemies of Terrestrial Molluscs (Ed. by Barker, G. M.), pp. 599-611. Wallingford: CAB International.

Reichardt, A. R., C. Burla, H. Baur, B. 1985. Causes of Death and Possible Regulatory Processes in Arianta arbustorum. Basteria, 49, 37-46. 
Rupp, J. C. and Woolhouse, M. E. J. 1999. Impact of Geographical Origin on Mating Behaviour in Two Species of Biomphalaria (Planorbidae : Gastropoda). Animal Behaviour, 58, 1247-1251.

Salas, M., Bonnaut, C., LeBel, S. and Chardonnet, L. 1997. Activity and Food Intake of Captive Placostylus fibratus (Gastropoda: Bulimulidae) in New Caledonia. New Zealand Journal of Zoology, 24, 257-264.

Schulte-Hostedde, A. I., Zinner, B., Millar, J. S. and Hickling, G. J. 2005.

Restitution of Mass-Size Residuals: Validating Body Condition Indices. Ecology, 86, 155-163.

Schupbach, H. U. and Baur, B. Contact-Based Transmission Models in Terrestrial Gastropod Populations Infected with Parasitic Mites. International Journal for Parasitology, 40, 1045-1050

Segade, P., Kher, C. P., Lynn, D. H. and Iglesias, R. 2009. Morphological and Molecular Characterization of Renal Ciliates Infecting Farmed Snails in Spain. Parasitology, 136, 771-782.

Shoemaker, C. A., Evans, J. J. and Klesius, P. H. 2000. Density and Dose: Factors Affecting Mortality of Streptococcus iniae Infected Tilapia (Oreochromis niloticus). Aquaculture, 188, 229-235.

Silva, L., Meireles, L., Vargas, T., Junqueira, F. O. and Bessa, E. C. A. 2009. Life History of the Land Snail Habroconus semenlini (Stylommatophora: Euconulidae) under Laboratory Conditions. Revista De Biologia Tropical, 57, 1217-1222.

Silva, L. C., Meireles, L. M. O., Junqueira, F. O. and Bessa, E. C. A. 2008.

Development and Reproduction in Bulimulus tenuissimus (Mollusca : Bulimulidae) in Laboratory. Revista Brasileira De Zoologia, 25, 220-223.

Simkiss, K. 1977. Bio-Mineralization and Detoxification. Calcified Tissue Research, 24, 199-200.

Solorio-Rivera, J. L., Rodriguez-Vivas, R. I., Perez-Gutierrez, E. and Wagner, G. 1999. Management Factors Associated with Babesia bovis Seroprevalence in Cattle from Eastern Yucatan, Mexico. Preventive Veterinary Medicine, 40, 261-269.

Stiven, A. E. and Walton, C. R. 1967. Age and Shell Growth in a Freshwater Snail Goniobasis proxima (Say). American Midland Naturalist, 78, 207-\&.

Stringer, I. A. N., Bassett, S. M., McLean, M. J., McCartney, J. and Parrish, G. R. 2003. Biology and Conservation of the Rare New Zealand Land Snail Paryphanta busbyi watti (Mollusca, Pulmonata). Invertebrate Biology, 122, 241-251. 
Stringer, I. A. N. and Grant, E. A. 2007. Captive Rearing and Biology of the Endangered Land Snail Placostylus ambagiosus and P. hongii (Pulmonata: Bulimulidae). DOC Research and Development Series 279. 36 pp.

Stringer, I. A. N. and Montefiore, R. 2000. Distribution and Biology of the Endangered Kauri Snail, Paryphanta Busbyi Watti. Science for Conservation 163.42 pp.

Stringer, I. A. N. and Parrish, G. R. 2003. Unsuccessful Transfer of Captive-Bred Land Snails to a Cage at Te Paki Farm Park, North Auckland. DOC Science Internal Series 97. 10 pp.

Stringer, I. A. N. and Parrish, G. R. 2008. Transfer of Captive-Bred Placostylus hongii Snails to Limestone Island. DOC Research and Development series 302.18 pp.

Timmis, K. N. 2002. Pseudomonas putida: A Cosmopolitan Opportunist Par Excellence. Environmental Microbiology, 4, 779-781.

Todd, S., Whitehead, A., Stallard, N. and Whitehead, J. 2001. Interim Analyses and Sequential Designs in Phase III Studies. British Journal of Clinical Pharmacology, 51, 394-399.

Tomiyama, K. 1996. Mate-Choice Criteria in a Protandrous Simultaneously Hermaphroditic Land Snail Achatina fulica (Ferussac) (Stylommatophora: Achatinidae). Journal of Molluscan Studies, 62, 101-111.

Tompa, A. S. 1976. Comparative-Study of Ultrastructure and Mineralogy of Calcified Land Snail Eggs (Pulmonata - Stylommatophora). Journal of Morphology, $150,861-887$.

Tonge, S. and Bloxam, Q. 1991. A Review of the Captive-Breeding Programme for Polynesian Tree Snails Partula Spp. International Zoo Yearbook, 30, 51-59.

Trewick, S. A., Walker, K. J. and Jordan, C. J. 2008. Taxonomic and Conservation Status of a Newly Discovered Giant Landsnail from Mount Augustus, New Zealand. Conservation Genetics, 9, 1563-1575.

Walker, K. J. 2003. Recovery Plans for Powelliphanta Land Snails. Threatened Species Recovery Plan 49. New Zealand Department of Conservation. 208 pp.

Walker, K. J., Trewickz, S. A. and Barker, G. M. 2008. Powelliphanta augusta, a New Species of Land Snail, with a Description of Its Former Habitat, Stockton Coal Plateau, New Zealand. Journal of the Royal Society of New Zealand, 38, 163-186. 
Watson, P. J. 1990. Female-Enhanced Male Competition Determines the 1st Mate and Principal Sire in the Spider Linyphia litigiosa (Linyphiidae). Behavioural Ecology and Sociobiology, 26, 77-90.

Wayne, N. L. 2001. Regulation of Seasonal Reproduction in Mollusks. Journal of Biological Rhythms, 16, 391-402.

Williamson, P. 1976. Size-Weight Relationships and Field Growth-Rates of the Land snail Cepaea nemoralis L. Journal of Animal Ecology, 45, 875-885.

Wolda, H. 1970. Variation in Growth Rate in the Land Snail Cepaea nemoralis. Researches on Population Ecology, 12, 185-204.

Wolda, H. and Kreulen, D. A. 1973. Ecology of Some Experimental Populations of the Land Snail Cepaea nemoralis Part 2: Production and Survival of Eggs and Juveniles. Netherlands Journal of Zoology, 23, 168-188.

Zar, J. H. 1974. Biostatistical Analysis, First edn. London: Prentice-Hall. 
Appendix A: Weight-loss and Mortality in the Stocking Density Experiment.
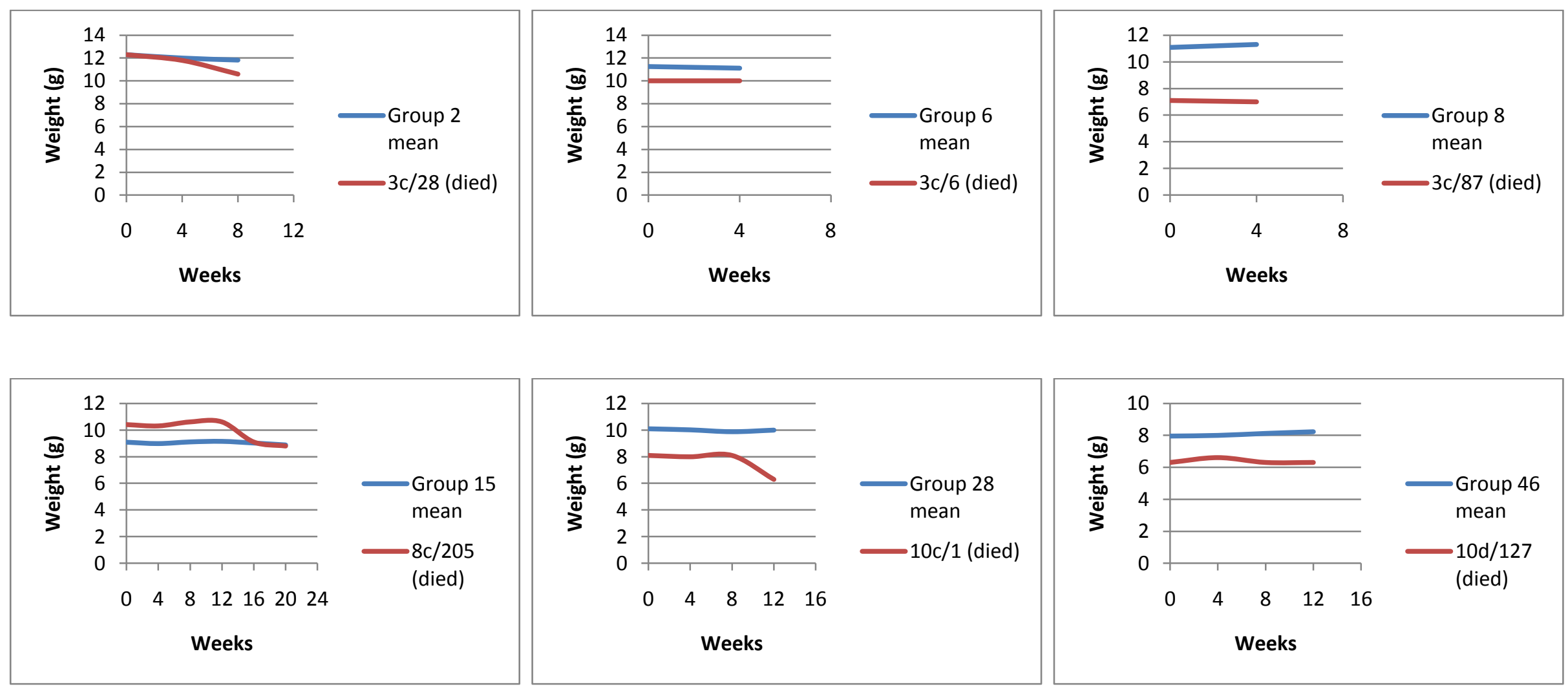

The graphs show the weights of those snails which died after more than four weeks in the experiment, as well as the means for the other five members of their group. The snails were found dead either two, or four weeks after the last weight was recorded. 
Appendix B: Regression Diagnostic Plots (chapters 5, 6 and 7).

\section{Chapter 5:}

Arcsine-squareroot (proportion of activity spent courting) vs. body condition

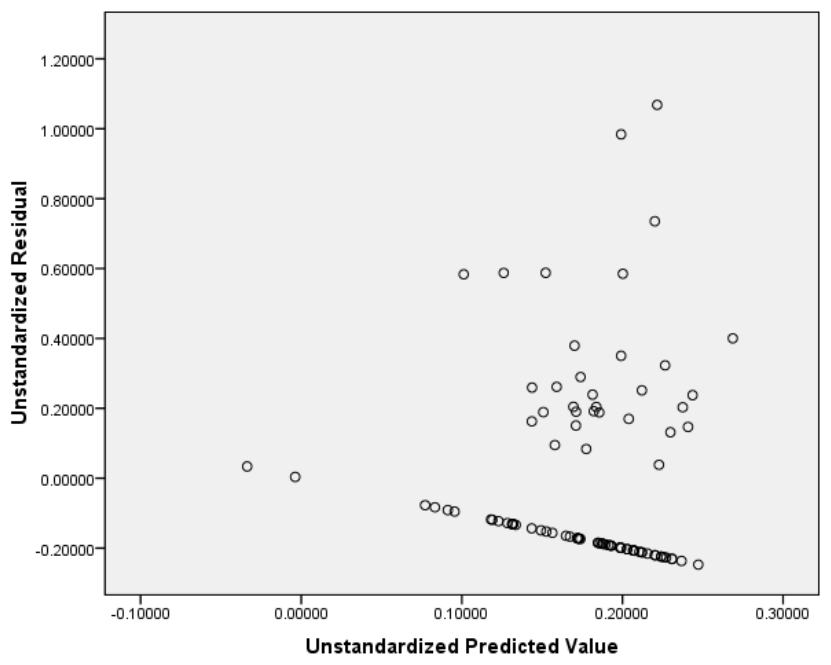

Residuals vs. predicted values.

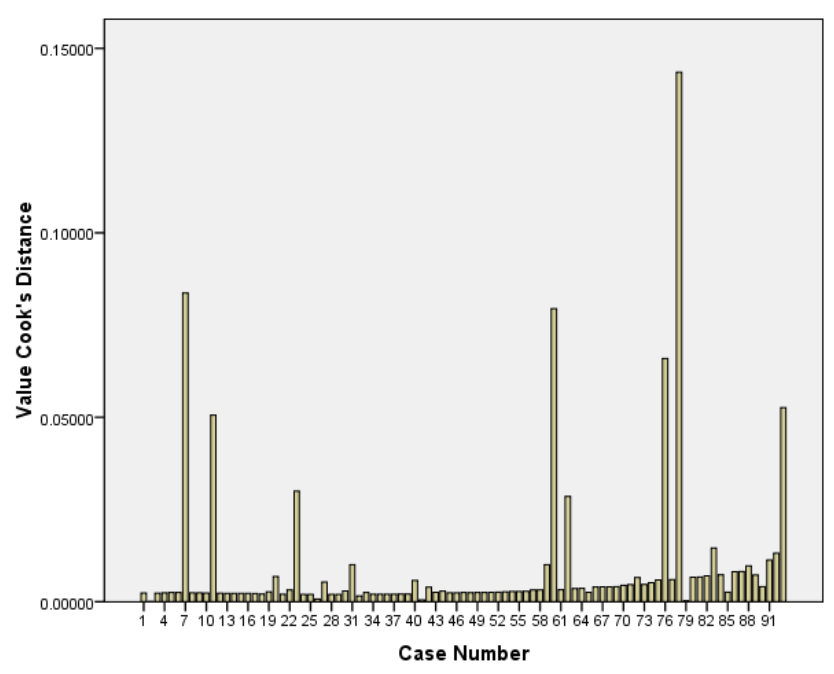

Cook's distance.

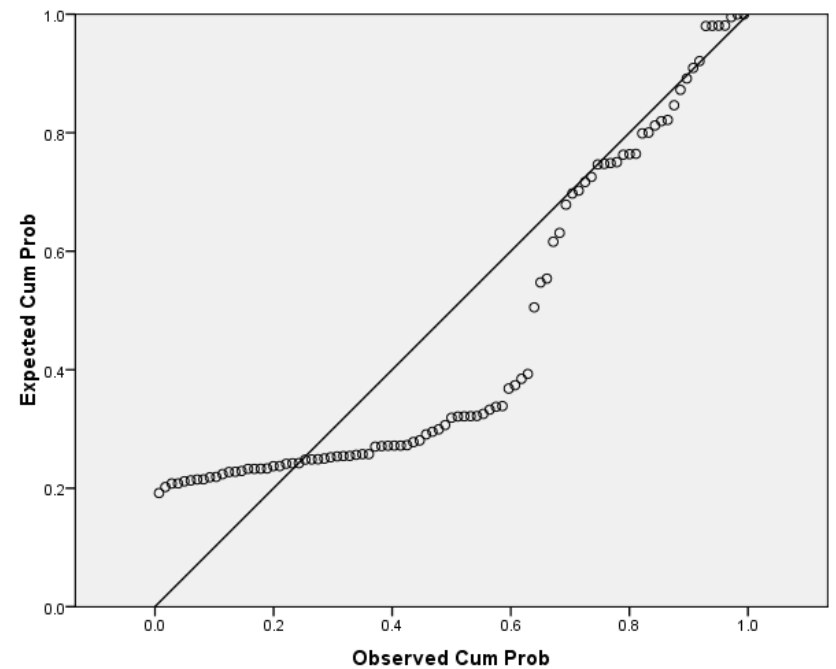

Normal P-P plot of standardized residuals. 


\section{Chapter 6:}

Mass vs. size for 5371 Powelliphanta augusta at time of capture, after the removal of two outliers

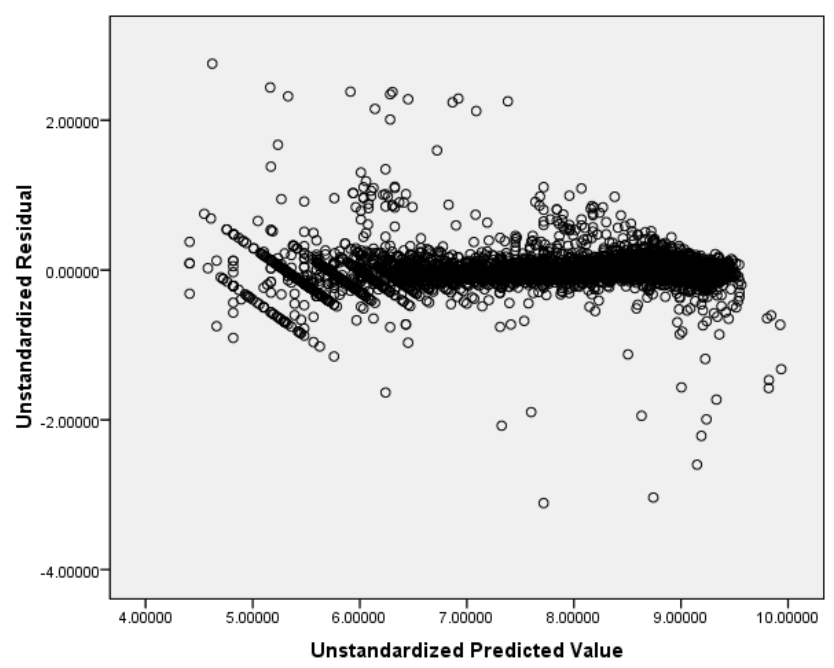

Residuals vs. predicted values.

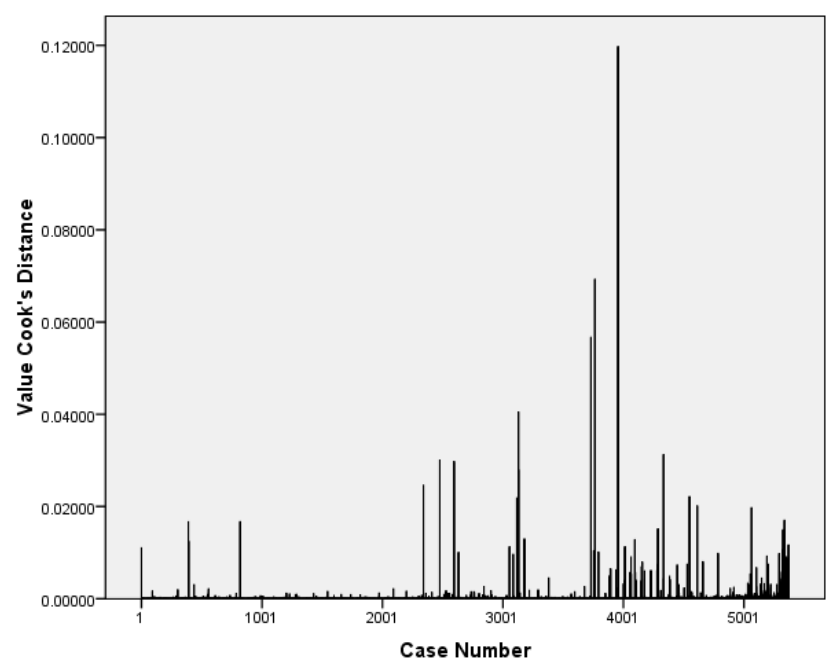

Cook's distance.

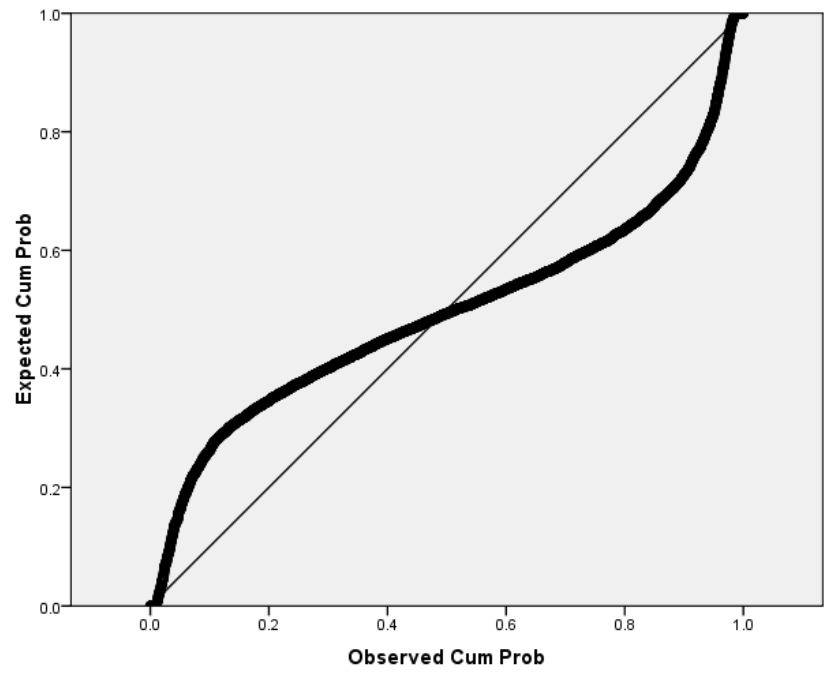

Normal P-P plot of standardized residuals. 


\section{Chapter 6:}

Mass vs. size for 1228 Powelliphanta augusta captured in December 2006 and January 2007.

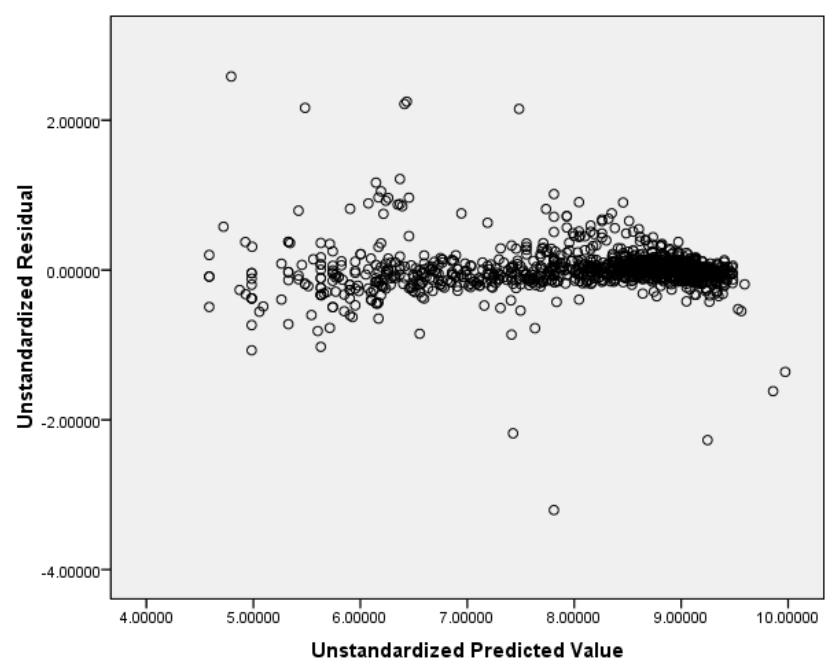

Residuals vs. predicted values.

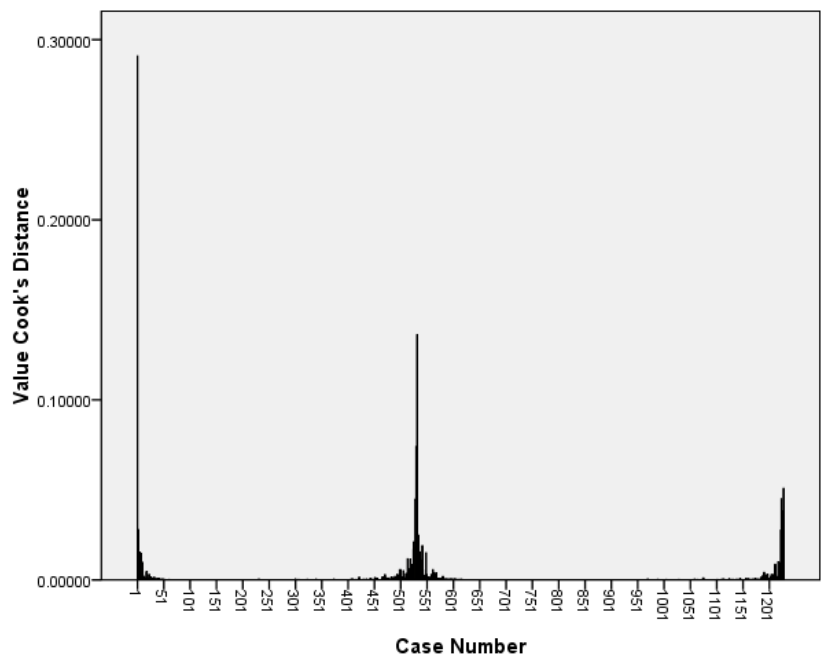

Cook's distance.

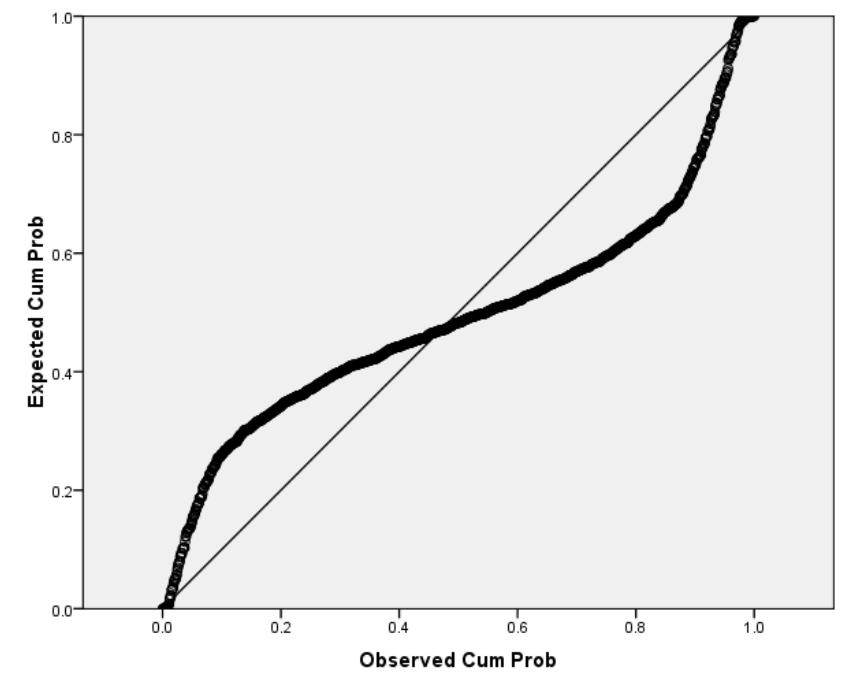

Normal P-P plot of standardized residuals. 


\section{Chapter 7:}

Growth rate vs. size for 204 captive Powelliphanta augusta

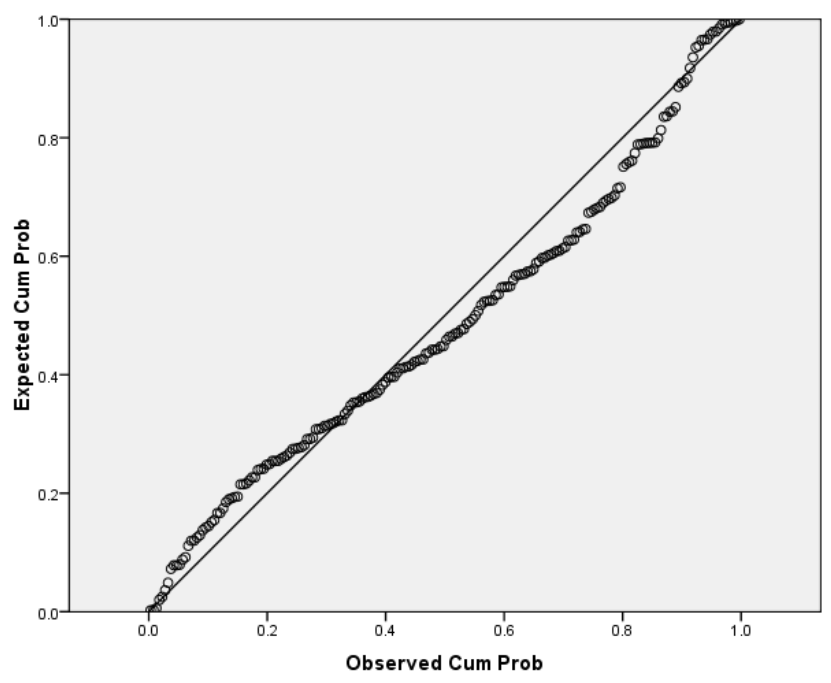

Normal P-P plot.

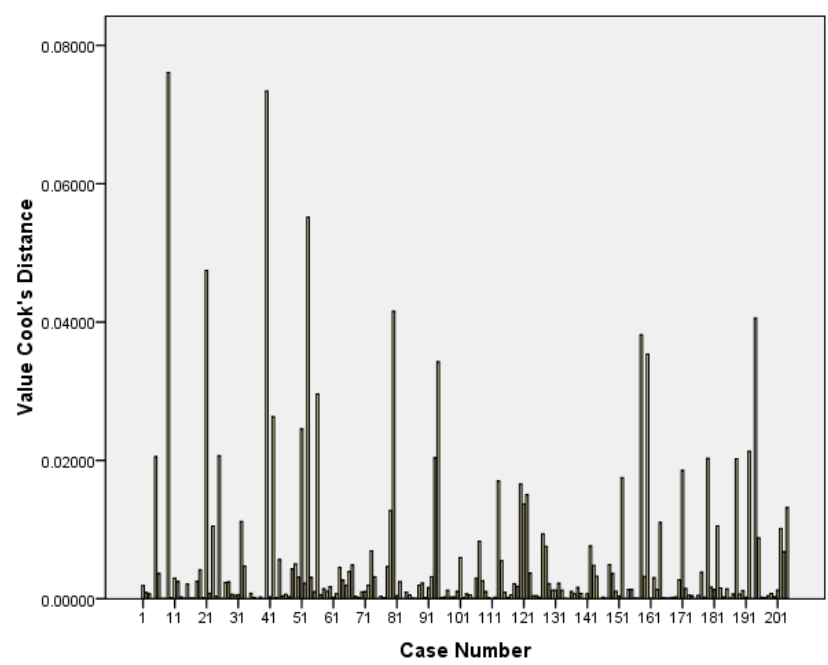

Cook's distance.

Growth rate vs. mass for 204 captive Powelliphanta augusta

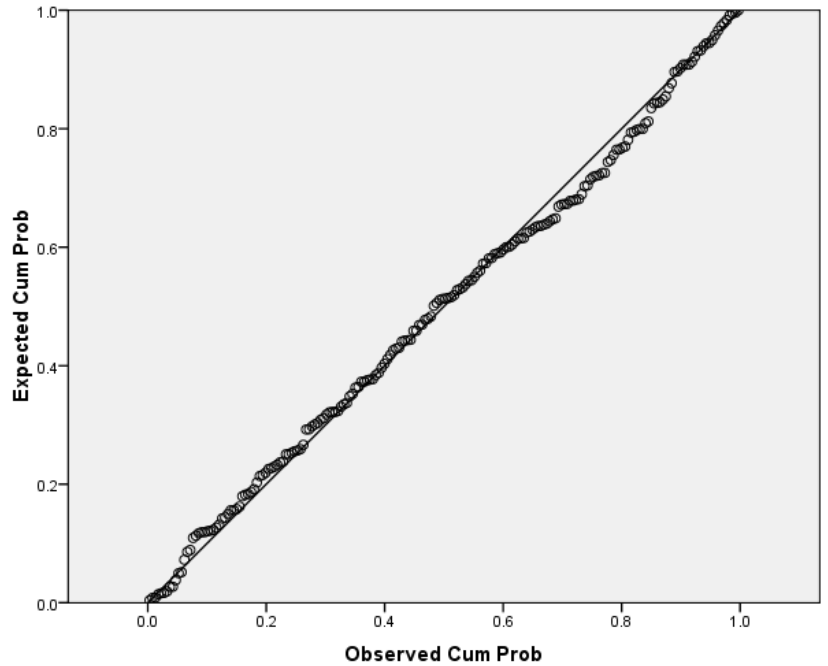

Normal P-P plot.

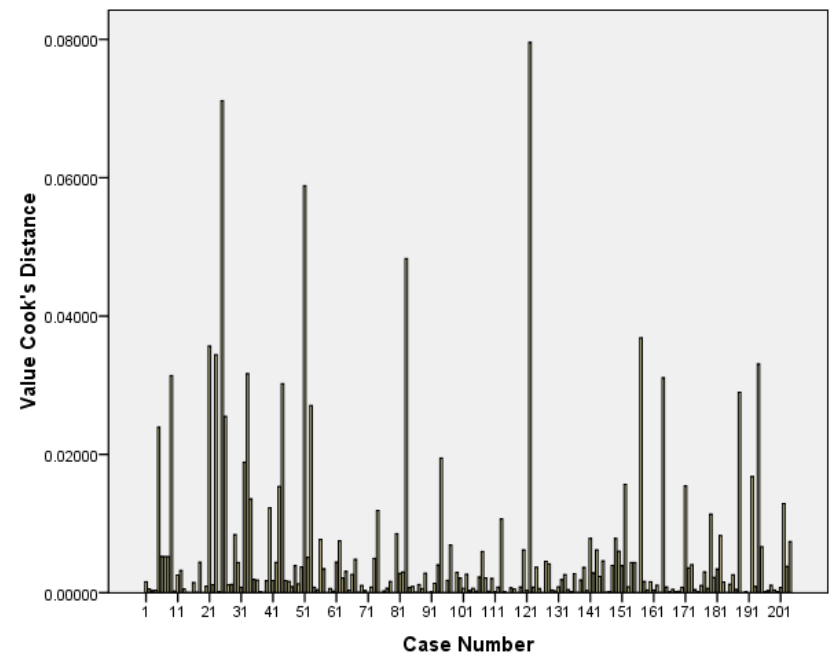

Cook's distance. 
